\title{
Energy Smart Schools - Applied Research, Field Testing, and Technology Integration
}

\author{
Final Technical Report
}

\author{
Submitted by \\ Nebiat Solomon \\ December 2004
}

\section{DOE Award Number DE-FC26-00NT41010}

\author{
NASEO \\ 1414 Prince Street, Suite 200 \\ Alexandria, VA 22314
}

Robin Vieira, Co-Principal Investigator

Florida Solar Energy Center (FSEC)

phone: (321) 638-1404

e-mail: robin@fsec.ucf.edu

William L. Manz

Commercial \& Industrial Programs Manager

Ohio Department of Development

Office of Energy Efficiency

77 South High St., P.O. Box 1001

Columbus, OH 43216-1001

(614) 466-7429 Fax: (614) 466-1864

wmanz@odod.state.oh.us

\author{
Claudia Orlando \\ California Energy Commission \\ 1516 Ninth St. MS 26 \\ Sacramento, CA. 95814 \\ 916-653-5285
}

Kimberlie A. Schryer

NYSERDA

Associate Project Manager

17 Columbia Circle

Albany, NY 12203-6399

(518)-862-1090 ext. 3410

Fax: (518)-862-1091

kas@nyserda.org

Abby Vogen

Senior Project Manager

Energy Center of Wisconsin

595 Science Drive

Madison, WI 53711 


\section{DISCLAIMER}

This report was prepared as an account of work sponsored by an agency of the U.S. government. Neither the United States Government nor any agency thereof, nor any of their employees, makes any warranty, express or implied, or assumes any legal liability or responsibility for the accuracy, completeness, or usefulness of any information, apparatus, product, or process disclosed, or represents that its use would not infringe privately owned rights. Reference herein to any specific commercial product, process, or service by trade name, trademark, manufacturer, or otherwise does not necessarily constitute or imply its endorsement, recommendation, or favoring by the U.S. government or any agency thereof. The views and opinions of authors expressed herein do not necessarily state or reflect those of the U.S. government or any agency thereof. 


\section{Table of Contents}

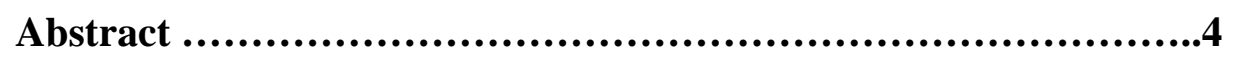

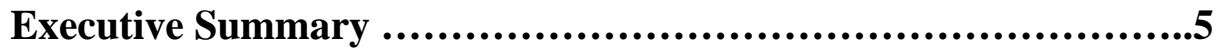

Task 1 ..............................................................6

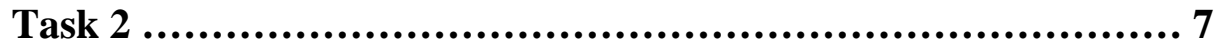

Task 3 ..........................................................18

Task 4 ................................................................. 29

Task 5 ......................................................... 40

Task 6 .......................................................... 47

Task 7 ........................................................... 69

Task 8 ............................................................ 88

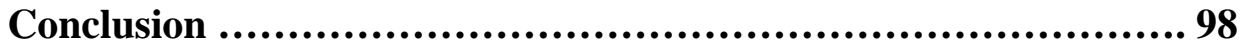




\section{Abstract}

The National Association of State Energy Officials (NASEO) in conjunction with the California Energy Commission, the Energy Center of Wisconsin, the Florida Solar Energy Center, the New York State Energy Research and Development Authority, and the Ohio Department of Development's Office of Energy Efficiency conducted a fouryear, cost-share project with the U.S. Department of Energy (USDOE), Office of Energy Efficiency and Renewable Energy to focus on energy efficiency and high-performance technologies in our nation's schools. NASEO was the program lead for the MOU-State Schools Working group, established in conjunction with the USDOE Memorandum of Understanding process for collaboration among state and federal energy research and demonstration offices and organizations.

The MOU-State Schools Working Group included State Energy Offices and other state energy research organizations from all regions of the country. Through surveys and analyses, the Working Group determined the school-related energy priorities of the states and established a set of tasks to be accomplished, including the installation and evaluation of microturbines, advanced daylighting research, testing of schools and classrooms, and integrated school building technologies.

The Energy Smart Schools project resulted in the adoption of advanced energy efficiency technologies in both the renovation of existing schools and building of new ones; the education of school administrators, architects, engineers, and manufacturers nationwide about the energy-saving, economic, and environmental benefits of energy efficiency technologies; and improved the learning environment for the nation's students through use of better temperature controls, improvements in air quality, and increased daylighting in classrooms. It also provided an opportunity for states to share and replicate successful projects to increase their energy efficiency while at the same time driving down their energy costs. 


\section{Executive Summary}

The Energy Smart Schools cooperative agreement has been in place for several years and has accomplished all the objectives that were originally set forth in the proposal. NASEO and its partners have been able to successfully implement educational programs, explore innovative new ways of creating classroom environments that are energy smart and at the same time healthier environments for students. New schools were built using energy efficient standards, thus allowing schools to refocus their valuable resources to the students rather than energy costs, new technologies were also implemented in existing schools to make them more energy efficient. Professionals in the building industry were also given training on how they can integrate energy efficient techniques in their school design.

The Energy smart schools project had eight specific tasks associated to it:

1. Planning and coordination

2. Installation and evaluation of microturbines

3. Portable classroom characterization

4. Advance daylighting research

5. Integrated school building technologies

6. Scale Study and Diagnostic Testing of Schools and Classrooms

7. Technology integration and

8. Applied engineering and design assistance

Each task had its own set of challenges and lessons learned but overall there were more successes and strides forward in this area. Sharing the outcomes of this project with a wider audience will be beneficial for all those involved in education, design and building of schools. In addition to creating healthier school environments for the future generations, these individual tasks are creating a path toward energy and resources conservation and environmental protection. 


\section{Task 1}

Planning and Coordination - NASEO

NASEO had a significant role to play as the entity coordinating the various activities and assisting the partners in accessing information as well as any other assistance/ technical training that they may need. This was done in a variety of ways including several partnership meetings where all the partners and NASEO would meet with the funder, DOE and share the activity progress to date. This was also the opportunity for project partners to learn about each other and the resources they each had. This aspect of the project is important because it will allow for future partnership possibilities as well as increased peer to peer exchanges.

In addition several conference calls were held to discuss status reports from each of the sub-recipients. NASEO attended a number of conferences and provided status reports to important stakeholders group such as the rebuild America group.

NASEO also assembled the SWG and a limited number of representatives of the Energy Smart Schools program, National Laboratories (ORNL, NREL, LBNL), and participating states to refine workplans, discuss opportunities for leverage and coordination, and outline communication and results feedback mechanisms in the beginning stages of the project implementation. NASEO also established and maintained electronic communications among the participants.

NASEO developed a web site which was used as a data depository for all the information generated by the partners for this project. NASEO also set up a list serve via our web site so that all of the project participants can communicate via the internet at the touch of a button. There were also informational flyers developed in conjunction with the rebuild America program.

The planning and coordination tasks also included specific one on one assistance to partners such as completing extensive work with the Florida Solar Energy Center on portable classroom efficiency measures and working at length with the Ohio Energy Office on procurement issues in relation to the microturbines. 


\section{Task 2}

Installation and Evaluation of Microturbines - Ohio

\section{Objective of Project}

The Ohio demonstration project was to field test and document the improved energy performance of emerging micro-turbines and waste-heat activated absorption technologies in a large high school in Canton, Ohio. The technologies will target the natatorium facility at the Canton McKinley High School. Results of this work will include the following innovations and advancements for these technologies:

- Demonstration of the viability of microturbine technology in combination with microabsorption technology in a school setting;

- Determination of field related issues that will need to be addressed to ensure the successful commercialization of these technologies;

- Introduction of these emerging technologies to key markets and decision makers.

\section{System Description}

After several years of planning, designing and installation, the $\$ 425,000$ project began operating in January 2003 and continues today as a commercial demonstration of the microturbine and waste heat recovery technologies. It is the first of its kind in Ohio, providing electricity, heating and cooling from two natural-gas-fueled, micro-turbine generators with a combined capacity of 56 kilowatts. As the generators produce electricity, the system's exhaust is then used to heat the swimming pool and to drive an ammonia based absorption chiller to provide air conditioning to the building's offices.

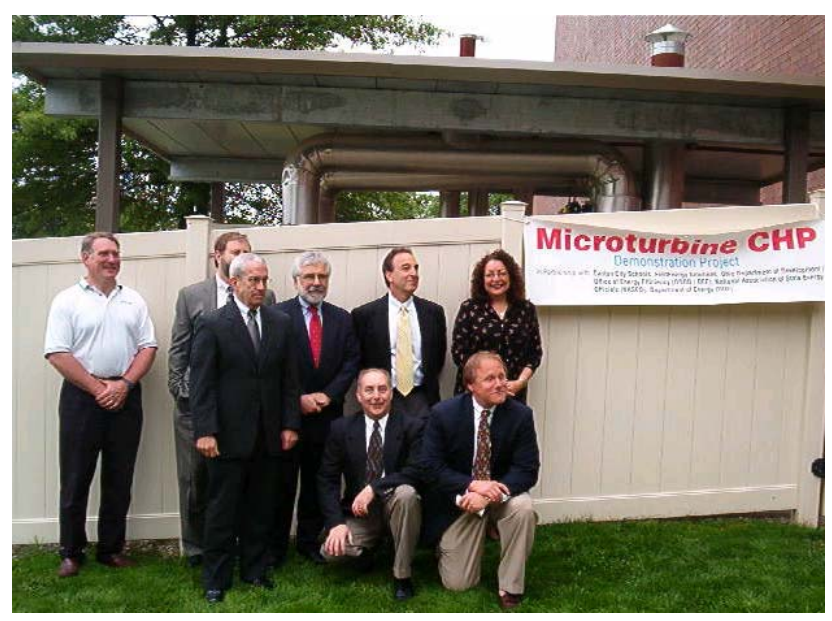


The combined cooling, heating, and power design is intended to deliver higher levels of energy efficiency than individual applications alone. FirstEnergy Solutions, a subsidiary of Akron, Ohio-based FirstEnergy Corp., designed the integrated system and is collecting the performance data for improving future applications.

The Canton City Schools Microturbine Project is the only project of its kind in the state to use natural gas to create electricity, and provide pool heating and air conditioning through an on site integrated system. Since the implementation of the Canton project, a second microturbine project at the Toledo Museum of Art has also been installed. The Canton City Schools Microturbine Project utilizes two Capstone $28 \mathrm{kw}$ microturbines that use natural gas to generate a total of $56 \mathrm{kw}$ of electricity, about half of the natatorium facility's electrical load. One unique feature of this

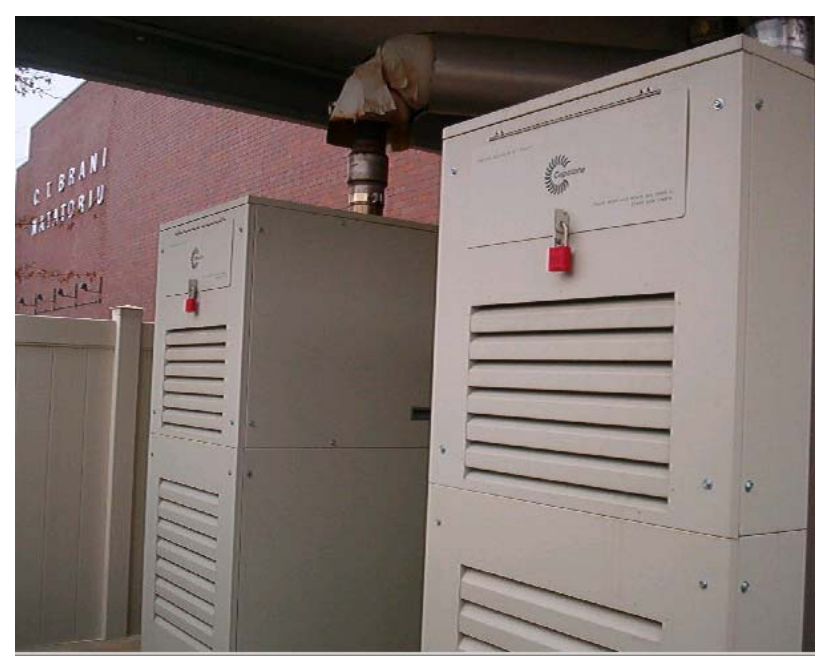

installation is that the microturbines utilize the gas at normal building pressure of $1 / 4 \mathrm{psi}$, where other microturbines would require the gas supply to be at a higher pressure of 5 psi to 60 psi. This system operates in parallel, grid connected to the local electric utility having utility approved fault protection equipment and settings internal to the microturbines. In addition under a loss of electric utility power the microturbines will reconfigure to stand alone operation isolated from the utility and provide electric service to a portion of the building's electric load including about 1/3 of the pool lighting as well as hallway and some other facility lighting and services. 


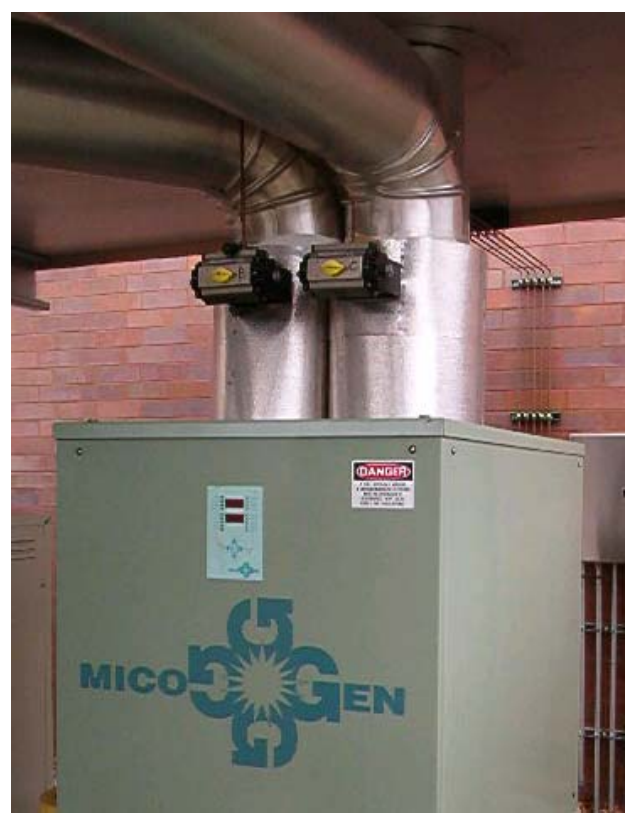

The waste heat from the combustion of the natural gas in the microturbines is ducted to the Unifin Micro-Gen heat exchanger to heat the 600,000+ gallons of pool water maintaining roughly an $80 \mathrm{~F}$ pool temperature. Even during warm summer days the pool loses a significant amount of heat to the atmosphere. Through this system, enough heat is recovered that it is anticipated the only heating required to sustain the pool temperature during the summer will be provided through recovery of the waste heat from the microturbines. This will allow shut down of the main boiler in the field house during the summer, which will provide operating savings to the Canton City Schools. The field house boiler normally provides steam for heating the pool as well as for heating the field house and natatorium buildings

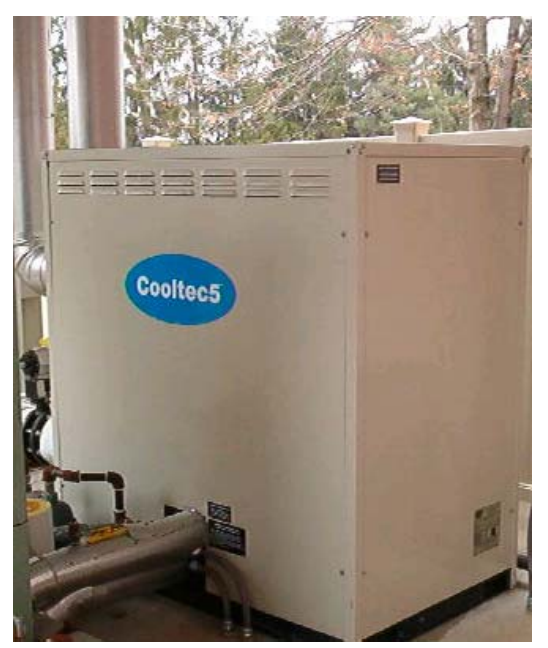

In addition to heating the pool, some of the waste heat is also recovered through a Cooltec 5Rton absorption chiller to provide air conditioning to the buildings offices, classroom, and the hallway, 
improving the comfort of the normally humid atmosphere for the students, staff and spectators.

The absorption chiller is dual fired, primarily using the waste heat from the microturbines, however it is also capable of supplementing this heat with natural gas for quickly attaining operating temperature, or firing completely on natural gas should the microturbine waste heat not be available as during a maintenance shut down. This absorption chiller is only the second unit of its kind with the dual fired feature, and was specifically developed for this application.

The integrated system is monitored with a data collection system to record the fuel use, electricity generated, electricity provided by the utility, heat recovered for pool heating and air conditioning and other operating characteristics. Analysis of operating data to date has indicated fuel input BTU usage and recovery efficiencies in excess of $70 \%$ for the overall combined heating and power system (CHP).

The system also has freeze protection and other automatic controls designed into the operation to redirect the exhaust gas flow in the event of shut down of a component, as well as a dial out function for notification of alarms. System operating status can also be checked from a remote location through a telephone line connected to the data collection system.

\section{$\underline{\text { Results }}$}

I have included (attached) a table of data collected at the site for the calendar year 2004 describing certain attributes of the project including:

- Kwh provided by the utility

- Kwh generated by the microturbines

- KW demand avoided

- Microturbine operating hours

- \% microturbine availability

- Heat recovered by the heat exchanger

- Cooling provided by the absorption unit

- Natural gas consumed by the microturbine

- Natural gas consumption avoided (due to waste heat recovery)

- KW demand avoided due to cooling from absorption unit

- Kwh avoided due to waste heat used by absorption unit

In reviewing the information, and in keeping with the "demonstration" perspective of this project, we can see that the microtubines had some initial hiccups and we spent nearly a year cleaning up various technical issues associated with the operation of the microturbines and the CoolTec absorption cooling unit. The data also suggests that (during 2004) when the system was operating, it met the requirements of the program and demonstrated that the "system" approach was a viable concept.

Canton School District was able to generate electricity and utilize the waste heat for heating and maintaining pool water temperature, as well as provide cooling through the use of the waste heat 
absorption cooling unit. The overall system efficiency was in the $60-70 \%$ range depending upon the use of the waste heat.

There were field related issues with the equipment that are described in detail below. For the most part, however, close working relationships with the Capstone microturbine company and extended warranties that were purchased on the units, helped to alleviate any additional costs to the project.

The third concept that we were demonstrating was to promote the concept to other key companies, developers, etc.... We have had some good press in local papers, as well the AHSRAE Journal. Several project developers have visited the site and we have other projects underway that are utilizing some facets of the Canton project.

\section{Overview of Project Timeline}

- Proposal Development March 2000

- Grant Solicitation

- Grant Awarded

November 2000

- Seclection of Project Manager

July 2001

- Develop Plans/Review w/CCSD

December 2001

- Prepare Specs/Requisition Equip

December 2001

- Prepare Construction DWGs

January 2002

- Coordinate with contractors

March 2002

- Construction Startup

March 2002

- Construction Complete

September 2002

- System Startup/Check

October 2002

- Begin Operation/Data Collection

January 2003

- Project Complete

December 2004

- Final Report to NASEO

February 2005

\section{Problems/Issues and Resolutions}

A combined heat and power CHP system was installed at the Canton City Schools CT Branin Natatorium utilizing 2 Capstone C30 microturbines, a Unifin heat exchanger and an absorption chiller with system checkout in December 2002. Below describes the experiences with the microturbines over the first year of operation. Capstone microturbines serial numbers 2588 and 2589 are both model C30 rated 28kw each equipped with a battery for stand alone operation capability, foil bearing RFC to allow operation on fuel pressure as low as 1/4psi per Capstone 
publications, and housed in the industrial outdoor cabinet. The microturbines are configured to operate in dual mode, multipac operation.

Microturbine 2588 is the main with 2589 as the backup microturbine. The system is constructed to provide the electrical output of the microturbines in grid connect to the facility reducing the electrical demand of the facility from the utility and utilize the waste heat from the operation of the microturbines to heat the pool water year round and provide air conditioning to the facility offices during the warmer months. Site construction was performed in the fall of 2002 with equipment and system checkout in December of 2002, including commissioning checkout and initial startup of the microturbines.

Below is a history of the experiences and problems that have occurred over the first year of operation indicating some severe failure prone equipment and reliability issues with the Capstone microturbines causing frequent and long duration out of service periods for the microturbines and the system. The client has been extremely accommodating and patient through the adverse operation of the microturbines.

\section{December 2002, System Checkout}

Microturbine 2588- system failed to start, worked with Capstone, determined component failure, and replaced part... before system could be checked out for commissioning Microturbine 2589, system failed checkout test for fuel leaks. Extensive troubleshoot time to locate fuel leak determined the fuel manifold was leaking. Awaited delivery of replacement fuel manifold from Capstone before unit could be safely started, checked out and commissioned.

System electrical connection- Capstone service bulletin of December 2002 noted Capstone microturbines to not be connected in corner grounded delta configuration. This was contrary to system design that had been reviewed and designed in communication with Capstone staff in spring of 2002 during project engineering. Although this introduced additional cost and delay in check out and startup of microturbines and system, electrical connections were revised to accommodate Capstone bulletin.

Fuel filters- Capstone recommends in line fuel filters prior to fuel entry to microturbine. The Capstone provided fuel filters create such excessive pressure drop for a low-pressure system that the system can not operate as advertised by Capstone at the $1 / 4$ psi fuel pressure. The pressure 
drop across the fuel filter is indicated to be 1 psi by the manufacturer (discovered after some searching) far in excess of the 1/4 psi available pressure from the local gas utility and Capstone published operating pressure. The significance of this issue is that since the natural gas supply pressure by the local utility in this region of the United States is 7 inches water column (1/4 psi) the ability of the Capstone microturbine to operate at the utility provided pressure is large benefit that eliminates the need for special pressure adjustment and re-regulation at a site to accommodate an on site generation system, thus simplifying design and construction efforts and reducing project costs.

Reconfiguration of the fuel piping system to eliminate the fuel filters as agreed by Capstone staff and remove the already installed filters also caused additional project cost and delay.

\section{May 2003}

Engine failure on microturbine 2588. Engine failed on May 2003, diagnosis took several days with Capstone service personnel. Happening to be at site at time of failure it was noted that the failed microturbine required excessive cool down time in excess of one hour, as it appeared to not be flowing air through the unit. Capstone service personnel continually requested troubleshooting methods for failed electronic components in spite of repeated explanations of the cool down problem and lack of air and exhaust flow including my statements that even if their recommended troubleshoot were performed it would not allow operation of the unit due to the inability of the unit to flow air through the system. Finally, Capstone identified a procedure to verify an engine failure. Engine failure was verified and Capstone provided a replacement engine in time for the scheduled project Ribbon Cutting Ceremony on June , 2003.

\section{July 2003}

Microturbine 2588 experienced the same fault codes and excessive cool down problem as the May incident. Visual examination of the internal engine by the previously prescribed Capstone engine failure procedure indicated another engine failure, with three chipped blades in the engine. FirstEnergy requested Capstone technical personnel perform an on-site review of the installation to assess the system. Greg Gillis Smith of Capstone performed a site review on Aug 2003 and prepared a report shortly thereafter essentially indicating approval of the site design and installation with minor comments. FirstEnergy responded with clarifications and corrections to the report and included a list of items discussed with the Capstone technical rep during the site review and as yet unresolved regarding the microturbines and the Unifin heat exchanger. One of 
which was concern for condensate developing in the exhaust system of a microturbine that I shutdown while others are operating in a common ducted system. It was noted to Capstone rep that the failed engine when removed from the unit for replacement had a significant amount of condensate in the engine even though the external exhaust system valve at the Unifin has been closed to deter exhaust flow to the failed engine. Capstone indicated a new backflow damper design was being developed and tested to prevent backflow of exhaust into a non-operating microturbine in a common ducted system. Capstone's assessment of the Canton City schools natatorium installation assessed that operation of one microturbine at this site while the other is shutdown would be acceptable especially if the external exhaust system damper at the Unifin was closed to deter backflow of exhaust to the failed microturbine. Capstone indicated the new backflow damper design would allow continuous operation of a common ducted system with any unit shut down without concern for backflow issues into any non-operating units in the system.

After sufficient documentation was provided to Capstone another engine was placed on order in September 2003. The engine arrived nearly 3 months later in late November of 2003. During discussions related to the engine failure and documentation issuance to Capstone, Capstone advised of another electrical connection change requirement to disconnect the microturbine neutrals from ground. This would be the second change and third electrical connection recommendation from Capstone beginning with the initial recommendation during the engineering in early 2002.

While awaiting delivery of the second replacement engine, and new design backflow dampers, new fuel heat exchangers were delivered for each microturbine 2588 and 2589. Also while awaiting delivery of the warranty parts and subsequent to a troubleshooting session Capstone advised of a potential operating problem with ducted systems relating to the possibility of excessive fuel entering the duct and potentially igniting on automatic restart of a microturbine.

The temporary fix for this by Capstone is to disable auto-restart, and this was done at the Canton City Schools as well as the other installation Fe has a ducted system. Curious to note, Capstone records indicated a FE ducted system for a microturbine that was not in a ducted configuration. The FE microturbine that is in a ducted configuration Capstone did not have identified as ducted. 
Also during this time multiple shutdowns of the remaining operating microturbine were occurring. Troubleshooting with Capstone service revealed high voltage at the site might be causing the microturbine trip on protection settings prescribed by the local electric utility.

Further investigation of data and subsequent advising to client resulted in resolution of high voltage issue allowing the remaining microturbine to be restarted and operated. Since microturbine 2588 had been out of service since July and multiple warranty replacements were necessary which required shut down of both microturbines to perform it was decided to wait for the engine and backflow dampers to arrive to perform all work during the same outage.

Multiple calls were placed to Capstone to assess the delivery date of the backflow dampers. Once a delivery date of the second week of December was identified, a tentative work date was scheduled. Anticipated delivery of the backflow dampers on Friday 12/12/03 or the end of the second week of December. On late Thursday 12/11 received notification the backflow dampers would not be delivered until 12/16. Having already scheduled assistance for the engine replacement performed scheduled replacement of engine and fuel heat exchanger for microturbine 2588, and separation of microturbines neutrals from ground on 12/12. Capstone service assisted with installation of software associated with the new backflow dampers and checkout and successful reconfiguration of both microturbines to dual mode multipac operation after completion of warranty work and left them in operation. Data monitoring indicates microturbine 2588 failed the next day, Saturday 12/13. Troubleshooting with Capstone service on $12 / 15,16,17$, and 19 indicated the failure to be an electronic failure and a replacement DPC was placed on order.

Since the backflow dampers had been installed Capstone Service approved operation of the microturbines in dual mode multipac even though the main unit had failed and would not run. Additionally, the external exhaust valve at the Unifin heat exchanger for microturbine 2588 was disabled to the closed position to deter exhaust from the operating microturbine from flowing back toward microturbine 2588.

While microturbine 2589 was operating and the insulation was being reinstalled around the new 
backdraft dampers, the technician installing the insulation noted condensate dripping from the overlapping slip fit connection of backflow damper of microturbine 2588, the non operating microturbine. On 12/25 while checking operation of the system, and attempting to interpret occurrences of operating shutdowns and restarts of the remaining operating microturbine the remaining operating microturbine (2589) had shut down. Anticipating a restart, and not knowing the reason for shutdown and to limit any condensate the system was commanded to shut down.

\section{November 2003}

Microturbines tripped offline. It was suspected that voltage at the Natatorium site in excess of the local utility prescribed protection setting levels was causing the microturbine to trip offline. The high voltage situation at the Natatorium was corrected on Thursday Nov. 20 at approx.

10AM. All three of the phase voltages began to operate closer together and without the extreme peaks. Data logging equipment on the microturbines show the change in voltage. Operation of MT2 at the site was restored

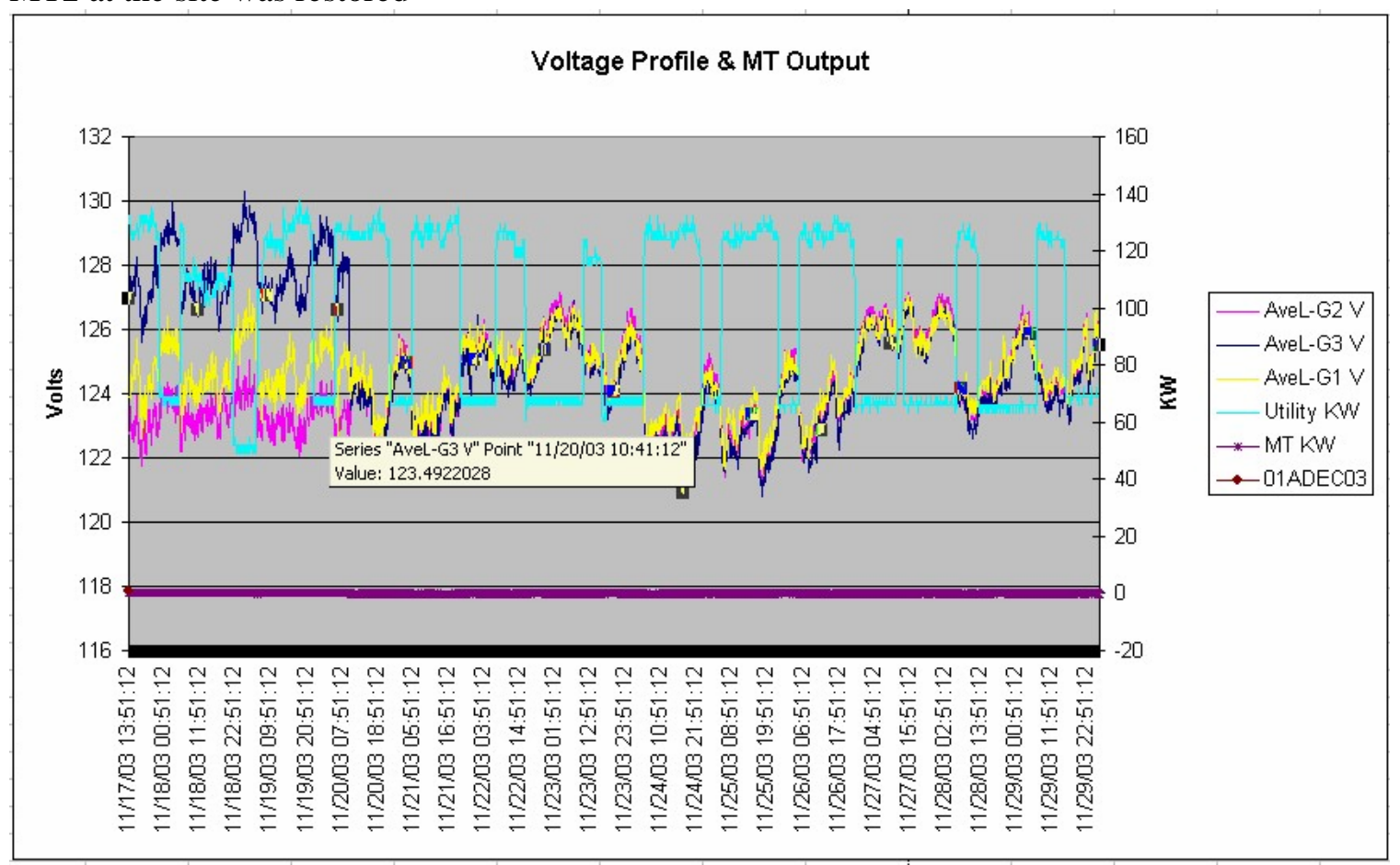

The CoolTec absorption cooling unit had several issues that caused concerns for continued use of the unit. This new technology seemed to work well when in operation, but the time it took to fix any problems caused significant downtime. Much of the time was associated with getting CoolTec to respond to calls for maintenance and for replacing parts that caused the unit to go 
down. This is a new technology (utilizing waste heat for generation of cooling) and additional testing of the unit will be necessary before the unit is ready for commercial deployment.

\section{Conclusions}

The overall objective of the demonstration was successful. The Canton project:

- Demonstrated the viability of microturbine technology in combination with microabsorption technology in a school setting;

- Identified field related issues that will need addressed to ensure the successful commercialization of these technologies;

- Introduced these emerging technologies to key markets and decision makers.

The demonstration was not without its problems. As identified, the equipment is not ready for applications where separate units are needed to capture the waste heat products without significant project management intervention. First Energy shouldered much of the work above and beyond their original scope in an effort to learn about the technology and implications for the emerging CHP market in Ohio. Without their role, I believe that the school district would have become upset with the technical issues that popped up during the test and data collection period. That being said, Capstone has developed an "integrated” approach to capturing the waste heat for utilization. This technology is already in operation at another site in Ohio (Toledo Museum of Art) and the project management for this project is more in line with the original expectation for CHP projects.

We are working with Canton SD in an effort to take this project to the next step. A third party has been asked if they would be interested in owning and operating the system for CSD, providing the natatorium with electricity and heated water for the pool. This company is an authorized Capstone distributor and hopes to use the own/operate model in developing the CHP business in Ohio.

\section{Recommendations}

From a technology perspective, the integrated system approach appears to have eliminated many of the issues that the Canton project had to address. Of particular note, when developing these projects, one must consider that fitting this technology into existing infrastructure does cause escalation of project costs. The best time to incorporate these concepts is during original construction.

In addition, the current spark spread (due to rising natural gas prices) places many of these types of projects in the business world on the back burner. Focus should be given to those projects in the institutional sector due to their ability to justify projects with longer payback periods. 


\section{Task 3}

Portable classroom characterization and Research - FSEC

\section{Task 3: Portable Classroom Characterization and Research Final Report}

\section{Executive Summary}

This report summarizes work performed for Task 3 of the NASEO schools project. This task sought to evaluate measures for portable classrooms to improve energy efficiency and improve learning conditions through improved indoor air quality and the enhanced interior lighting. Research highlighted both theoretical potential as well as the measured performance. Task 3A aimed to identify a portable classroom baseline upon which the project could analyze various options. Information was collected from portable manufacturers around the U.S. The baseline represented standard portable classroom characteristics in terms of the envelope and equipment within the facilities. A simulation model was developed based on the DOE-2 hourly simulation and was used to simulate portable classrooms in various climates. The simulation showed that the potential existed to cut energy use in portables by 44 - $48 \%$ with the greater potentials in milder climates. Strategies yielding the best performance differed by climate. In the coldest climates, high levels of insulation and reductions to infiltration and duct leakage were most important. In mild climates, the best performing options were reductions to roof and window solar gain and improvements to lighting system efficiency. Ventilation interactions and duct heat gain looked important in all climates.

Based on the results from Task 3A, we designed, specified and built standard baseline and energy-efficient portable classrooms in three varied climates. Two matched pair portable classrooms were located, instrumented and monitored in three locations: Cornwall, New York (cold climate), Chapel Hill, North Carolina (mixed climate) and Orlando, Florida, (hot-humid climate). The features installed in the classrooms were intentionally different. These represented a cold, mixed and hot climates, respectively.

\section{Figure E-1: Measured daily electricity use in comparative portable classrooms in Orlando, Florida, 2003-2004}

In each location we found that annual portable energy requirements were dominated by heating and cooling end-use - with lighting only about $10-15 \%$ of total. The monitored long-term measured energy savings of the efficient models were 36\% in New York, 46\% in North Carolina and 80\% in Florida. Superior interior lighting with integrated skylights in the experimental model was uniformly demonstrated. However, incremental costs were much greater than anticipated, largely due to the experimental nature of the research. Even so, payback from energy savings were between 12 and 18 years. Documented "lessons learned" should allow integration of identified technologies in a more cost effective fashion. For instance, the combination of tubular skylights with a sealed attic plenum with insulated roof deck system covered by a reflective roof in the Florida portable showed superior performance at potentially lower costs.

Task 3C expanded on the design and evaluation task of the portable classrooms, by creating improved procurement specifications. The task listed the detailed specifications 
for the various identified design elements, A report appendix shows on-line web pages for the project to achieve wide-dissemination of the key research results. This includes a detailed vendor list.

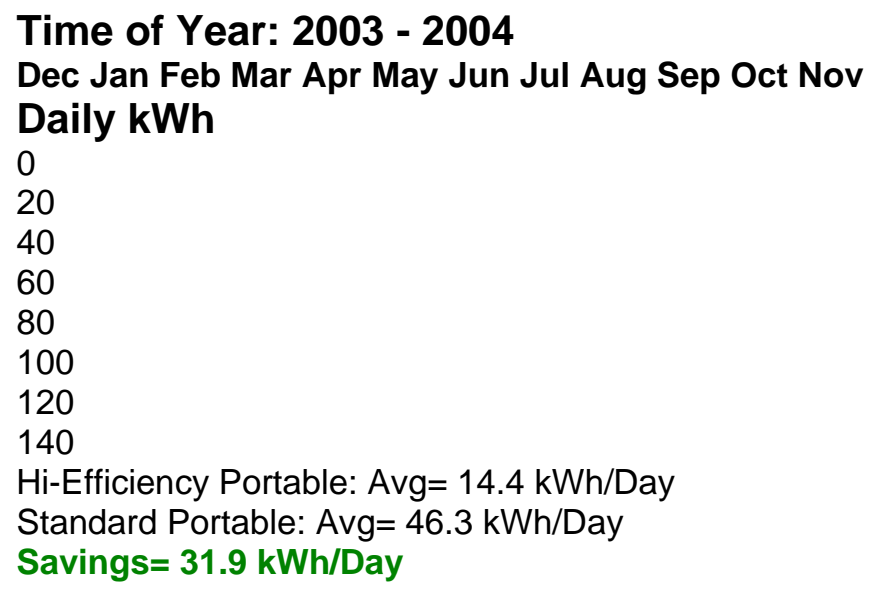

This final report summarizes the work performed for Task 3 of the NASEO schools project. Task 3 sought to analyze and predict strategies that could be applied to portable classrooms to improve energy efficiency and improve learning conditions through improved indoor air quality and the enhanced interior lighting.

The report describes the various analytical and experimental methods uses in the project as well as summarizes lessons learned within the research. Practical recommendations are made regarding how the identified technologies could be applied in a broad fashion with portable classrooms nationwide. Conclusions are based on theoretical and empirical research results within the project. Further opportunities are identified as well as those program elements needing more research to enhance energy saving goals. The report is organized into three distinct parts. Each of these report sections are selfcontained.

Task 3A aimed to identify a portable classroom baseline upon which the project could analyze various options. The baseline looked to represent standard portable classroom characteristics in terms of the envelope and equipment within the facilities. We also looked to summarize available research on the baseline and on portable classroom energy efficiency in general.

Task 3B aimed to design, specify and build standard baseline and energy-efficient portable classrooms in varied climates. Each set of two matched pair portable classrooms were monitored in three locations: Cornwall, New York (cold climate), Chapel Hill, North Carolina (mixed climate) and Orlando, Florida, (hot-humid climate). Section 3B of this report describes the measured energy savings of the standard classroom compared to the energy efficient model in each climate. Findings summarize the elements that were found to be critical to effective results. 
Task 3C expands on the design and evaluation task of the portable classrooms, by creating improved procurement specifications. This is done by a listing of the key design elements, the specification differences and some of the lessons learned with the project design and execution that would be vital to large scale successful energy-efficient portables projects. Very important lessons were learned in the design, development and building of the portables as well as experience from the monitoring. All these are summarized in the final section of the report.

An appendix shows the on-line web pages that have been created within the project to achieve wide-dissemination of the key research results.

\section{Task 3A: Establishment of a Baseline for Evaluation of Energy-Efficiency Improvements to Modular Classrooms}

\section{Introduction}

The objective of our investigation is to evaluate innovations that would enable modular classroom builders to improve the energy performance of their classrooms. We investigate improved insulation, better windows, daylighting, cross-ventilation, sensible and latent heat recovery of ventilation air and light colored surfaces and radiant barriers for cooling dominated climates. The tasks associated with this work are as follows:

- Create a simulation software.

- Establish a baseline reference building using a standard modular classroom building.

- Parametric evaluation of the impact of ventilation and school schedule on energy use.

- Determine the feasibility of improving insulation and envelope systems.

- Determine the feasibility of using windows and overhead skylights to reduce electrical lighting and mechanical cooling.

- Simulate improvements to lighting and HVAC system controls.

- Examine improvements to heating and cooling system efficiency.

\section{Classroom Simulation Model}

We created a building energy simulation to model the energy performance of modular classrooms. We utilized a modified version of EnergyGauge USA to accommodate classroom schedules and occupancies. The program uses DOE-2.1E as the simulation engine. The model and its validation are more completely described elsewhere (Parker et al., 1999; Fuerhlein, 2000). Separate schedules were developed for lighting and HVAC use based on a conventional school year (August 15th - May 15th) and one which includes summer school. The schedule assumes the school day to extend from 7 AM to 5 PM based on both occupancy and after-school activities. The degree with which HVAC equipment and lighting systems are positively switched off is based on previous 
monitoring and surveys (Callahan et al., 1999). The performance of enthalpy recovery ventilators (ERVs) and the application of ASHRAE Standard 62-1989 are based on a detailed monitoring evaluation of such equipment (Shirey et al., 1997).

\section{Preliminary Research}

Our work plan had several tasks: collect data, prepare computer models, develop a baseline building, evaluate design possibilities, generate design alternatives and evaluate their performance. Later, we plan to analyze costs and select the final designs. The baseline modular classroom building (Figures 1 and 2) is 28' x 64' and has the following energy-related specifications: walls R-11, floors R-11, roof R-30, (2) aluminum frame slider type windows $U=1.17$, (2) insulated steel doors, 2' x 4' recessed four-tube fluorescent light fixtures - $50 \mathrm{Fc}$ and a 3-ton air conditioner with $10 \mathrm{~kW}$ of strip resistance heating.

\section{Figure 1. Baseline modular classroom building.} Figure 2. Floor plan of the baseline modular classroom.

We plan to analyze the heating and cooling loads of the baseline modular classroom building with its long side facing east in seven different climates: Tampa, Florida; Sacramento, California; Rochester, New York; Raleigh, North Carolina; Cincinnati, Ohio; Dallas, Texas and Phoenix, Arizona using a specially produced DOE-2.1E software. Each climate presents a different challenge to mitigate the energy consumption of the classroom against the prevailing weather conditions. However, for this initial analysis we simulated the two heating and cooling extremes (Rochester, New York and Tampa, Florida) as well as a mixed climate (Raleigh, North Carolina).

The analyses were used to redesign the modular classroom to integrate daylighting, windows and envelope design, and heat recovery for ventilation air as appropriate for each climate. Based on individual parametric analyses, we assemble successful groupings of measures (packages) for each climate.

\section{Building Geometry}

While modular classrooms come in different sizes and configurations a double-classroom structure with a common wall and a low-slope roof appears to dominate the market. To characterize the modular classroom market, we evaluated submitted designs from the manufacturers: United Modular (Glenrose, TX), Roger Carter (Kingston, NC) and Walden Structures (Capistrano, CA). By far the most models are double classroom units with dimensions of twenty-four (24') to twenty-eight feet (28') in width and from fifty-six (56') to sixty-four (64') feet in length. The study baseline unit is one half of a 28' x 64' two classroom unit with a restroom (see Figures 1 and 2). This type of unit is comprised of two 14' wide by 64' long modular sections. This unit has a pitched roof with the ridge running in the 64' direction. A T-bar suspension ceiling is typical with the ventilation of the roof plenum as a construction variable. The unit is also equipped with two exterior 
door and two windows per classroom. The construction of this unit is consistent with The Uniform Building Code (UBC) type 5 non-rated construction, light frame wood. The occupancy classification is E-1, educational, with 25 occupants. The following is a brief summary highlighting some of the standard features of this baseline modular classroom.

\section{Floor Construction}

The floor construction is comprised of light wood framed joists with plywood floor sheathing, fiberglass batt insulation, and typically carpet for a finish.

\section{Wall Construction}

The exterior wall construction is comprised of light wood frame studs with a plywood combination siding and structural sheathing (i.e., T1-11), fiberglass batt insulation and an interior finish of a pre-decorated gypsum board.

\section{Roof Construction}

The roof/ceiling construction is made up of light wood framed trusses with plywood sheathing, fiberglass composition shingles, fiberglass batt insulation and a suspended acoustical tile ceiling system. Consistent with the submitted plans, the roof top structure is a low-slope metal roof.

\section{Heating and Ventilating System}

This unit is equipped with a 3-ton wall-hung package unitary heat pump with $10 \mathrm{~kW}$ back-up electric resistance heating. A 32 foot supply duct runs down the classroom centerline and is located in the plenum space (attic).

\section{Electrical System}

The main electrical service for this unit is a 200 amp 120/240 volt single-phase system controlled by a main distribution panel. Provisions are made for lighting, electrical convenience outlets, fire alarm systems, intercom and clock systems as well as serving power to the heating, ventilating and air conditioning system.

\section{Energy Baseline for Various Climates}

We plan to perform simulations for the following seven climates representing much of the market areas and climatic variation within the U.S.

- Tampa, Florida

- Sacramento, California

- Phoenix, Arizona

- Raleigh, North Carolina

- Dallas, Texas

- Cincinnati, Ohio 
- Rochester, New York

For this draft preliminary report, an analysis was done on the two extreme climates (Tampa and Rochester and a mixed climate- Raleigh. The hourly simulation uses Typical Meteorological Year (TMY2) data for each location to perform the calculations.

The energy baseline was simulated using the information gathered during the early phase of the project based on submitted plans. The simulations use a nine-month schooling period. The schedules for people, lights, and equipment are based on a study of classroom modules in Florida. The simulation was performed with the assumption that each classroom holds 25 students and 1 teacher (26 people total) that generate 240 $\mathrm{Btu} / \mathrm{hr} /$ person of latent heat and $100 \mathrm{Btu} / \mathrm{hr} /$ person of sensible heat into the space. Impact of the large interactions of waste heat from the lighting system and heat loss and gains from the building envelope are intrinsically computed within the simulation. In order to accurately simulate the performance of the HVAC system, the performance data for the units was input for a Packaged Terminal Air Conditioner (PTAC) unit with heat-pump as the heat source. The data was obtained from the manufacturer (Bard, WallMount heat pump, model WH361-A). Three different sets of performance data were input: the Cooling Capacity, the Heating Capacity, and the Heating Electric Input Ratio (EIR) and Cooling Electric Input Ratio (CEIR) of the system.

\section{Comparison of Simulation Model to Measured Data}

In order to verify the accuracy of our baseline simulation, we compared the simulation's fuel use predictions to energy use records collected for a Florida classroom building. Detailed monitoring has been performed within this project (Callahan, et. al., 1999). Daytona Beaches' climate data was used for simulating the module classroom in Port Orange, Florida due to its geographical proximity and climatic similarity.

Teachers in the modular buildings for the academic year 1998 were interviewed. The questionnaire included clarifications regarding the number of students occupying the classroom, the schedule for the equipment use, and the use of lights and hot water, and the schedule of the class for the whole academic year. No alteration was required from the established schedule.

However, to approximately match the predicted performance of the baseline case with the actual energy use, the following rough changes were made to the baseline case.

- Classroom window geometry was altered to conform to actual configuration.

- Lighting fixture density was increased (monitored portable had $2.16 \mathrm{~kW}$ installed)

- Cooling thermostat settings were taken from metered data.

The simulation model results for Daytona Beach weather that was compared to energy use records with the following results.

Table 1

End Use Predicted and Simulated at Silver Sands Portable Classroom kWh per Day 
End Use Measured kWh* Predicted kWh Error (\%)

\begin{tabular}{|l|c|c|l|}
\hline End Use & Measured kWh* & Predicted kWh & Error (\%) \\
\hline \hline Cooling & 14.0 & 15.4 & $+10 \%$ \\
\hline Heating & 3.6 & 3.2 & $-11 \%$ \\
\hline Lighting & 13.1 & 11.1 & $-15 \%$ \\
\hline Total & 31.4 & 29.7 & $-5 \%$ \\
\hline
\end{tabular}

* Source: M.P. Callahan, D.S. Parker, J.R. Sherwin and M.T. Anello, 1999, Evaluation of Energy Efficiency Improvements to Portable Classroms in Florida, FSEC-CR-1133-99, November, 1999 (see Figure 3).

The degree of correspondence is particularly good considering that the specific schedules and weather data were necessarily approximate to the corresponding conditions associated with the measured performance. Our prediction was within $5 \%$ of the actual energy use indicating that our simulation is fairly representative of the monitored modular classroom building. This also gives confidence in the simulation results.

\section{Baseline Reference Building}

We analyzed a series of efficiency measures in each climate location for the reference modular classroom. The base building in each location had R-11 walls and floor insulation, R-19 ceiling insulation (suspending between the trusses), single glazed windows with two insulated doors.

The space conditioning system consisted of a 3-ton air conditioner (SEER 9) with $10 \mathrm{~kW}$ of electric strip heat. The supply duct was located in the attic space; the duct related leakage of the distribution system amounted to $168 \mathrm{cfm}$ at a tested system pressure of 25 $\mathrm{Pa}(\mathrm{Qn}=0.15)$. This characterization is in agreement with an assessment done by Cummings (1998) on seven portable classrooms in Florida.

We note that many of the space conditioning systems in portable classrooms have significant leakage around the through the wall penetrations for the side-mount AC units. The lighting system consists of six four-tube flourescent fixtures with $40 \mathrm{~W}$ tubes and magnetic ballast (180 Watts each). Based on our experience with the lighting energy use in the two monitored portables in Port Orange, Florida (Callahan, et.al., 1999), we assume that lighting is accidentally left on about $10 \%$ of the time over night and about $5 \%$ of the time over weekends and holidays.

We also assume that the HVAC systems are accidently left on for similar periods. These assumed rates for human error allow evaluation of the potential savings of occupancy based controls. 


\section{Issues Associated with Ventilation and Infiltration}

Based on our survey of manufacturers and installers, as well as from local units surveyed in Florida we learned that nearly all modular classrooms are shipped with outside air dampers closed. No installers with which we spoke indicated that these were opened when installed in the field although the mechanical engineers associated with the modular designs were aware of the potential issue. Although we analyzed a specific case with dampers closed as they are likely installed, we assumed that the dampers were placed in the first stop $(150 \mathrm{cfm})$ for our reference case. Since we assumed average occupancy for the purposes of ASHRAE Standard 62-1989 (25 students and teachers in the classroom), this amounts to $6 \mathrm{cfm} /$ student and corresponds well to previous studies (Callahan, et.al., 1999). It is noteworthy that this is not adequate to meet the requirements for ASHRAE Standard 62-1989 which requires $15 \mathrm{cfm} /$ student. In recent years, much attention has been leveled at improving school ventilation as a means to improve indoor air quality (Construction Specifier, 1999; Energy Design Update, 1997).

Thus, for our analysis of potential improvements we compare compliance with ASHRAE Standard 62-1989 with a case where only $6 \mathrm{cfm} /$ student is being provided. We do this so that the predicted energy savings associated with the suggested changes to modular classrooms will not be altogether out of keeping with the actual achieved savings. Another conservatism associated with the analysis is that we assume that the roof/plenum is not ventilated as is done with some models. When this is done with the dominated Tbar suspended ceiling, the attic vents become a site for major envelope air leakage. This has been observed in work done on building leakage and air change rates on seven portable classrooms in Central Florida (Cummings, 1998). For instance, those with T-bar ceilings with ventilated plenums were found to have total envelope leakages averaging 22 ACH @ 50 Pa pressure. On the other hand, with one building which had a rigid ceiling, the leakage was only $7 \mathrm{ACH}$ at $50 \mathrm{~Pa}$. Thus, within the analysis we assumed that although T-bar ceilings would be used, that the attic plenum would not be vented.1 This was the case for two of the three submitted plans which were reviewed.

\section{Analyzed Measures}

Below we list and briefly describe the specific measures analyzed for each site.

\section{Roof/plenum}

As options we evaluate increases to roof insulation thickness from R-19 hr-ft2-F/Btu to $\mathrm{R}-30$ or R-38. We also predict the impact of the addition of a perforated foil face to the roof insulation creating an attic radiant barrier. We also evaluate the impact of choosing a reflective white metal roof rather than an unfinished galvanized surface. Both of these measures are demonstrated to reduce cooling, although the reflective roofing will increase heating somewhat (Callahan et al., 1999).

\section{Walls}

We analyze how a thicker 2 x 6" wall with R-19 will improve performance. We also examine how adding 1 inch of isocyanurate sheathing to the exterior of the R-11 wall would alter heating and cooling. Finally, we also evaluate how a light pastel wall color 
would reduce cooling as compared to the base line medium tan color (solar absorptance $=$ $0.6)$.

\section{Windows}

We evaluate double clear glass compared with the single glass normally assumed (U= $0.69 \mathrm{Btu} / \mathrm{h}-\mathrm{ft} 2-\mathrm{F})$. We also evaluate double glazed units with a low-e coating $(\mathrm{U}=0.59)$. And finally, we evaluate the above with a solar control outer lite designed to reduce cooling needs (SHGC =0.38). All glazing units were assumed to have aluminum frames.

1 We assume 9 ACH@ 50Pa as the building envelope leakage within the reference simulation analysis.

\section{Ducts}

We evaluate a sealed air distribution system where tested leakage to outdoors is only 54 $\mathrm{cfm}(\mathrm{Qn}=0.05)$. We also evaluate the impact of moving the supply duct to the interior of the conditioned classroom to avoid duct conduction losses.

\section{Lighting}

We evaluate the substitution of slim-line T-8 lamps with electronic ballasts for the T-12 system with magnetic ballasts in the baseline system. This reduces the 4-tube fixture wattage from 180 watts to about $110 \mathrm{~W}$. We also estimate the savings from using occupancy sensor control to positively shut off lights during unoccupied periods.

\section{Daylighting}

We evaluate a proposed daylighting package with a reduction to fixture lighting density. This involves adding three 22" tubular solar skylights spaced evenly down the center line of the classroom along with a strip of one foot high glazing located along the sides of the building up by the top of the door-line. These would include an interior light shelf to prevent glare and to reflect daylight to the ceiling. To achieve savings, the lighting fixtures would be altered from four tube to two-tube T-8 fixtures. This simple expedient would insure lighting systems, save on costs and result in a simple and robust system to harvest daylight.

\section{Heating and Cooling Systems}

The baseline air conditioner would be altered to a more efficient SEER 10 unit, or with a heat pump with supplemental strip heat. Finally, occupancy based HVAC controls would be evaluated to provide positive off during unoccupied periods. 


\section{Ventilation}

Parametric evaluation considers no ventilation as many modular classrooms are shipped and operated, as well as compliance with Standard 62-1989 without heat recovery, but with a 4-ton heating and cooling system. Other evaluation would be made of use a $60 \%$ effective enthalpy recovery ventilator (ERV) in compliance with 62-1989 providing 375 $\mathrm{cfm}$ of outdoor air to the classroom. Based on performance data, the required fan power for such systems is approximately $0.9 \mathrm{~W} / \mathrm{cfm}$ which was modeled within DOE-2. Such a system was modeled with standard strip heat and with a heat pump. Finally, we evaluate the impact of using operable windows in the daylighting package to provide cross ventilation to reduce cooling needs.

\section{Measures Packages}

Based on the parametric evaluation of the specific measures, ones were chosen which showed the potential to produce promising systems. These are noted in the Tables A, B and $\mathrm{C}$ that follow and are marked with an asterisk (*). The combined performance of the packages is shown for the standard school schedule and for one including summer school.

\section{Results}

The results of the simulation parametric analysis and the grouping of measure packages is given in Tables A, B and C (pages 10-12) for Rochester, NY, Tampa, FL and Raleigh, NC, respectively. Even though the annual energy consumption in the simulated model matched to within 5\% of the actual energy consumption in our test evaluation where metered data was available, it would be desirable to obtain similar data from a cold climate location. Even thought the measures differed with different locations the predicted energy savings were approximately $45 \%$ in all locations. An implicit assumption within our analysis is that the attic/plenum space will be sealed. This is important given the findings by Cummings (1998) showing that T-bar ceilings in portable classrooms are inherently leaky.

A general summary of the results is as follows:

- In hot, cooling dominated climates such as Tampa, measures which reduce lighting and its internal heat generation show greatest promise to reduce building energy needs. Daylighting looks particularly attractive in this location although solar control glass looks important to reduce the space cooling liability. Similarly, light colored surfaces and solar control glazing looks more important than insulation. Heating system type is not as critical as cooling efficiency. Floor insulation is counterproductive.

- In cold, heating dominated climates such as Rochester, New York, insulation measures and duct air leakage control measures look to be most important. The results would further suggest that ground source heat pumps (GSHPs) or natural gas heating may be attractive alternatives to air-source heat pumps. Daylighting, while producing savings in lighting energy, tends to increase heating budgets and is not as attractive as insulation and heating system measures. It appears important that a successful daylighting strategy in 
12 such location utilize highly insulated glazing (double glazed low-e was assumed) in order to be successful. Floor and wall insulation is important, solar control glass is counterproductive.

- Mixed climates, such as Raleigh, North Carolina, evidence an amalgam of the preceding extremes. Insulation with a radiant barrier looks to be the best strategy for the roofing system as it helps control both heating and cooling needs. However, daylighting is quite attractive as it reduces lighting energy and substantially reduces space cooling. Insulation measures, duct leakage control and a more efficient heating system all look to be promising measures. Specification of a heat pump is important to controlling heating costs.

All packages show that ventilation heat recovery is vital to prevent energy savings from envelope and lighting measures from being swamped by the thermal impacts of complying with ASHRAE Standard 62-1989. Similarly, occupancy based control of lighting and HVAC systems is beneficial in all locations. A summary of results is given below in Figure 3.

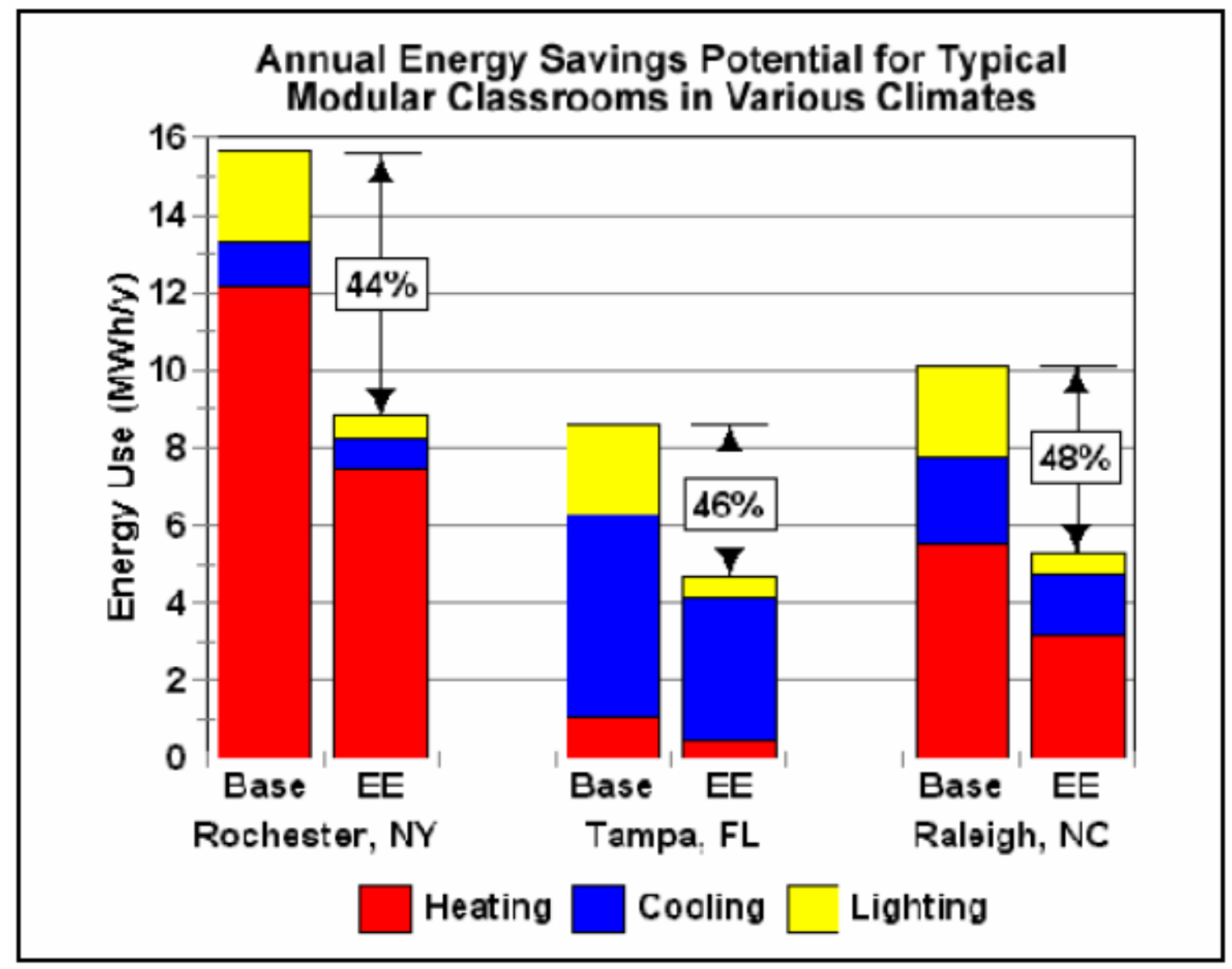

Figure 3 


\section{Task 4}

Advanced Daylighting Research - Energy Center of Wisconsin

\section{PROJECT OVERVIEW}

The Association of State Energy Research and Technology Transfer Institutions, Inc. (ASERTTI) and the National Association of State Energy Officials (NASEO) with the Department of Energy (DOE) and the EnergySmart Schools Program conducted a joint project that encompassed applied research, field testing and technology integration.

As part of the overall project there were eight distinct tasks outlined, each with its own set of goals, activities and deliverables. This document was created to summarize the work done under Task 4: Advanced Daylighting Research.

This report is organized by the five specific sub-tasks of the Advanced Daylighting Research project each of which were researched, studied and analyzed:

1) Baseline Information

2) Roundtable/technical Review

3) HVAC Performance Research

4) Demonstration Sites, Monitoring and Evaluation

5) Design Guidelines and Training Materials

Each sub-task has a summary sheet that addresses the areas of: challenges; solutions; results; and future recommendations. Additional information can be found on-line at http://www.daylighting.org/naseo.htm

The following organizations worked collectively to conduct this research:

Energy Center of Wisconsin

Iowa Energy Center

Lighting Research Center

Lawrence Berkeley National Laboratory

\section{EXECUTIVE SUMMARY}

This project produced significant daylighting data, which will serve as a foundation to strengthen the knowledge base for both daylighting researchers and practitioners. Each of the five subtasks highlight key findings and the significant data their specific research produced. This information is detailed in the Results section of each subtask and is also summarized below.

Research key findings:

- Databases on energy usage and design features directly relating to classroom spaces were virtually non-existent

- Cool Daylighting is recommended as a no or low first cost, simple approach to daylighting schools 
- Laboratory results indicate the lighting and HVAC operating cost savings for the subject high-performance classrooms was considerable and represented a savings of nearly $25 \%$ on operating costs of about $\$ 1.13$ per square foot

- Demonstration classrooms successfully adapted the principles of daylighting to create comfortable, bright and cheerful environments. The occupants consider their classrooms to be superior to non-daylit rooms.

Perhaps as significant as the research key findings are the areas identified where additional research and/or field testing would greatly increase our knowledge base and provide critical data for the daylighting market. The research pointed out areas where data is either non-existent or does not offer robust data from which strong recommendations can be made or actions taken. This information is detailed in the Future section of each subtask and is also summarized below:

Future recommendations

- Develop a robust database with information on classroom energy use, window glazing design and skylights

- Provide "why to daylight” training sessions to school boards/administers and "how to daylight" training sessions to architects and engineers

- Run DOE-2 energy analysis simulations on typical classrooms and then on daylighting enhanced classrooms

- Analyze additional classrooms for extended periods of time to further help quantify energy usage in order to make recommendations to a wider base of schools

- Widely publicize and disseminate the research and test results to educate and encourage daylighting features to be designed into future new construction projects and become mainstream design practices.

Energy Smart Schools - Applied research, field testing and technology integration: Subtask 1 - Baseline Data

\section{CHALLENGE}

Obtain and analyze existing and emerging school building energy performance data in four states: California, Florida, New York, and Wisconsin. The goal of this data collection was to deliver a baseline database or recommendations for such a database that could contain window and daylighting features and energy performance characteristics of Kindergarten through $12^{\text {th }}$ grade (K-12) school buildings (or those of classrooms when available).

\section{SOLUTION}

Collected and compiled data from:

California CEUS databases 1992-99

Florida FSEC data \& report (Callahan et al. 1997)

Wisconsin WEI-2 school survey data (1997-98)

National level: Commercial Buildings Energy Consumption Survey (CBECS) 


\section{RESULTS}

After reviewing existing databases developed on the utility, state, and national levels, and key parameters used in the Energy Star models developed by the EPA, we have found 1) that there is scattered K-12 school data available from utilities and some states such as Florida and California; and 2) that CBECS appears to be the best identified to contain similar information on the national level, but that it only contains aggregated data with other educational facilities, e.g., university and college buildings. Data on energy usage and design features directly related to "classroom" spaces was virtually non-existent in our investigations. 
School Energy Use Intensity (aggregated)

\begin{tabular}{|c|c|c|c|c|c|c|}
\hline \multirow[b]{3}{*}{$\begin{array}{l}\text { Energy Use and } \\
\text { Floor Areas }\end{array}$} & \multirow[b]{3}{*}{ Statistics } & \multicolumn{4}{|c|}{ State } & \multirow{2}{*}{$\begin{array}{c}\text { National } \\
\text { CBECS (Education) }\end{array}$} \\
\hline & & CA & $\mathrm{FL}$ & NY & WI & \\
\hline & & $\begin{array}{c}\text { sum of electricity and } \\
\text { natural gas use per square } \\
\text { foot of school building } \\
\text { floor area }\end{array}$ & \begin{tabular}{|c|} 
total energy use per \\
square foot of air \\
conditioned floor area
\end{tabular} & - & $\begin{array}{l}\text { total energy use per } \\
\text { square foot of school } \\
\text { building floor area }\end{array}$ & $\begin{array}{l}\text { total energy use per } \\
\text { square foot of } \\
\text { education floor area }\end{array}$ \\
\hline \multirow{4}{*}{$\begin{array}{c}\text { Statistics of EUI } \\
\left(\mathrm{kBtu} / \mathrm{ft}^{2} \mathrm{Yr}\right)\end{array}$} & Median & 45.2 & - & - & - & - \\
\hline & Mean & 59.2 & 68.0 & - & - & 75.0 \\
\hline & Max & 215.0 & 226.0 & - & - & - \\
\hline & Min & 27.0 & 2.0 & - & - & - \\
\hline \multirow[b]{2}{*}{$\begin{array}{l}\text { Building Size - } \\
\text { Floor Area }\left(\mathrm{ft}^{2}\right)\end{array}$} & Median & 37,434 & - & - & - & 8,000 \\
\hline & Mean & 54,546 & $\begin{array}{c}98,900 \text { (Gross) } \\
87,151 \text { (AC) } \\
\end{array}$ & - & - & 26,456 \\
\hline Schools & Total number & 37 & 654 & - & - & 327,000 \\
\hline
\end{tabular}

\section{FUTURE}

The various databases studied in this project provide a lot of good information on school energy use and/or window glazing features, and some possible correlations among such parameters, but none of the databases is adequate for providing robust information and relational information on classroom energy use, window glazing design, and skylights. Given the weaknesses of current databases, we opted to recommend key information to be included in future databases rather than focus on achieving a new and powerful database that already contains such information.

Following is a list of recommended parameters and information to be included for future efforts. Energy information:

- Annual energy use and costs: types of energy use (electricity, natural gas, other fuels), building areas served, equipment types and usage

- Climate: climate zones and weather information

- Services: notable services and equipment that may impact the on-site energy use Building design and operation information:

- Building and school type (e.g., high school, middle school, vocational school, and elementary school; portable classrooms, regular classrooms)

- Gross floor area, classroom floor area, number of months in use, number of personal computers (PCs), number of students and faculty, operation schedule (e.g., weekly operating hours, monthly, non-school days), \% of space air conditioned, \% of space heated, ventilation.

- Information about on-site cooking facilities, meals, gymnasium, athletic facilities with showers, swimming pool, hot tubs, auditoriums, media centers/computer center, cafeteria, refrigerators or freezers

- Vintage and retrofits

- Lighting equipment types, control, and operation 
- Mechanical systems, control, and operation (e.g., thermostats, humidity problems, central cooling set points, ceiling fans, demand controlled ventilation, light colored roofs, heat pump, HVAC type)

Features of window and daylighting:

- The design features of windows, glazing, shading, and daylighting. This includes the information on glazing layer, glazing types (tinted, reflective, clear), glazing feature (gas-filled, low-e), window frame (wood, metal, etc.), interior shading and types (fixed, movable, none), window/wall area ratios, orientation, exterior shading, and skylight

- Operational characteristics such as operable windows and their use

Energy Smart Schools - Roundtable and Technical Review - Subtask 2

\section{CHALLENGE}

Conduct a review of the Cool Daylighting curriculum to determine its applicability to New York schools.

\section{SOLUTION}

The Lighting Research Center (LRC) and the Energy Center of Wisconsin (ECW) convened a group of national experts to review the Cool Daylighting curriculum and a group of local architects, engineers and building officials to determine whether Cool Daylighting was appropriate for New York schools.

\section{RESULTS}

Technical Review

LRC selected four outside technical experts in the field of daylighting, as well as three LRC staff, to read selections from the curriculum and provide comments. Comments included:

- Cool Daylighting has much excellent material and is commendable as a no or low first cost, simple approach to daylighting schools.

- The presentation at the NYS training sessions should include only school examples, particularly ones in New York State.

- The Cool Daylighting team should consult commonly accepted sources for human factors claims, word such claims carefully, and cite them explicitly. Some claims are over-stated and call into question the objectivity of the material.

- People will want to see an energy analysis simulation for New York State, including impact on HVAC systems. It should include a base case of typical practices, a second case with just Cool Daylighting window recommendations, and a third with both window and electric lights. Results should be listed in terms of both first cost (for architects) and energy (for maintenance people). 
- State more clearly that Cool Daylighting is a general system of building strategies, with low or no additional first cost, for use in typical schools. It does not preclude "high end" daylight design.

- Low- or no-first-cost is achieved through incorporation of a downsized HVAC system.

- Mechanical engineers will accept reduced HVAC system for tinted glass and window size, but not savings for lighting controls.

Roundtable

LRC convened a roundtable of local architects, engineers and building officials to discuss typical school lighting systems, HVAC systems and windows, project decision-making, school usage patterns, and general attitudes towards daylighting in schools. The roundtable included four architects, one electrical engineer, two state building officials, one general contractor, and representatives of both project sponsors and of the project team. Key points include:

NYS characteristics:

- There is much diversity in school building stock. There is a substantial amount of school renovation and additions going on, as well as new construction.

- New York State Education Department has established code requirements for minimum glazing area, operability of windows, and egress.

- Architects often have limited flexibility on building orientation.

Response to Cool Daylight:

- It's difficult to get mechanical engineers to rethink assumptions. One must meet with them early in the project to ensure the HVAC savings get implemented.

- If you can make a specific energy or maintenance cost savings argument to school districts, Cool Daylighting will be easy to implement.

- Right now, this program is just a first step. Cool Daylighting needs to grow to accommodate other spaces than classrooms within schools.

Decision process:

- Daylighting should be part of the decision process very early on prior to funding. Curriculum suggestions:

- The materials need to show school examples, not offices. Ideally these examples should be actual installations in New York State, as they become available.

- Examples are needed of how to implement Cool Daylighting with historic facades.

- A local classroom “copy room” that people can visit would be very helpful.

- School board members may need a "why to" training session, in addition to the "how-to" session for architects and engineers

- Cool Daylighting personnel will need to provide "second-look" design assistance for at least the first project that each firm designs. 


\section{FUTURE}

Based on the reviews of the Cool Daylighting curriculum, the Lighting Research Center recommends the following for the Cool Daylighting curriculum in New York State classrooms, funding permitting.

- Run a DOE2 energy analysis simulation for the following conditions: 1) a typical NYS classroom; 2) the classroom with recommended glazing locations and thermal properties, and, 3) the classroom with both window and electric lighting recommendations.

- Base workbook costs and savings on typical electrical rates in New York State.

- Conduct a human factors evaluation of a classroom copy room, including comfort and acceptability of low transmittance glazing and window layout.

- Avoid "over-hyping” the benefits of daylighting, to solidify the objectivity of the approach.

- Present more strongly the argument that one-time installation of glass reduces maintenance costs compared to investment in HVAC equipment that needs periodic replacement. This is a compelling argument for school officials.

- Emphasize the introduction of the glazing shading coefficient early in the design process so that the mechanical engineer will downsize the mechanical equipment.

- This program is just a first step. Cool Daylighting needs to grow to accommodate other spaces than classrooms within schools. It does however make sense to continue to emphasize cool daylighting in the classroom environment (rather than specialty spaces) because this is likely to positively affect the greatest number of people.

- A "why to" training session would be valuable for school board members, in addition to the "how-to" session for architects and engineers.

Energy Smart Schools - Field demonstration of lighting and HVAC cost savings from high performance design: Subtask 3

\section{CHALLENGE}

Demonstrating actual lighting and HVAC impacts from high performance glazing and daylighting strategies is difficult. While many schools and other buildings have been designed and built using these strategies, attempts to compare energy consumption with standard designs must confront the myriad ways in which any particular building differs from other buildings. This leaves open the question of the extent to which measured differences in energy consumption are due to deliberate design strategies versus other uncontrolled factors such as operation schedules and building orientation.

\section{SOLUTION}

An experiment was conducted at the Iowa Resource Station near Des Moines, Iowa in two sets of identical rooms with independent lighting and HVAC delivery systems. One set of four rooms ("high performance") was configured with high-performance glazing with reduced visible transmittance as well as direct/indirect electric lighting with photo 
sensor dimming. The other set of four rooms ("standard") was configured with standard clear-glass glazing and ceiling-mounted fluorescent fixtures with no dimming.

Each configuration comprised one east-facing, one south-facing, and one west-facing room - as well as an interior room with no fenestration. All rooms were the same size $\left(276 \mathrm{ft}^{2}\right)$ and the two sets were oriented identically. Both configurations were operated as typical variable air-volume (VAV) systems with a central chilled-water coil and terminal hydronic re-heat coils. This set-up allowed for a direct comparison of lighting and HVAC energy consumption through the analysis of the more than 600 parameters that are recorded at one-minute intervals in this highly instrumented facility.

The experiment was conducted in three rounds during the summer, fall and winter of 2003, comprising a total of 70 days of operation. Within each round, three slightly different configurations of the high-performance rooms were tested: (1) base case, as noted above; (2) reduced fenestration, simulated by partially covering windows in the high-performance rooms with exterior panels with an insulating value comparable to the adjacent exterior walls; and, (3) addition of an interior light shelf to improve the distribution of natural light to the interior of the rooms.

\section{RESULTS}

The lighting and HVAC operating cost savings for the high-performance rooms are considerable, and represent a savings of nearly 25 percent on operating costs of about $\$ 1.13$ per square foot. ${ }^{1}$ The table below shows how these costs and savings break out:

\begin{tabular}{llll}
\hline & $\begin{array}{l}\text { Standard } \\
\text { configuration } \\
\text { annual operating } \\
\text { costs } \\
\text { (cents/ft }{ }^{2} \text { ) }\end{array}$ & $\begin{array}{l}\text { Savings for } \\
\text { High-Performance configuration }\end{array}$ \\
\hline Lighting energy & 22 & 7 & Percent \\
Cooling energy & 19 & 5 & $32 \%$ \\
Heating energy & 6 & -0.1 & $25 \%$ \\
Fan energy & 13 & 0.3 & $-1 \%$ \\
Demand charges & 53 & 15 & $3 \%$ \\
\hline Total & 113 & 27 & $28 \%$ \\
\hline
\end{tabular}

Lighting Energy. The dimmable fixtures in the high-performance rooms operated at reduced output much of the time. These fixtures used about half the electricity as the fixtures in the standard rooms on sunny days. The overall savings is somewhat less due occasional overcast conditions, shorter days during the winter, and the fact that daylighting was not possible for the interior room, which represents a quarter of the floor space.

${ }^{1}$ These are based on typical Midwestern utility time-of-day utility rates of: 6 cents/kWh for on-peak electricity, 3 cents/kWh for off-peak electricity, $\$ 6 / \mathrm{kW}$ monthly demand charge, and $\$ 1 / \mathrm{kW}$ rolling-demand charge. The analysis is also based on 250 days of annual week-day, non-holiday operation. 
Cooling Energy and Chiller Sizing. On a weather normalized basis, the high performance rooms require 25 percent less cooling than the standard rooms. These savings derive from three differences between the two configurations: (1) reduced need to remove heat from dimmed electric lighting; (2) reduced heat gain through the highperformance windows; and, (3) reduced cooling required to condition ventilation air, which increases as the other cooling loads increase. Under hot conditions, the last two factors dominate, as electric lighting represents only about 10 percent of the building's cooling load. Analysis of hourly cooling loads on the two systems show that the highperformance configuration results in 26 percent lower cooling load at the Des Moines summer design temperature of $93^{\circ} \mathrm{F}$.

Heating Energy. Reduced solar gain and electric lighting loads should translate into higher winter heating costs for the high performance configuration, and the data do reflect this effect at temperatures below about $40^{\circ} \mathrm{F}$. However, the data also reveal that the high performance rooms require less reheat energy at higher temperatures. This is presumably due to less time in which cooling is needed in only one or two rooms to deal with high solar and electric lighting loads. On balance, these two effects effectively cancel out, and the impact on heating energy is negligible.

Fan Energy. The high performance rooms require somewhat less fan energy during hot weather, due to reduced need for VAV-system airflow to meet the cooling load. At other times, the two systems used about same amount of fan energy.

Demand Charges. Analysis of 15-minute combined lighting and HVAC system demand shows a substantial reduction in monthly (and rolling annual) demand charges, representing more than half of the total operating cost savings. These savings are predicated on the assumption that a school using the high performance configuration tested here would be installed with a 25 percent smaller chiller, with a comparable reduction in chiller power draw when it is operating. Demand savings without chiller downsizing would be much smaller, since it only takes one 15-minute period of chiller operation in a given month to set the peak demand charge for the month (as well as the rolling demand charge for the year). These results reinforce the need to couple high performance glazing and lighting specifications with chiller sizing.

Effect of Different High Performance Configurations. The data did not show large differences in lighting or HVAC energy use across the three high-performance configurations tested. The configuration with reduced fenestration area had somewhat higher lighting energy use due to decreased daylight availability, and the configuration with the light shelf was between this level and the standard configuration. None of the configurations showed statistically significant differences in HVAC energy, though this is at least partly a consequence of less statistical precision when analyzing across varying weather conditions rather than being able to directly compare energy use across configurations under identical conditions. 


\section{FUTURE}

The results of this experiment show that that there is significant potential for reduced lighting and HVAC operating costs - as well as upfront capital costs for chillersthrough careful attention to glazing characteristics and lighting configuration.

Energy Smart Schools - Daylighting Demonstration Sites, Monitoring and Evaluation Subtask 4

\section{CHALLENGE}

The challenge was to study and understand the effects of daylighting on human factors and energy efficiency in a school setting.

\section{SOLUTION}

The following four schools were selected as demonstration sites, all of which have daylighting incorporated into their building design.

1. Congress Elementary School, Milwaukee, WI

2. Georgina Blach Intermediate School, Los Altos, CA

3. Solon High School, Solon, IA

4. Zach Elementary School, Fort Collin, CO

These schools were selected for their varied geographic locations, building design and willingness to participate in the study.

\section{RESULTS}

Tinted glass is considered visually comfortable in all classrooms; contrary to expectations of other daylighting experts, there were almost no complaints that the tinted windows appeared dark. However, the window tinting alone is insufficient to promote visual comfort when direct sun is streaming in (Congress, Solon, Zach). For this reason, shading devices are necessary, both for everyday teaching, as well as audio-visual projector use. Teachers object to spaces where blinds require frequent adjustment, particularly when the blinds are difficult to access. If blinds are functionally inaccessible, they will be left in one position (Solon and to a lesser extent, Blach). Teachers objected to being asked to restrict their use of blinds (Solon), and posting of materials on glass (Congress).

In summary, all four of the schools have successfully adapted the principles of Cool Daylighting to create comfortable, bright and cheerful environments. All four schools find their classrooms visually comfortable, and think their lighting is comparable or superior to other schools. See attached chart for details.

Energy efficient results are more complicated to capture and vary greatly because of the following factors

- Differences in occupant behavior

- Savings from controls only apply when lights are on

- Light switches must be available to turn lights off

- Savings from daylighting occur when lights are off 
- Savings from daylighting are reduced when blinds are closed for audio-visual purposes or glare

\section{FUTURE}

An additional study of more daylit schools over an extended period of time could help quantify energy usage in order to make recommendations for future school buildings and major retrofits.

\section{Classroom Summary Table}

\begin{tabular}{|c|c|c|c|c|}
\hline & $\begin{array}{l}\text { Congress Elementary } \\
\text { School }\end{array}$ & Zach Elementary School & $\begin{array}{l}\text { Georgina Blach } \\
\text { Intermediate School }\end{array}$ & Solon High School \\
\hline Location & Milwaukee, Wisconsin & Ft Collins, Colorado & Los Altos, California & Solon, lowa \\
\hline Grades & $\mathrm{K}-6$ & $\mathrm{~K}-6$ & $7-8$ & $9-12$ \\
\hline School type & Urban & Suburban & Suburban & Rural \\
\hline Demo size & $\begin{array}{l}2 \text { classrooms } \\
\text { (grades 1-2) }\end{array}$ & $\begin{array}{l}\text { Whole school } \\
\text { (24+ classrooms) }\end{array}$ & $\begin{array}{l}\text { Whole school } \\
\text { (25 classrooms) }\end{array}$ & $\begin{array}{l}\text { Whole school } \\
\text { (20 classrooms) }\end{array}$ \\
\hline $\begin{array}{r}\text { Construction } \\
\text { scope }\end{array}$ & Small Retrofit & New construction & New/Substantial retrofit & New construction \\
\hline Fenestration & Window wall, East-facing & $\begin{array}{l}\text { Punched window openings, } \\
\text { mostly North-facing, some } \\
\text { South }\end{array}$ & $\begin{array}{l}\text { Clerestory and roof } \\
\text { monitors, North-facing }\end{array}$ & $\begin{array}{l}\text { Punched window } \\
\text { openings, North- and } \\
\text { South-facing }\end{array}$ \\
\hline Blinds (Upper) & Venetian blinds & $\begin{array}{l}\text { North, none; South, venetian } \\
\text { blinds }\end{array}$ & Perforated roller shades & Venetian blinds \\
\hline Blinds (Lower) & $\begin{array}{l}\text { Black perforated roller } \\
\text { shades }\end{array}$ & $\begin{array}{l}\text { North, venetian blinds; South, } \\
\text { black perf. shades }\end{array}$ & Curtains (on sliding doors) & Venetian blinds \\
\hline Lighting & Direct-indirect pendants & Direct-indirect pendants & Direct-indirect pendants & Pendants, indirect \\
\hline $\begin{array}{r}\text { Photosensor } \\
\text { location }\end{array}$ & On fixture & Outside & On fixture & Outside \\
\hline Controls type & Dimming & Switching & Dimming & Switching \\
\hline LRC Visited & September 2003 & April 2004 & March 2004 & September 2003 \\
\hline \multirow[t]{2}{*}{ Survey Scope } & $\begin{array}{l}2 \text { teacher interviews } \\
\text { (children too young for } \\
\text { survey) }\end{array}$ & $\begin{array}{l}\text { 140+ students, } \\
\text { grades } 4-6\end{array}$ & $\begin{array}{l}240+\text { students, } \\
\text { grades } 7-8\end{array}$ & $\begin{array}{l}80+\text { students } \\
\text { grades } 9-12\end{array}$ \\
\hline & $\begin{array}{l}\text { Automatic dimming not } \\
\text { noticeable } \\
\text { Dimming override } \\
\text { appreciated by teacher } \\
\text { Window tinting not } \\
\text { noticeable }\end{array}$ & $\begin{array}{l}\text { Windows, blinds, lighting } \\
\text { generally well-accepted } \\
\text { Window tinting not noticeable } \\
\text { Few complaints of switching } \\
\text { being noticeable } \\
\text { No major concerns about } \\
\text { restricted view }\end{array}$ & $\begin{array}{l}\text { Windows, lighting, well- } \\
\text { accepted } \\
\text { Dimming works well, not } \\
\text { noticeable } \\
\text { No major concerns about } \\
\text { restricted view } \\
\text { Many choose to work } \\
\text { without electric lighting }\end{array}$ & $\begin{array}{l}\text { Window tinting not } \\
\text { noticeable } \\
\text { No major concerns } \\
\text { about restricted view } \\
\text { Use of blinds does not } \\
\text { impact electric lighting } \\
\text { energy savings }\end{array}$ \\
\hline \multirow[t]{3}{*}{ Cons } & $\begin{array}{l}\text { Eastern exposure, too } \\
\text { much sun in mornings }\end{array}$ & $\begin{array}{l}\text { Insufficient shading on South } \\
\text { side, making blinds essential. }\end{array}$ & Some find the space dark & $\begin{array}{l}\text { Upper blinds are } \\
\text { inaccessable, and thus } \\
\text { are left closed. }\end{array}$ \\
\hline & $\begin{array}{l}\text { Numerous blinds must } \\
\text { constantly be adjusted, } \\
\text { inaccessible. }\end{array}$ & $\begin{array}{l}\text { Overlighted in some spaces } \\
\text { (kindergardens). }\end{array}$ & Some blinds inaccessible & $\begin{array}{l}\text { Insufficient shading on } \\
\text { South side, making } \\
\text { blinds essential. }\end{array}$ \\
\hline & $\begin{array}{l}\text { Diminished space for } \\
\text { posting teaching aids }\end{array}$ & & $\begin{array}{l}\text { Some find the space } \\
\text { insufficiently dark for } A N\end{array}$ & $\begin{array}{l}\text { Switching somewhat } \\
\text { noticeable at first, but } \\
\text { became accustomed }\end{array}$ \\
\hline $\begin{array}{l}\text { Other Staff } \\
\text { Comments: }\end{array}$ & $\begin{array}{l}\text { The school is awaiting } \\
\text { outcome of energy } \\
\text { monitoring before } \\
\text { applying Cool Daylighting } \\
\text { widely }\end{array}$ & $\begin{array}{l}\text { Would like after-hours lighting } \\
\text { override } \\
\text { HVAC comfort complaints }\end{array}$ & $\begin{array}{l}\text { Occupancy sensors false- } \\
\text { off when working } \\
\text { afterhours; lamp } \\
\text { seasoning not being done } \\
\text { when spot relamping }\end{array}$ & \\
\hline
\end{tabular}


Energy Smart Schools - Daylighting Design Guidelines and Training Materials Subtask 5

Coming soon.........

\section{Task 5}

Integrated School Building Technologies - California Energy Commission

\section{School Building Energy Efficiency Applied Research}

\section{ISSUE}

New school construction is projected to grow at a steady rate in the next five years. It is critical that these new projects are not only as energy efficient as possible and include recent research on building environmental quality and student performance, but also are good learning environments. California's timing is critical because there has been a lack of funding for school facilities in the last ten years. This is changing with the recent bonds that have passed and recent legislation that has been introduced. Construction and modernization projects are in the planning stage and it is important that examples are out there for these upcoming projects.

Prior to this project, there were few examples of High Performance Schools; schools with superior energy efficiency, schools that ensure healthy indoor environmental quality, schools that are good environmental citizens and schools that teach.

\section{PROJECT OBJECTIVE}

To create a network of Integrated High Performance School Demonstrations throughout California for design teams and school districts to learn from. The Collaborative for High Performance Schools (CHPS) formed in 2001 to assist school districts and design teams in creating public k-12 schools that are energy efficient, well lit, have good indoor air quality, are good learning environments, and are cost effective to design and construct. The intent of this project was to demonstrate high performance design concepts that provide good lighting, meet improved acoustical standards, use advanced HVAC technologies and monitor and control indoor air quality and reduce energy use. This would be done by creating a network of demonstration schools in various climate zones and for different use types in California public k-12 schools. California has 16 climate zones so having a series of demonstration schools is a great opportunity for all of the United Sates to learn from. The grant funds would be awarded to two school districts that would serve as demonstration projects using CHPS criteria chosen by the school districts. 


\section{SUMMARY OF ALL WORK PERFORMED}

The California Energy Commission (CEC) was awarded a \$518,000 grant from National Association of State Energy Officials (NASEO) in May of 2001.

The CEC then announced a Program Opportunity Notice on June 11, 2001 for a High Performance School Grant. Applications were to be submitted from design teams that included both the architect and the k-12 public school district. The school district had to be the applicant of record.

Press releases were sent out as well as a letter generated from the Department of Education announcing to school districts that this grant was available.

Criteria were developed to competitively select two projects that could demonstrate high performance design concepts in differing climate zones and differing educational level use. The following six applications were submitted: Fontana High School \#4, Tahoe Truckee Middle School, Los Angeles Unified School District (LAUSD) High Tech High School, Oakland Unified School District Elementary School, Petaluma City Jr. High and Santa Ana Elementary School.

A panel of reviewers was formed that included Daryl Mills the program manager, Al Garcia the contract/project manager and Maziar Shirakh P.E. the division's mechanical engineer. The projects were rated on the design team's commitment and experience to sustainable design, energy efficiency, commissioning, lighting and mechanical experience. The evaluation team looked at thirty two different aspects of school design. These aspects were divided into four separate categories: Owner Team experience, A\&E Team Experience, Mechanical Team Experience and Lighting Team Experience. Two projects were selected and two other projects were awarded Honorable Mention. The two Honorable Mention projects received assistance from the Bright Schools program. The Honorable Mention projects were High Tech High, Los Angeles and Lorin Griset, Santa Ana. Through the Bright Schools program our independent engineers assisted the design teams by reviewing the existing designs for energy efficiency and assisted in prioritizing criteria for CHPS self certification. The two projects the team selected to receive \$250,000 grants were Oakland Unified School District's Elementary and Tahoe Truckee Unified School District’s Middle School projects.

Tahoe Truckee Unified School District eventually named their school the Alder Creek Middle School. Oakland Unified School District named their school the Cesar Chavez Education Complex.

The Lorin Griset project was subsequently selected up by the California Integrated Waste Management Board as their demonstration CHPS project. This project was later renamed the Heroes Elementary School.

A contract was executed between the Energy Commission and Tahoe Truckee Unified School District and the Energy Commission and Oakland Unified School District. Each 
district would eventually receive $\$ 250,000$. Portions of the grant were released to each school as they completed progress on the school project. The tasks and funding released for each task were as follows:

- Task 1 - Construction Design Plan; recipient was required to produce a construction design plan that would result in a 20\% improvement in energy utilization over California Administrative Code, CACTitle 24, part 6 (2001). No funds released at completion of this task.

- Task 2 - Provide documentation of project acceptance by The Division of State Architect (DSA) - \$50,000 released at completion of this task.

- Task 3 - Provide documentation of project approval from DSA. No funds released at completion of this task.

- Task 4 - Provide proof of State Allocation Board funding - \$25,000 released at completion of this task.

- $\quad$ Task 5 - Quarterly Progress Reports - \$5,000 released at submittal of each report. Eight reports were required to be submitted for a total of $\$ 40,000$ released for this task.

- Task 6 - Each recipient was required to submit a Final Report that described the project design and philosophy considerations, the actual design considerations, and CHPS certification data. \$35,000 released at completion of this task.

- Task 7 - Recipient required to provide certification from project's Architectural and Engineering contractor that the facility, as constructed, will perform at $20 \%$ better that the CAC Title 24 (2002). \$25,000 released for the completion of this task.

- $\quad$ Task 8 - Recipient required to submit commissioning plan. \$25,000 released at completion of this task.

- $\quad$ Task 9 - Recipient required to submit a CHPS scorecard signed by the architect of record. The scorecard must have earned at least 28 points out of the 81 possible points. These points, although self certifying, need to be verifiable as this is a demonstration project. $\$ 50,000$ released at the completion of this task.

During design of the schools, each project was supported by the Energy Commission's Bright Schools Program. Through the Bright Schools Program, the Commission used existing architectural and engineering contracts to review the designs and make recommendations to each projects building site strategies, energy efficiency, material selection, and CHPS achievement. Design charettes were conducted for both of the projects. At the design charettes, the architect, utility provider, electrical and mechanical engineer and a sustainable materials consultant participated by contributing to ideas and strategies for the project. The architect made changes to the design accordingly. The Bright Schools program also was available to help each district write a request for qualifications for a commissioning agent and to assist the district in interviewing potential candidates.

Meetings were held with the design team throughout the design and construction process. Energy Commission staff also conducted site visits to the schools throughout the construction and commissioning process. 
The Energy Commission involved CHPS partners throughout the design and construction of each school. PG\&E assisted with the commissioning at the Cesar Chavez education complex and California Integrated Waste Management Board assisted at the Tahoe Truckee Middle school in the selection of sustainable materials. Also, Tahoe Donner Public Utility District assisted in the design and installation of the ground source heat pump at the Alder Creek Middle School project. CHPS and PG\&E helped with the grand opening event at the Cesar Chavez Education Center.

Both Schools were complete in 2004. The Cesar Chavez Education Complex opened its doors on January 5, 2004. The grand opening event was held on January 21, 2004.

Alder Creek Middle School completed their projects and school began September 7, 2004. The grand opening event for this project was September 18, 2004.

The current status of the two Honorable Mention Projects: LAUSD will have a grand opening event for the High Tech High School on Wednesday November 17, 2004. Santa Ana Unified School District’s Heroes Elementary School (formerly known as Lorin Griset) is in final design and will complete construction to be open for the school year in September 2006.

\section{RESULTS AND DISCUSSION}

Cesar Chavez Education Complex:

- 95,000 sq.ft. community elementary school

- 600 K-5 students, two small schools with shared multi-use facilities and open space

- 72 student Child Development Center

- Joint use M-P Room/Gym with dedicated community room, kitchen and parent resource room

- Daylighting Features; .7 watts per sq. ft.

- Two Story

- Natural Ventilation

- \$240 per sq. ft.

- Features Recycled Content and Low V.O.C. Materials

- 33 points on CHPS Scorecard

- Will Use 25\% Less Energy Than a Typical School of This Size and Use

Alder Creek Middle School

- 1,000 Students

- Ground Source Heat Pump

- 92,000 Square Feet

- Two Story with Cafeteria and Gymnasium

- Demand Control Ventilation

- $\$ 253$ per sq. ft.

- Daylighting Features; .7 watts per sq. ft.

- Features Recycled Content and Low V.O.C. Materials

- 30 Points on the CHPS Scorecard 
Both schools are open and students are being taught in the classrooms. The Energy Commission and CHPS partners will be looking at the actual energy use and indoor air quality of both the Alder Creek and Cesar Chavez schools. It will take at least a year to get the information that we need to evaluate the projects.

Each project had a very good experience with the commissioning process. Having a commissioning agent on the project saved a lot of time and money for both the building owner and the construction contractor. The commissioning process greatly reduced the number of call backs. The presence of a commissioning agent required communication between all parties involved in the construction process. It also allowed for the design intent to be carried through to the end of the project and not get lost in value engineering or change orders.

Market transformation needs to continue for the selection of materials for CHPS schools and schools choosing to use materials with low emitting Volatile Organic Compounds (VOC) and high recycled content. As the project evolved, more of these products became available. In order to avoid receiving high prices from the construction contractors through the bid process, it was very important to thoroughly research the products available and include in the construction documents at least three manufacturers of the product we were specifying.

\section{BUDGET}

Original Budget NASEO awarded the CEC for this project was $\$ 518,000$. $\$ 500,000$ was to be directly passed to the schools to assist in using CHPS criteria. $\$ 18,000$ was for administrative purposes.

Both Tahoe Truckee and Oakland Unified school districts were each awarded \$250,000 for successfully completing the milestones as set in the contract agreement. The administrative budget was fully expended.

The grant share match that was required was $\$ 2,860,817$. The total grant shared match achieved was $\$ 3,049,931$ which exceeded required grant share match. Grant share match is as follows:

CEC - \$636,837

CHPS Partners

- Pacific Gas and Electric Company - \$1,000,000

- California Integrated Waste Management Board - \$675,000

- Southern California Edison - \$513,423

- Southern California Gas Company - \$39,000

- San Diego Gas and Electric Company - \$55,671

- The California Division of the State Architect - \$100,000

- Sacramento Municipal Utility District - \$30,000

Grant Share Match Total - \$3,049,931 


\section{CONCLUSION}

The project was a success not only for NASEO and the CEC, but for CHPS and the future of public school construction. CHPS partners are all fully participating in building this demonstration network of CHPS schools. Partners provide design assistance through programs such as the CEC's Bright Schools program and the utilities Savings by Design programs. Through these programs the partners are able to make energy efficiency design recommendations and assist the project in achieving CHPS recognition. The following is a listing of CHPS partners and the projects they are involved in:

\section{Pacific Gas and Electric (PG\&E):}

- Los Altos Unified School District’s Blach Intermediate School; opened 9/02.

\section{Southern California Edison (SCE):}

- Los Angeles Unified School District's Southeast Learning Center; opened 9/04.

- El Segundo Unified School Districts’ El Segundo High School; opens 9/05.

- Newport Mesa Unified School District's Newport Coast Elementary; opened 9/02.

- High Performance portable classroom demonstration project at Pomona Unified School District’s Pueblo Elementary School; opened 9/04.

\section{California Integrated Waste Management Board (CIWMB):}

- Santa Ana Unified School district's Heroes Elementary School; opens 9/06.

\section{San Diego Gas and Electric's (SDG\&E):}

- San Diego Unified School district's San Pasqual Elementary School; opened 9/02.

- Del Mar Union School District’s Sorrento Hills Elementary. This school is currently in final design phase.

Eleven School districts in California have passed resolutions adopting CHPS criteria in all new school construction projects. Those districts are: Los Angeles, Santa Ana, San Francisco, Dry Creek Jt. Elementary, San Marcos, San Diego, Burbank, Vacaville, Visalia and San Rafael City Unified School Districts and Coast Community College District.

The Commission believes if energy efficiency is properly introduced into the design of public schools, there will be a positive effect on the indoor air quality, acoustics, and daylighting. Through proper planning, school projects using the CHPS design guidelines can be designed and constructed for the same cost as a typical public school. There will also be reduced operating and maintenance costs and increased average daily attendance. Public school districts throughout the United States can't afford to not use guidelines such as the CHPS guidelines. Children deserve to have healthy learning environments. 

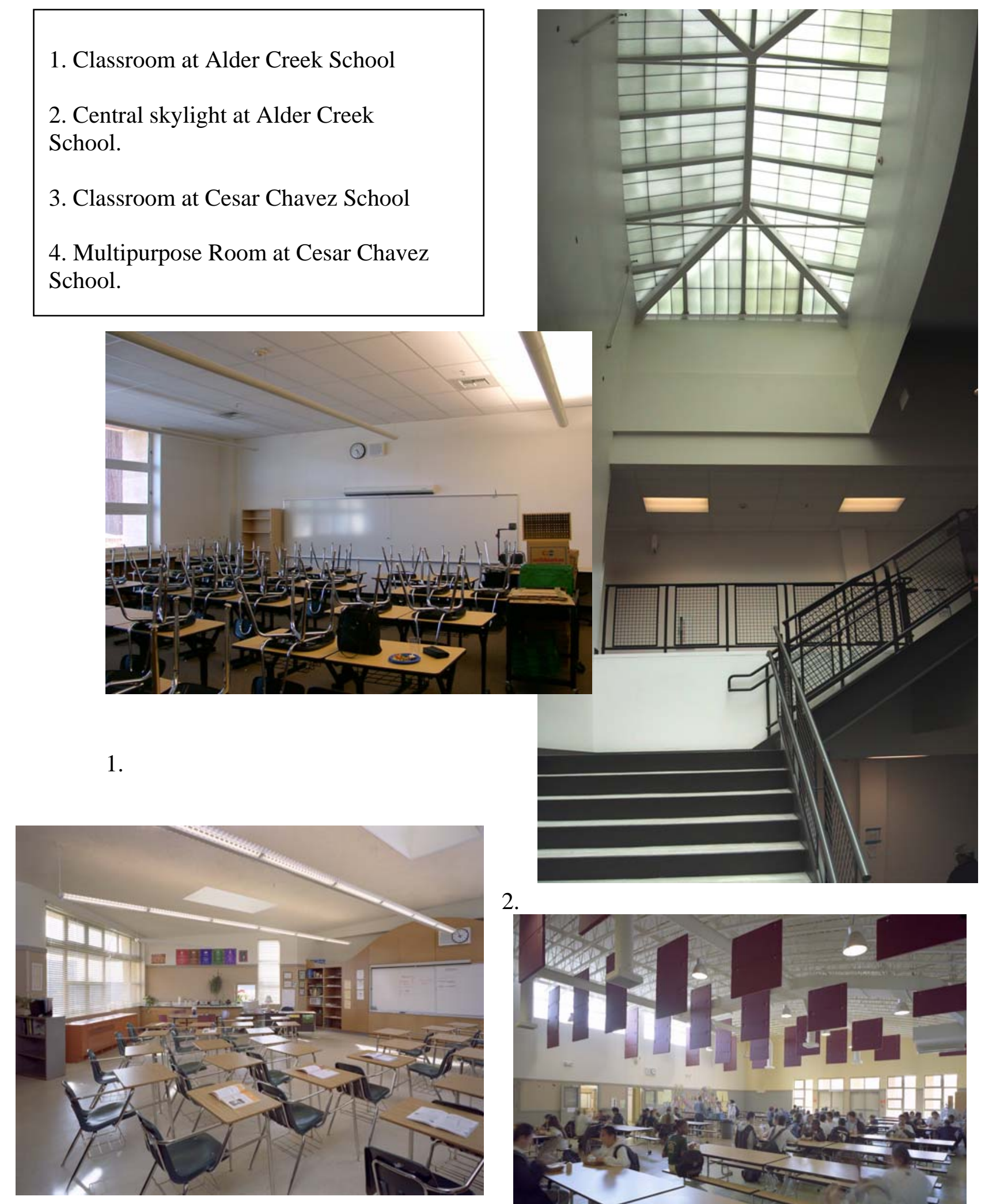

3.

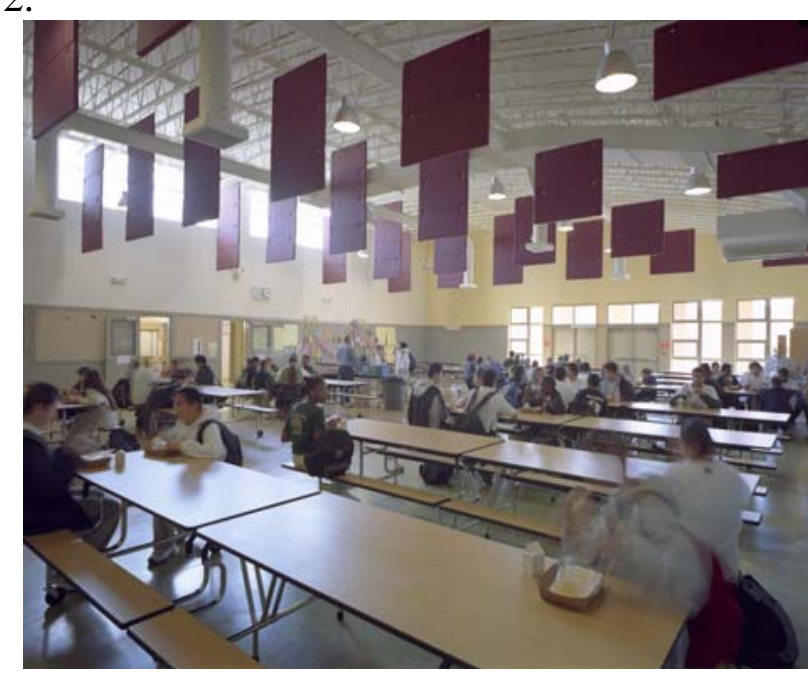

4. 


\section{Task 6}

Large Scale Study and Diagnostic Testing of Schools and Classrooms - FSEC

NASEO School Building Energy Efficiency Applied Research

\section{EXECUTIVE SUMMARY}

The issue addressed in the Task 6 study is the significant indoor air quality problems in schools throughout the U.S.. The study employed three main sub-tasks to investigate these problems:

- A nationwide, web-based survey designed to determine the levels of occupant satisfaction or dissatisfaction with the IAQ, thermal, lighting and acoustical conditions in schools and classrooms

- Characterization of actual operating conditions of schools and classrooms through field audits and diagnostic tests and measurements

- Conducting retrofits in problem schools and classrooms to alleviate problems.

A two part on-line survey instrument was developed that included general questions about the school and its operation, subjective questions concerning comfort conditions at the school and energy use specific questions. Although the survey response rate was low, some useful data was obtained. Temperature was by far the greatest comfort complaint in regular classrooms, with 50.5\% of respondents indicating "many" or "chronic" problems. Indoor air quality (IAQ) and then humidity were the next greatest areas of complaints in regular classrooms, with $20.4 \%$ and $13.1 \%$ of respondents indicating many or chronic complaints in these categories respectively.

While there were significant difficulties in locating schools willing to be audited, conditions audits were finally conducted in a total of eight schools in Florida, Minnesota, New York, Oregon, Texas and Washington. The audits typically included zone pressure mapping, ventilation tests, sampling and monitoring of indoor temperatures, $\mathrm{CO}_{2}$ levels and $\mathrm{RH}$, and in some cases a blower door building air tightness test. Ventilation problems were found at each of the eight audited schools. These problems appear to be occurring due to a combination of factors including lack of maintenance, lack of knowledge of the systems and in some cases poor system design. It also appears that since ventilation air problems are not easily identified unless comfort or other conditions issues arise, they typically go unresolved.

Retrofit opportunities were pursued at each audited school and a total of four retrofit projects were completed. Since the funding offered through this project would have only covered a small percentage of the work recommended, none of the schools opted for any large scale retrofits. However, two of the audited schools that were willing to carry out more modest projects were also willing to provide additional funds to accomplish them. Once a retrofit was underway, it was often very difficult to get timely follow-through 
cooperation from the schools. Also, specifications were modified by the school or contractor in two cases and other implementation problems were encountered. While these problems limited the effectiveness of the retrofits or the ability to confirm benefits, post-retrofit monitoring and resurveying did indicate that there was still some success realized in several schools.

While the level of participation in the survey, audits and retrofits was significantly less than desired, some conclusions can still be made. These include that:

- School conditions improvements are possible. The limited results from project retrofits indicate that conditions problems can be successfully diagnosed and solved.

- Schools must have real incentive(s) to participate.

- A qualified energy analyst must be paid to supervise all work.

- Schools in humid climates need to be designed with separate means of treating outside air.

The results from this project and even the lack of participation on the part of the schools indicate that without substantial funding being made available for school maintenance, widespread significant improvements will not be realized. Even beyond funding issues, there is a matter of priorities for schools. School boards and administrators need to prioritize the health and welfare of the students and that in turn requires better maintenance of school facilities. Education departments may need to provide energy/air quality specialists with significant authority in order to ensure acceptable comfort conditions for school children. The alternative will likely be an escalation of lawsuits.

\section{BACKGROUND}

The issue addressed in the Task 6 study is the significant indoor air quality problems in schools throughout the U.S.. These problems are well documented in previous work.

A 1995 report on the condition of public schools by the US General Accounting Office (GAO) to members of Congress provides data on "the overall physical condition and prevalence of schools that need major repairs." 1 The report is based on estimates given by school officials in a national sample from over 5,000 school districts. It notes that half of all schools surveyed reported at least one unsatisfactory environmental condition involving ventilation, heating, lighting or physical security, most of these schools having multiple problems.

The report breaks down unsatisfactory or very unsatisfactory environmental conditions as follows:

$\begin{array}{lcrr}\text { Condition } & \text { \% of Schools } & \text { \# of Schools } & \text { \# of Students } \\ \text { Lighting } & 15.6 & 12,200 & 6,682,000 \\ \text { Heating } & 18.9 & 15,000 & 7,888,000 \\ \text { Ventilation } & 27.1 & 21,100 & 11,559,000\end{array}$




$\begin{array}{llll}\text { Indoor Air Quality } & 19.2 & 15,000 & 8,353,000 \\ \text { Noise Control } & 28.1 & 21,900 & 11,044,000 \\ \text { Physical Security } & 24.2 & 18,900 & 10,638,000\end{array}$

This GAO study and a number of others have identified classroom ventilation as a major concern. For example, inadequate ventilation of elementary schools in Texas was shown in the Texas Elementary School Indoor Air Study. In this study, single day monitoring of 120 randomly selected Texas elementary school classrooms found time averaged CO2 concentrations over $1000 \mathrm{ppm}$ in $66 \%$ of the classrooms and peak $\mathrm{CO} 2$ concentrations of over $3000 \mathrm{ppm}$ in $21 \%$ of the classrooms. ${ }^{2}$

A school conditions researcher with experience working in approximately 400 northwest schools notes that his team has found that roughly $40 \%$ of all the classrooms they surveyed are under ventilated, that operation and control strategies are rarely optimized and the school personnel lack both the knowledge and resources to monitor and improve conditions. ${ }^{3}$

The same General Accounting office report referred to above estimated that over \$101 billion was needed at that time to complete all work required at schools to restore them to good overall condition. SchoolDude.com (a web-based educational facilities management company) reports a current deferred maintenance and adequacy conditions backlog in K12 schools estimate of over $\$ 250$ billion. ${ }^{4}$

\section{EXPERIMENTAL}

\section{School Survey Overview}

A two part on-line survey instrument was developed. Part 1 had general questions about the school and its operation, and subjective questions concerning comfort conditions at the school. Part 2 included energy use specific questions. The survey was reviewed by six school professionals including a school energy manager, a school energy and education specialist and a DOE school technical advisor. A number of their recommendations were implemented in the survey. Also, before the survey was made available, approval to use the survey on human subjects was obtained from the University of Central Florida Institutional Review Board.

A web site was developed for the survey (www.energysurvey.org) that includes a project introduction, instructions, a letter from NASEO, support contact information and the two part survey (Appendix A includes print outs of all survey web pages). A toll-free phone number was also provided for support and/or to allow participants to take the survey over the phone.

Participants identified their school by entering their zip code and selecting from a schools listing provided by the web site, or by entering their school information. Participants had the option of including their contact information or sending the survey back anonymously. As an incentive it was noted that if contact information was included, the 
school would be eligible to be selected for one or more energy improvements. While other incentives were considered (including a computer give-away) contract restrictions significantly limited what was possible.

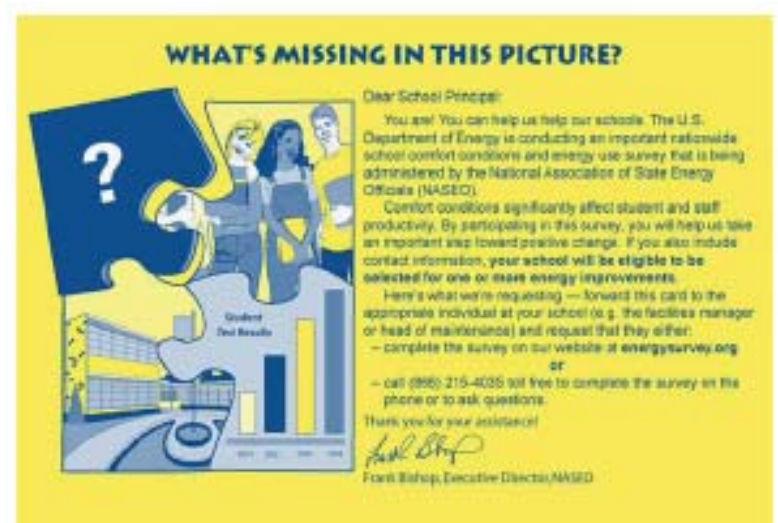

Figure 1: Post card sent to 90,000+ U.S. schools introducing the school conditions survey.

Postcards introducing and encouraging participation in the survey were sent to over 90,000 schools. Figure 1 shows the actual postcard. In addition to the direct mailing, several other means of getting the survey out to schools were employed. A web-based educational facilities management company, SchoolDude.com, emailed it's membership requesting that they participate. A number of other school groups were also contacted including school boards, maintenance organizations and a school administrators association. A number of these groups forwarded the participation request to their members.

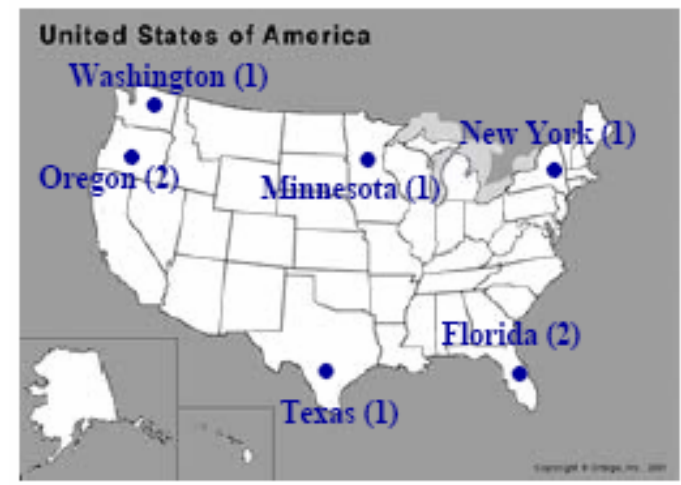

Figure 2: Locations of conditions audit schools.

\section{Comfort Conditions Audits Overview}

A group of 16 "problem" schools and another group of 15 "good” schools were identified from which to select the schools to be audited. Problem schools were defined as schools for which the survey respondents indicated either "many" or "chronic" complaints last year about the indoor air temperature and indoor air quality in regular classrooms. Good schools were schools for which the respondents indicated either "none" or "a few" 
complaints last year about the indoor air temperature, humidity and air quality in regular classrooms.

An FSEC conditions audit team was formed to perform audits in the southeast states. To perform audits in other parts of the country, five firms and organizations were originally contacted. Each of these groups has been recommended to us by a nationally recognized building science expert and we further verified that each is experienced in conducting school conditions audits. Three of these firms and organizations were finally selected for the project. The FSEC team conducted three audits (in Florida and Texas), a northwest based team three audits (in Oregon and Washington), a midwest team one audit (in Minnesota) and a northeast team one audit (in New York) for a total of eight. Figure 2 shows the locations of the audited schools.

While it was intended that all audited schools be selected from the original list obtained from the school survey, there was considerable difficulty in obtaining cooperation from these schools and in the end, only two of the eight audited schools came from the survey. One audit incident provides an example the generally poor level of cooperation experienced in working with project schools. The midwest audit team was not able to secure cooperation from any of the originally surveyed schools, so they approached schools in their area that they were aware of that had conditions problems consistent with those targeted for the study. After several attempts at locating a school, they were given permission to audit a Minnesota school from the school's principal. However, the school superintendent found out about the audit while it was already in progress and asked them to leave immediately. Some useful data were already collected, but the audit could not be fully completed.

\section{Conditions Audits Process}

Audits were either scheduled through the original school survey contacts or by an audit team contacting other schools known to have conditions issues appropriate for this study. Audits generally took $1 \frac{1}{2}$ to 2 days and included staff interviews, a visual inspection of the school building and a number of tests designed to determine conditions in the school and identify causes of any existing conditions problems. The tests performed typically included most or all of the following:

- zone pressure mapping (measuring pressure differences between different areas in the school and between the school building and outdoors)

- a blower door building air tightness test

- tracer gas ventilation rate test (designed to test how much outside air is brought into the building under normal operating conditions)

- sampling and monitoring of indoor conditions (typically including temperature, relative humidity and $\mathrm{CO}_{2}$ measurements).

\section{Retrofits Overview}

Retrofit opportunities were pursued at each audited school, based on expected retrofit cost, funds availability and expected school cooperation. It was only possible to provide 
part of the total retrofit cost at each school, so either only a partial retrofit was planned or the schools added some funds to those provided through this project.

A total of four retrofit projects were completed. One additional small-scale retrofit was attempted with a Florida school that was recently audited for a separate project via the Florida Department of Education. A preliminary meeting was held during which it was determined that the school would be good fit for the project, and a retrofit assistance offer was made to the school. However, mainly due to three of the hurricanes that impacted Florida this year, it was not possible to work out details with the school within the project time constraints.

School cooperation was again an issue during the retrofits. In one case, a school agreed to begin retrofit work, but did not actually start the retrofit process, and in another case, after a first retrofit change out was made, other recommendations were not implemented. In general, as in the initial audit process, there were difficulties in getting timely responses and consistent participation.

\section{RESULTS AND DISCUSSION}

\section{Survey Results}

Most responses were directly on-line, with a few coming in by phone.

There were 239 total respondents ( $0.25 \%$ response rate). There was at least one response from each of 46 states. However, there were only 48 respondents that provided energy bill information, thus some of the questions that were attempts to substantiate differences in energy use were not useful. A 1996 Florida survey which included pressure from the Florida department of education lead to significantly higher returns and found a number of significant factors that could explain differences in energy use. ${ }^{5}$ Those factors had been included in the on-line national survey. In retrospect, without the teeth of each state's educational department director, the survey should have just focused on the comfort conditions and be kept shorter.

A survey with answer mean averages (for quantitative questions) and mode answers for multiple choice answers, as well as frequency percentages is shown in Appendix A.

\section{School characteristics}

The mean average enrollment was 504 students with an average daily attendance of 462 and student classroom stations of 396. The mean average enclosed area was 85,000 square feet with a median of 54,000 square feet. On average there were 30 classrooms and 54 employees.

The average age of the oldest school building was 49 years, and $77 \%$ of respondents indicated that the majority of the school was over 20 years old. The majority of schools have weekend events, community night time events and non-academic summer events. Classes were in session an average of 9.5 months, with 55\% of respondents classifying 
their school as traditional nine months and 31\% as traditional plus summer, and only $1 \%$ choosing year-round. Eighty percent of respondents indicated energy was used for cooking at their schools and 98\% have hot water with 55\% having shower facilities. Thirteen schools had pools; eight of them heated by gas, zero by solar and four by other (most likely electric heat pump).

The majority of schools did not have any portables, however, $16 \%$ had three or more portables. Over eighty percent of respondents indicated that all classrooms were of a traditional type with its own door and walls up to the ceiling. Forty-two percent of respondents indicated their school was a single multi-wing building as opposed to single rectangular building (35\%) or multi-building (23.5\%). One story schools represented $57 \%$ of the surveyed schools.

About $75 \%$ of surveyed schools indicated that most or all of the school roof was flat as opposed to sloped. Carpeted classrooms answers were split, with 54\% selecting some or none and $46 \%$ choosing most or all. Hallways were typically not carpeted while administrative areas were carpeted.

\section{Complaints}

Temperature was by far the greatest comfort complaint in regular classrooms, with 50.5\% of respondents indicating "many" or "chronic" problems. Indoor air quality (IAQ) and then humidity were the next greatest areas of complaints in regular classrooms, with $20.4 \%$ and $13.1 \%$ of respondents indicating many or chronic complaints in these categories respectively.

\section{Percent of respondents indicating chronic problems}

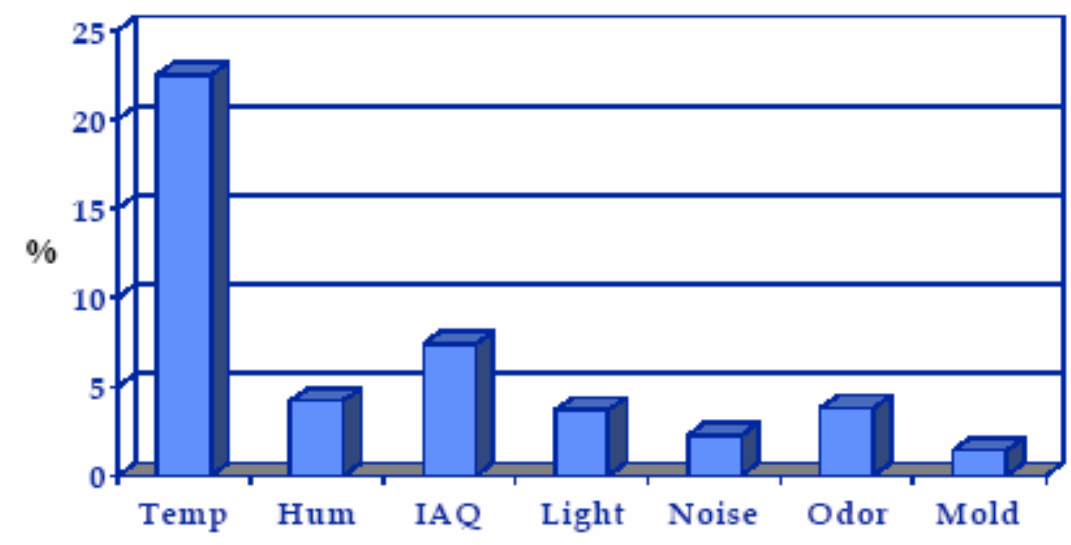

Figure 3: Chronic complaints by category.

At $22.5 \%$ of respondents, temperature was by far the greatest cause of chronic complaints, followed by IAQ, humidity and odors. Only $1.4 \%$ of respondents reported chronic mold problems, while $68.7 \%$ reported no mold problems. Conversely, only $2 \%$ of respondents reported no temperature problems at their school (see Figure 4). Twenty-nine percent (29\%) of respondents thought most or all the classroom temperature complaints were likely caused by not having enough thermostats or zones, while $37 \%$ \% thought none of the temperature complaints were due to those factors. 
There were very few temperature, humidity, indoor air quality or mold complaints indicated in portable classrooms relative to the regular classrooms. Not surprisingly, $72.5 \%$ of respondents indicated water damage in at least some regular classrooms during the "last several years," while only $20.7 \%$ of the portable classrooms indicated the same.

Administrative, cafeteria, gymnasium, auditorium and special function rooms were indicated as having fewer complaints than either regular or portable classrooms.

\section{Energy Education}

Thirty percent of respondents indicated there was "an active energy educational program in place at the school, while $40 \%$ indicated there was one in place at the school district.

\section{Comfort Conditions Audits Results}

Audit teams in the southeast (FSEC team), northeast, midwest and northwest regions completed a total of eight comfort conditions audits between October 2002 and March 2003. The eight school audits are summarized below, and a complete report for each audit is included in Appendix B.

\section{Florida Elementary School \#1}

The school consists of one main building and a number of portables. Only the main building was tested. This building has about 50,000 square feet of floor space, and about 500 students plus staff occupy this building. Major spaces within the building include 30 classrooms, front office, library, courtyard, cafeteria/auditorium, and kitchen.

Reported complaints came from a number of locations throughout the facility. These complaints appear to be related to elevated humidity, moldy smells, health complaints (head aches, sickness, etc.), cold room temperatures, and general dissatisfaction with indoor conditions.

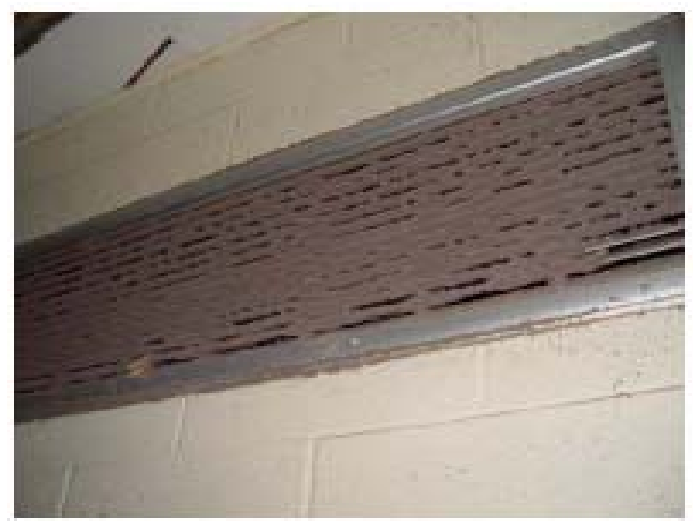

Figure 4: Main return grilles behind stage of cafetorium blocked b/c maintenance staff unaware of their locations. 
Significant audit observations included low classroom temperatures, high relative humidity levels and operations and maintenance problems (see Figure 5). Room temperature as low as $64^{\circ} \mathrm{F}$ were measured during the audit visit, with the average temperature of 13 rooms measured being $68.4^{\circ} \mathrm{F}$. Monitored temperature and relative humidity data from 7 classrooms during the week after the audit also showed a number of rooms with low temperatures and high $\mathrm{RH}$ levels. Of these, over a two day period with outdoor high temperatures of $86 \mathrm{o}_{\mathrm{F}}$ and an average dew point temperature of $68 \mathrm{o} \mathrm{F}$, temperatures in three classrooms, the cafetorium and library averaged at or below $70_{\circ} \mathrm{F}$, and $\mathrm{RH}$ levels in one classroom, the cafetorium and library averaged above 65\%. Dew point temperatures in Florida are commonly well above $70_{\mathrm{o}} \mathrm{F}$, so maintaining rooms at these low temperatures can provide surfaces on which water can condense.

Improvement recommendations at this school included:

- Adjust bathroom exhaust fan flow rates to be consistent with the Florida Building Code and ASHRAE Standard 62 calling for $50 \mathrm{cfm}$ per stall or urinal. Reduction in the exhaust flow rates, if possible, will make it easier to achieve positive pressure in the building and might reduce cooling energy use.

- Provide outdoor ventilation air by means of a dedicated outdoor air ventilation (DOAV) system (see testing report for recommended OA system options).

- Check the air flow balance in the kitchen. When the kitchen exhaust fan operates, it will be desirable for the kitchen to operate at neutral or positive pressure. The kitchen makeup air is interlocked with the exhaust fan operation. It would be desirable for the outdoor air of the kitchen AC system to also operate simultaneously with the exhaust fan so that the kitchen air flow balance is dependable.

- Evaluate the leak openings in the top of the fan coil units serving the classrooms. Determine, if possible, why they are there. Since the ceiling is not intended to be a return plenum, it appears that these return leak openings should be sealed.

- Consider tightening the building envelope. Tightening of the building envelope would be useful for two reasons; 1) to control natural infiltration, especially during unoccupied hours, and 2) to make it easier to get the building to operate at +2 pascals or greater positive pressure. If the building were made much more airtight, then indoor humidity would remain quite low for even up to a few days with the HVAC systems turned off.

- If a DOAV system is not installed on this school, then other steps would need to be taken to bring the school humidity levels under control while achieving positive building pressure.

The Florida Elementary School \#1 Testing Report in Appendix B documents the complete audit including airtightness, building pressure, ventilation rate and room conditions results, and a more detailed recommendations discussion. 


\section{Florida Elementary School \#2}

The school consists of two main buildings, a separate gymnasium building, and several portables. Only the two main buildings were tested. Building 1 contains the front office, several facility closets (janitor, electrical, etc.), and 16 classrooms. A single bathroom is also located in each classroom. This building has approximately 28,000 square feet of floor space. Building 2 contains the kitchen, cafeteria/auditorium, art and music classrooms, custodial room, media center (library), faculty break room, and 22 classrooms (in addition to the music and art classrooms). It has approximately 48,000 square feet of floor space.

Reported complaints have come from throughout the facility, and appear to be related to elevated humidity, moldy smells, health complaints (head aches, sickness, etc.), and general dissatisfaction with indoor conditions. Temperature and humidity plots recorded by school district personnel indicate that many rooms have humidity conditions in the range of $60 \%$ to $75 \%$, and some have humidity in the $85 \%$ to $100 \%$ range. Considerable testing by the school district has found relatively low levels of mold in the facilities except in certain isolated circumstances. Significant audit observations include high RH levels (60-70\%), leaky building envelopes and several instances of low classroom temperatures. At the time of the audit, portable dehumidifier "band aids" were commonly in use in the classrooms to help control RH levels (see Figure 5).

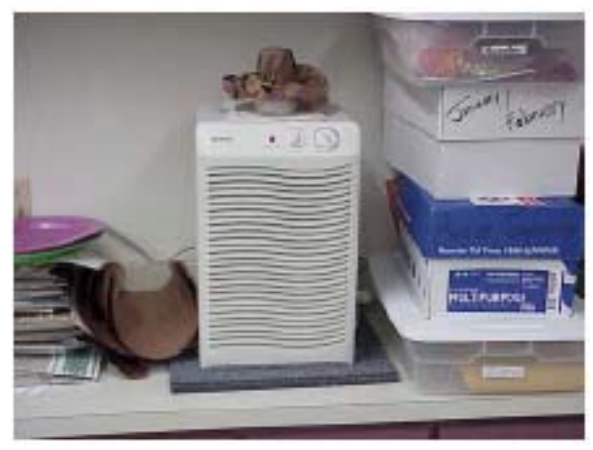

Figure 5: A portable dehumidifier used to reduce classroom humidity levels.

Improvement recommendations at this school included:

- Tighten the buildings by sealing the eave vents. This will make it easier to get the buildings to operate at positive pressure, reduce the natural infiltration rate, and allow indoor humidity levels to remain below $60 \%$ for extended periods (even several days at a time) with the conditioning systems off.

- Reduce the air handler flow rates to improve their dehumidification performance.

- Adjust the outdoor air intakes to $15 \mathrm{cfm}$ per person based on average occupancy. It is expected that once the buildings are tightened, the outdoor ventilation air will be sufficient to produce pressures in excess of a +2 Pascal target. 
- Operate the air conditioners only in the fan "auto" mode during hot and humid cooling periods. The "auto" fan setting will optimize latent removal (dehumidification) performance.

- Cooling system fans can be set to fan "on" on days when the outdoor dew point temperature is say $62 \mathrm{~F}$ or below.

- After making changes, monitor indoor relative humidity during hot and humid weather. If reducing air handler flow rates and operating the fan in the "auto" setting when the dew point temperature is 63F or higher does not achieve indoor humidity levels below $60 \%$ nearly all of the time, then some additional steps may be required to improve humidity control, such as the following. 1) Install dedicated outdoor air conditioning units to precondition the outdoor air. 2) Install high efficiency dehumidifiers to serve spaces which experience elevated humidity (note that high efficiency dehumdifiers remove moisture with much lower energy use per unit of moisture, and are much quieter, than standard dehumidifiers). Humidistats can be installed to cycle these units as needed.

The Florida Elementary School \#2 Testing Report in Appendix B documents the complete audit including airtightness, building pressure, ventilation rate and room conditions results, and a more comprehensive recommendations discussion.

\section{Texas Elementary School}

The Texas elementary school consists of two main classroom buildings, separate cafeteria and gymnasium buildings and several portable units. The two main buildings total just over 50,000 square feet, and accommodate approximately 750 students.

Significant audit observations include dust accumulation, negative pressure in part of the building, low ventilation rates and musty odors (see Figure 7). A visual inspection showed dust accumulation throughout the building, especially in the ceiling space, likely do to inadequate filtration of outdoor air or outdoor air bypassing the filters. Blower door tests showed that both main buildings are very airtight (south wing ACH50=1.0 and north wing ACH50=1.5). Pressure mapping found that with all operational HVAC equipment running, the main area of the south wing was operating under significantly negative pressure $(-8 \mathrm{~Pa})$ and the north wing was operating under somewhat positive pressure $(+2.3 \mathrm{~Pa})$. Tracer gas decay testing was also performed and indicated a ventilation rate of 0.47 ach or approximately $8.5 \mathrm{cfm}$ per student in the south wing, and an extremely low 0.10 ach or approximately $1.1 \mathrm{cfm}$ per student. It was also noted that two of the nine exhaust fans on the south wing were not working, and none of the exhaust fans on the north wing were working. 


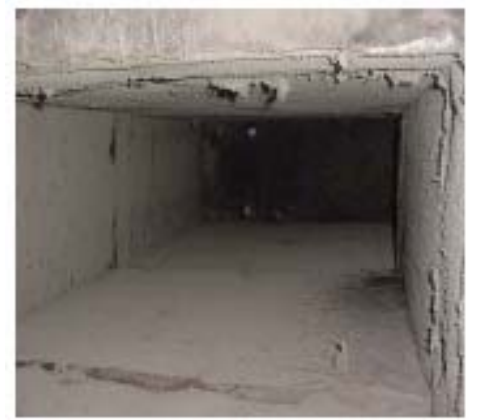

Figure 7: Dust in return duct after outside air intake

Improvement recommendations for this school included:

- Get exhaust systems operating per original design parameters.

- Install exhaust air on the janitor's closet.

- Repair bathroom fans and make sure bathrooms operate at negative pressure with respect to all adjacent spaces including the bathroom ceiling spaces. Also eliminate cases where the bathrooms are being depressurized by the adjacent mechanical rooms (which are acting as return plenums).

- Air conditioner fans should be set to "auto" to enhance the dehumidification performance of the system. However, the fans can be set to "on" for days when the outdoor dew point temperature is below 60F, because dehumidification of the indoor air will not be a critical issue under these conditions.

- Bring outdoor air into the building to meet two objectives; 1 ) to produce (approximately $+4 \mathrm{~Pa}$ ) positive pressure in the building and 2) to meet the ASHRAE Standard 62 ventilation rates (15 cfm per person or slightly less using occupancy averaging).

- Provide a high level of filtration of the outdoor ventilation air to eliminate the entry of most of the fine dust which is airborne in the area. The filters must have almost no bypass. Install a motorized damper on the dedicated outdoor air units so that they can be closed (to make the building tight) when not in use.

- Turn off the cooling system and all exhaust fans during nights and weekends. Exception: keep the janitor's closet exhaust fan operating continuously.

- During extended unoccupied periods (e.g., summer break), it may be necessary to run the cooling systems intermittently in order to maintain the desired humidity control.

The Texas Elementary School Testing Report in Appendix B documents the complete audit including airtightness, building pressure, ventilation rate and room conditions results, and a more detailed recommendations discussion.

\section{Washington State Elementary School}

The original single story brick building was built in the 1950s, with an addition of a library and 5 classroom in 1992 and a total remodel and addition in 2001/2002. Total size is approximately 45,000 $\mathrm{ft}^{2}$. During the remodel wall R-values were increased to R-19; 
ceilings to R-38; and window u-values to 0.60 . The building has carpet throughout except a hardwood floor in the gym.

Reported complaints include sewer gas odors in one classroom and odors in the gym since the renovation.

The most significant audit observation was a heavy odor in the gym (believed to be associated with off gassing from the curing hardwood floor finish). Tracer gas testing in the gym found that there was plenty of outside air entering the system, but the supply air was being short circuited to the return and not properly mixing. The gym has high ceilings (30') and the $\mathrm{CO}_{2}$ pooled in the first 10' above the floor, with almost no mixing. The air high in the gym quickly flushed but had little effect on the concentrations lower down. The odor problem associated with the curing floor finish is at least in part due to the failure to flush the VOCs at the floor level.

Improvement recommendations at this school included:

- Adjusting the throw of the supply diffusers in the gym needs to be adjusted to get better mixing and help dissipate the odor resulting from the pooling VOCs.

- Looking into $\mathrm{CO}_{2}$ ventilation controls.

The Washington State Elementary School Testing Report in Appendix B documents the complete audit including airtightness, building pressure, ventilation rate and room conditions results, and a more detailed recommendations discussion.

\section{Oregon Elementary School \#1}

The main two-story concrete block building was constructed in 1928. Floors are tile with some area carpets. Windows in the building are single glazed, metal framed, and retrofitted to reduce the original glazing area. There is also a smaller wood frame "portable" complex with 6 classrooms. Total building area is approximately 64,000 square feet.

Reported complaints at the school include periodic comfort issues (too hot, too cold), stuffiness and odors. Significant audit observations during the December audit include a classroom temperature over $76 \mathrm{~F}$, odors and ventilation issues (see Figure 8). Measured unit ventilator outside air flows and $\mathrm{CO}_{2}$ measurements showed that almost all of the classrooms appear to be under ventilated for their occupancy (average outside air flows were around $150 \mathrm{cfm}$ where 300 to $375 \mathrm{cfm}$ were appropriate). All of the exhaust fans in the restrooms had low flows (less than $50 \mathrm{cfm}$ ) and one was not functioning. The "portable" unit which has been in use for at least 40 years has no reliable system for providing outside air. The system of passive stacks in the central hall provides some air change but is dependent on wind conditions and outdoor temperature and becomes almost useless in mild weather or when teachers close the doors to their rooms. 


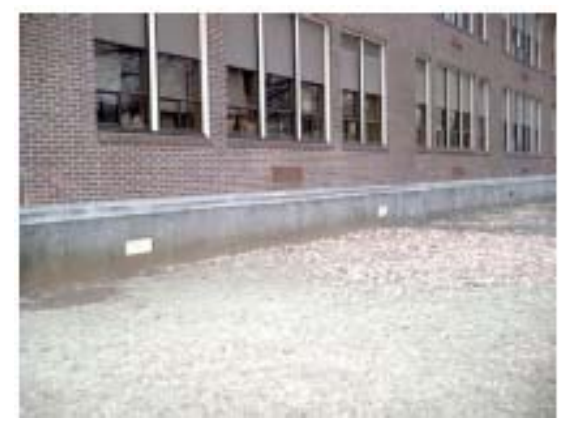

\section{Figure 7: Unit ventilator outside air intakes at the Oregon Elementary School \#1.}

The common areas of the main building including the gym, cafeteria and auditorium appear to be over ventilated for their occupancy. The main air handler serving these areas is operating at high speed and outside air set for full occupancy during the entire daily occupied time. A program to operate this system in coordination with actual use and occupancy patterns could.

One probably contributing factor at this school was that onsite custodial staff in the district had all been replaced in the last year and have no historical perspective and little understanding of HVAC operation.

Improvement recommendations for this school included:

- Adding a control strategy for the gym, cafeteria and auditorium air handlers to better match outside air with actual use and occupancy patterns. Such a strategy could potentially save significant heating cost while still maintaining adequate ventilation

- Outside air on all the unit ventilators should be adjusted and maintained to provide at least $15 \mathrm{cfm}$ per occupant

- Bathroom exhaust fans should be fixed/upgraded to help contain pollutants and odors

- An active ventilation system should be added to the wood frame portable complex including exhaust fans in the restrooms and outside air directly to each of the six classrooms.

The Oregon Elementary School \#1 Testing Report in Appendix B documents the complete audit including airtightness, building pressure, ventilation rate and room conditions results, and a more detailed recommendations discussion

\section{Oregon Elementary School \#2}

This Oregon elementary school is similar to the previous school. The main three story concrete and brick building was constructed in 1928. Floors are tile with some area carpets. Windows are single glazed, metal framed, and retrofitted to reduce the original glazing area. There are also three "portable” classrooms. Total building area is approximately 72,000 square feet and is used by approximately 330 students and staff. 
Reported complaints at the school included stuffiness and comfort issues. One teacher reports frequent headaches and almost always keeps a window open. There were several significant audit observations. While the average measured unit ventilator outside air of $230 \mathrm{cfm}$ was within the $225 \mathrm{cfm}$ and $330 \mathrm{cfm}$ calculated range, three classrooms were found to need maintenance. As was the case in the other audited Oregon elementary school, the common areas of the main building including the gym/cafeteria and auditorium appear to be over ventilated for their occupancy. The main air handler serving these areas is providing outside air for full occupancy during the entire daily occupied time. Also, a urine smell was observed in two of the portable unit bathrooms.

This school is in the same district as Oregon Elementary school \#1, so in this case again the district custodial staff had all been replaced in the last year with new personnel who have no historical perspective and little understanding of HVAC operation.

Improvement recommendations for this school included:

- Adding a control strategy for the gym/cafeteria and auditorium air handlers to better match outside air with actual use and occupancy patterns. Such a strategy could potentially save significant heating cost while still maintaining adequate ventilation

- Adjusting unit ventilators in three classrooms

- Maintenance for exhaust fans in two of the portable units.

The Oregon Elementary School \#2 Testing Report in Appendix B documents the complete audit including airtightness, building pressure, ventilation rate and room conditions results, and a more detailed recommendations discussion.

\section{Minnesota High School}

The Minnesota high school audit is abbreviated due to the fact that the audit team was forced to leave the school five hours into the audit (the principal of the school had agreed to the audit but the district supervisor found out about the audit after it was begun and did not allow it to continue).

Some observations were still made (see Figure 9). There was a general lack of maintenance of HVAC systems because of equipment replacement scheduled for the upcoming summer. In one case, an air handler drive belt was not repaired since the air handler was going to be replaced in the summer. Also, most of the unit ventilators were turned off because of the noise they generate. The audit team reported measured $\mathrm{CO}_{2}$ levels in one classroom over 3300ppm. 

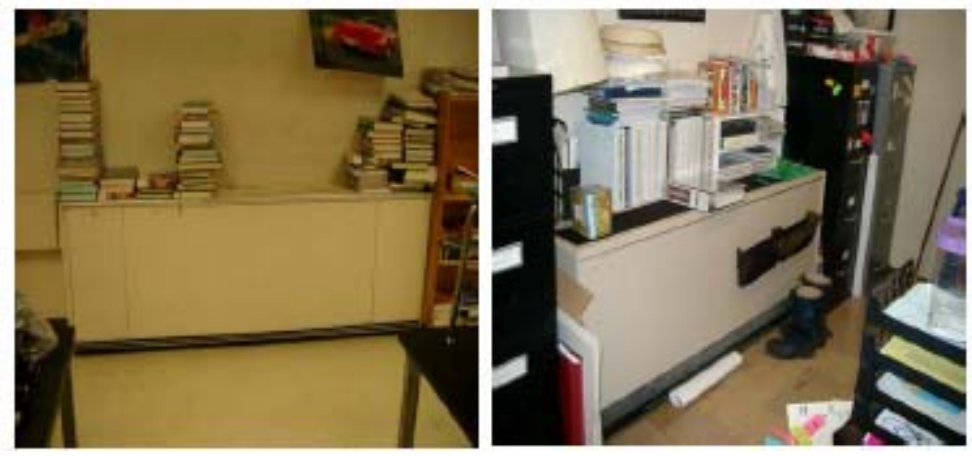

Figure 8: Unit ventilators at Minnesota school partially blocked by books.

The Minnesota High School Testing Report in Appendix B documents the work they were able to complete at the school.

\section{New York High School}

This school is an un-insulated two story brick and masonry building that was constructed in 1961. It consists of an administration wing, a gymnasium and cafeteria, a classroom wing, and an additional wing that was converted from a residence to classrooms and offices. Total floor space is about 58,000 square feet.

Significant audit observations include a number of inoperable exhaust fans, areas without thermostat control (requiring the windows to often be opened during cold weather to cool the rooms) and other controls problems. The audit report also notes that the school is poorly ventilated but spending the same amount on accidental ventilation that it would if it was airsealed and properly ventilated.

Improvement recommendations for this school include:

- $\quad$ Finding and airsealing the enclosure air leaks.

- Restoring operation of the ventilation equipment.

- Repair the thermostats controlling the convectors in the wing formerly used as residential rooms.

- Remove the existing outdoor air reset controls from the steam to hot water exchanger and replace them with new controls.

- Replace the light sensor controlling the outdoor lights.

- Several boiler room changes as outlined in the testing report.

The New York High School Testing Report in Appendix B documents the complete audit including airtightness, building pressure, ventilation rate and room conditions results, and a more detailed recommendations discussion.

\section{School Retrofits}

A total of four school retrofits were conducted for this study, two in the northwest and two in Florida. Each retrofit project is summarized below. 


\section{Florida Elementary School \#1 Retrofit}

At the Florida Elementary School \#1, the conditions audit testing and monitoring had found that the buildings were significantly leaky, to a large extent due to vented soffits that were connected to the ceiling space above the T-bar ceiling. High humidity levels and low air temperatures were also found in a number of the classrooms. It was decided that retrofit work would concentrate on one of the two main classroom buildings. Based on the findings, main retrofit and improvement recommendations included:

- tightening the building at the eave vents

- reducing air handler flow rates

- adjusting outdoor air intakes to $15 \mathrm{cfm}$ per person based on average occupancy

- operating the A/C systems in the fan "auto" mode during hot and humid periods.

See the Florida Elementary School \#1 Testing Report in Appendix B for the complete, detailed list of retrofit recommendations.

After discussions with school personnel, it was decided to begin retrofit work by sealing soffit vents around the perimeter of the building and make AC equipment changes in one of the classrooms as a test case.

Although outside soffit sealing was specified, the contractor was planning on attempting to seal off an opening inside the space above the eave. This plan still would have left significant areas unsealed at a cost of approximately $\$ 3,000$ more than what was specified finally costed. Figure 13 below shows the differences in the specified and planned sealing solutions.
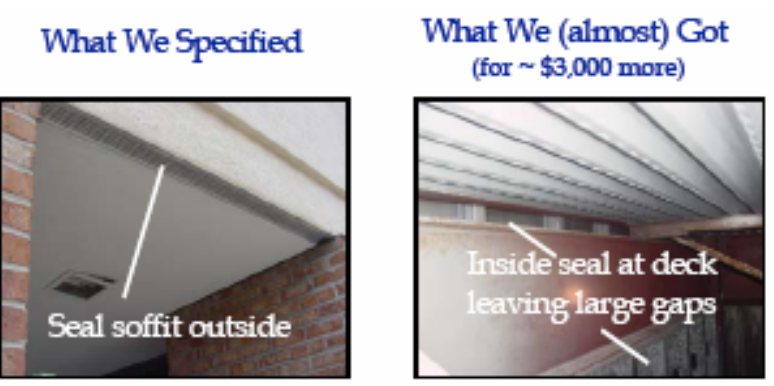

Figure 9: Specified vs. contractor planned soffit sealing solutions.

After school personnel reported that the soffit sealing was completed, FSEC staff returned to the school to retest building airtightness. At that time however, it was noted that about $25 \%$ of the building perimeter soffit had not been sealed. The building airtightness test was still completed, and results adjusted to account for the missing length of soffit sealing. After the soffit sealing was fully completed, additional $\mathrm{CO}_{2}$ and $\mathrm{RH}$ monitoring was conducted. 
The building is now significantly tighter, but monitored post retrofit $\mathrm{CO} 2$ and $\mathrm{RH}$ levels indicated that follow-up on other previously agreed to recommendations was still needed to improve the conditions in the building. However, after this initial retrofit phase, repeated phone calls and emails recommending further retrofit work went without response. As a result of the general lack of participation, it was not possible to realize the potential benefits that the retrofits might have provided.

\section{Florida Elementary School \#2 Retrofit}

At the second Florida elementary school, issues identified from the conditions audit included low classroom temperatures, high relative humidity levels and operations and maintenance problems. Room temperature as low as $64_{0} \mathrm{~F}$ were measured during the audit visit, with the average temperature of 13 rooms measured being 68.4.F. Monitored temperature and relative humidity data from 7 classrooms during the week after the audit also showed a number of rooms with low temperatures and high RH levels. Dew point temperatures in Florida are commonly well above $70_{\circ} \mathrm{F}$, so maintaining rooms at these low temperatures can provide surfaces on which water can condense. Recommended retrofits included:

- a dedicated outdoor air ventilation system

- tightening building envelope/evaluate fan coil leak openings.

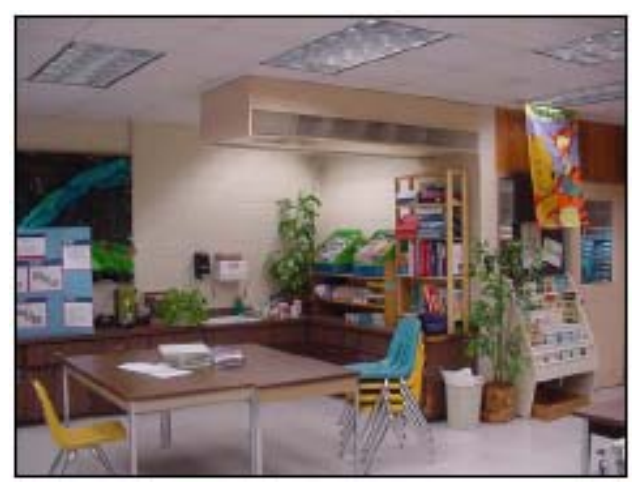

Figure 10: Air handler in one of the Florida Elementary School \#2 classrooms.

See the Florida Elementary School \#2 Testing Report in Appendix B for the complete, detailed list of retrofit recommendations. Primarily due to the scope and cost of the recommended retrofits, school personnel in this case were not willing to undertake the project. However, one of the most pressing issues at this school was the apparent occurrence of mold in two classrooms.

In order to resolve this situation, school personnel installed a ceiling mounted dehumidifier for the two classrooms. Pre and post dehumidifier installation conditions were monitored in the classrooms.

Relative humidity levels were found to be running between $40 \%$ and $50 \%$ most hours in these two classrooms, which is a significant drop from before the installation. While this 
retrofit strategy did not provide the school-wide conditions and energy benefits that the more comprehensive retrofit recommendations were designed to provide, the results do indicate that the dehumidifier is effectively controlling humidity in this area of the school. A school board engineer also later reported back that the dehumidifier was working well and the previous mold problems in these classrooms have not continued post retrofit. .

\section{Washington State Elementary School Retrofit}

During the conditions audit at the Washington State Elementary School three concerns were identified as targets for possible retrofit work. The ventilation for both the gym and large multipurpose community room was controlled by timers set for periods of

occupancy. The occupancy of these areas vary greatly even within the normally occupied. Controlling ventilation based on occupancy as indicated using $\mathrm{CO}_{2}$ sensors was proposed as a way to maintain recommended ventilation and potentially save on heating cost by reducing periods of over ventilation. The audit also identified a mixing problem in the gym. Ventilation air was short circuiting from the supply to the return without mixing into the occupied zone. The retrofit proposal included modifying and redirecting the supply diffusers to better ventilate the occupied area in the zone.

Actual retrofit work at the school included adding $\mathrm{CO}_{2}$ sensors to the control circuits for the gym and multipurpose room and altering the supply diffusers in the gym to provide more mixing and minimize short circuiting to the returns. Temperature, relative humidity and $\mathrm{CO}_{2}$ levels in the gym and multipurpose room were monitored for over 3 weeks both pre and post retrofit. Data on natural gas consumption for the monitoring period was collected and ambient weather conditions recorded. Outside air damper positions for the gym and multipurpose room were also recorded for the pre and post monitoring periods.

While initial analysis of the collected data indicated lower energy use in the building post retrofit with normalized weather, a review of recorded damper positions suggested that the control settings may not have been properly set for implementation of the desired control strategy. The control program was reset, and school district personnel confirmed that the changes made have in fact improved the existing air mixing problem, and complaints about odors from off gassing of the floor finish have ended. Also, no problems were reported from going to $\mathrm{CO}_{2}$ based ventilation control for the multipurpose room and gymnasium.

\section{Oregon Elementary School \#1 Retrofit}

During the conditions audit at the Oregon Elementary School \#1 three concerns were identified as targets for possible retrofit work:

- control ventilation based on occupancy as indicated by $\mathrm{CO}_{2}$ sensors to maintain recommended ventilation and potentially save on heating cost by reducing periods of over ventilation

- general maintenance was proposed for 27 unit ventilators to increase outside air to recommended levels while maintaining temperature control 
- add mechanical ventilation for a six classroom portable with restrooms that are presently without any mechanical ventilation.

It was anticipated that the energy savings from more efficient operation of the ventilation provided to the common core of the building (gym, cafeteria, and auditorium) would offset the added cost of providing proper ventilation to the classroom areas.

Within the limitations of the funding for this study and with additional funds provided by the school district, it was decided to address the first two items.

Maintenance performed by the district to address the unit ventilator recommendation was completed during the summer of 2003. Unit ventilators were cleaned including outside air intakes and calibrated. Dampers, controls and valves were checked, adjusted, and replaced as needed.

Ventilation of the gym, cafeteria, and large auditorium was also improved. The multizone fan system was reconfigured so that these areas could be operated as isolated zones by the operation of dampers controlled by $\mathrm{CO}_{2}$ sensors for the cafeteria and auditorium and an occupancy sensor for the gym. Installation of ventilation controls by an outside contractor proved to be problematic though, as a review of the installation identified incomplete work and nonfunctioning parts. These problems delayed the completion of the project and its review for a number of months.

Temperature, relative humidity and $\mathrm{CO}_{2}$ levels in the cafeteria and auditorium and selected classrooms were monitored pre and post retrofit. Maintenance on the unit ventilators in the classrooms produced a significant improvement in measured flows of outside air provided to each room with average outside air flows going from $149 \mathrm{cfm}$ preretrofit to $356 \mathrm{cfm}$ post retrofit with 16 out of 20 rooms appearing to be adequately ventilated now versus only 2 of 20 pre retrofit. $\mathrm{CO}_{2}$ monitoring also confirmed improved ventilation rates.

Much of the data collected post retrofit on $\mathrm{CO}_{2}$ levels in the cafeteria and auditorium appears corrupted making it difficult to confirm post retrofit system operation. Based on an energy audit performed by a private company as part of the state of Oregon's SB 1149 program however, energy savings from the multizone fan system retrofit are estimated at $308 \mathrm{MMBtu} /$ year with a dollar savings of $\$ 1,997 /$ year. This yields a simple pay back of 4.5 years on the $\$ 9,000$ investment. Note though that ventilation rates and energy saving are unconfirmed for the cafeteria, gym and auditorium.

\section{General Audit and Retrofit Observations}

Problems were encountered in the audit stage of the project. There was significant difficulty for all audit teams to secure initial school cooperation for the conditions audits, even with clear problems present and school personnel aware that funds might be available to help pay for retrofits. The Minnesota school, where the auditors were forced to leave the school, illustrates that there is often a greater desire to hide problems than have them resolved. 
Significant ventilation problems were present in each of the eight audited schools. These problems appear to be occurring due to a combination of factors including lack of maintenance, lack of knowledge of the systems and in some cases poor system design. It also appears that since ventilation air problems are not easily identified unless comfort or other conditions issues arise, they typically go unresolved. In cases where a problem has been detected, a solution may be provided that does not resolve the root problem(s). Bathroom and other exhaust fan problems were also a common find in the audits where the fans were either non functional or inadequate.

Audited schools were somewhat more open to going forward with retrofit work, but since the funding offered through this project would have only covered a small percentage of the work, none of the schools opted for any large scale retrofits. However, two of the audited schools were willing to carry out more modest projects and were also willing to provide additional funds to accomplish them.

Problems were encountered in the retrofit stage of the project. Once a retrofit was underway, it was often very difficult to get timely follow-through cooperation from the schools. Also, in two cases, although clear retrofit specifications were provided, the specifications were modified by the school or contractor. Had these modifications actually been implemented, they would have resulted in a less effective retrofit in one case and an ineffective retrofit in the other case. The northwest audit team lead noted that "even when resources are made available, successful implementation of changes in equipment and operational strategies is a hit and miss situation if not coupled with thorough commissioning including education of onsite staff.”

While the above problems limited the effectiveness of the retrofits or the ability to confirm benefits, post-retrofit monitoring and resurveying did indicate that there was still some limited success realized in several schools.

\section{CONCLUSIONS}

While the level of participation in the survey, audits and retrofits was significantly less than desired, some conclusions can still be made. These include that:

- School conditions improvements are possible. The limited results from project retrofits indicate that conditions problems can be successfully diagnosed and solved.

- Schools must have real incentive(s) to participate.

- A qualified energy analyst must be paid to supervise all work. From initial testing to verification of retrofit effectiveness, a knowledgeable professional needs to initiate, closely follow and verify all project steps.

- Schools in humid climates need to be designed with separate means of treating outside air. 
The results from this project and even the lack of participation on the part of the schools indicate that without substantial funding being made available for school maintenance, widespread significant improvements will not be realized.

Even beyond funding issues, there is a matter of priorities for schools. School boards and administrators need to prioritize the health and welfare of the students and that in turn requires better maintenance of school facilities. As seen in this project, even when problems persist and relatively low cost solutions are found, proper maintenance is not implemented. Education departments may need to provide energy/air quality specialists with decision authority in order to ensure acceptable comfort conditions for school children.

There has been a concerted effort across the country to assure that students are meeting learning objectives through standardized tests as early as elementary school. Quality building design, construction, operation, maintenance and continuing commissioning is essential if we want those students to have a healthy learning environment. States need to work on continuing education efforts for school facility managers and inspection programs/goal setting that creates incentives school administrators to create and maintain excellent buildings. The alternative will likely be an escalation of lawsuits.

\section{REFERENCES}

1. School Facilities: Condition of America's Schools, United States General Accounting Office, February, 1995.

2. Corsi, R.L., V.M. Torres, M. Sanders and K.A. Kinney, "Carbon Dioxide Levels and Dynamics in Elementary Schools: Results of the TESIAS Study", Precedings: $9_{t h}$ International Conference on Indoor Air Quality and Climate, 2002, Volume 2, pp. 74-79.

3. Email from David Hales, Washington State University, November 2004. 23

4. American School and University Magazine findings as reported on SchoolDude.com web site.

5. Callahan, M., Parker, D., Dutton, W., McIlvaine, J., "Energy Efficiency for Florida Educational Facilities: The 1996 Energy Survey of Florida School," FSEC-CR-951-97, Submitted to Florida Department of Education, July, 1997. 


\section{Task 7}

\section{Technology Integration - NYSERDA}

\section{Project Approach and Outcomes}

\section{Online Training for High Performance School Design}

The Online Training shall educate the design community on current "state-of-the-art" strategies, energy-efficient technologies, best design practices, and cost-effective operational strategies available for new K-12 school construction and existing school buildings. The proposed Internet training program will achieve these goals by extracting and synthesizing the essential elements of the U.S. DOE National Best Practices Manual for High Performance School Design and using "best of breed" technology to present an engaging, interactive, and effective learning environment for online participants. These tasks fall logically into five distinct categories of activity:

- $\quad$ Project Start-Up

- Course Content Development

- Course Software Development

- Continuing Education and Certification Process Development

- Course Implementation: Marketing, Hosting, and Technical Support

\section{Project Start-Up}

\section{Task 7.1. Organize Focus Group}

The Contractor shall organize and prepare for a focus group. The Contractor shall prepare and submit to the NYSERDA Project Manager two weeks from the project start date an agenda for the one-day focus group including meeting space required, break-out sessions (if necessary), focus group guides or questions, and preparatory material for focus group attendees. In cooperation with NYSERDA, the Contractor shall identify a focus group representing the target audience for the Web-based training. The Contractor shall interview NYSERDA recommended attendees and provide a final list of focus group invitees to NYSERDA. The Contractor shall establish a listserve of the focus group attendees to facilitate their ongoing participation in the project. This group shall include:

- Two architects: one from a large firm and one from a small firm (ideally, one with substantial experience designing schools and one with little or none)

- One member of the Council of Educational Facility Planners International (CEFPI)

- Two school facility operations personnel: one from a large district and one from a small

- Representatives from NYSERDA, ASERTTI, and NASEO

- Other personnel as recommended by NYSERDA

Project Outcome: Focus Group held on April 8, 2003, both the Attendee List and Focus Group Summary are provided respectively as Attachment A and Attachment B.

Task 7.2. $\quad$ Focus Group Draft Curriculum and Training Design Documentation The Contractor shall convene the Focus Group at NYSERDA headquarters in order to gather consensus on a curriculum plan and training design document. The Contractor shall facilitate the Focus Group to establish specific educational goals within each course category, finalize the course categories, overview, specific course modules, and discuss key lessons to be covered within each module. The Contractor shall work with the Focus Group to determine any additional 
topic categories, course module subject areas, and specific lessons important for the Cool and Humid climate zone. The Contractor shall discuss and solicit feedback from the Focus Group regarding specific training design elements (see Anatomy of a Course Module, Task 1.6) planned for the Internet-based training including: introduction to the overall topic; home page text, graphics, and streaming video; learning objectives, PowerPoint presentation, additional resources, instructional materials, and online tests to evaluate the user's understanding of the content. The Contractor shall work with the Focus Group to determine the course best suited for development as the Beta Course for which all training design elements can be designed, developed, and thoroughly tested. The Contractor shall work with the Focus Group and NYSERDA to determine which core curriculum modules will be considered first and second priority in terms of their deliverable dates.

The Contractor shall develop and deliver to the NYSERDA Project Manager two weeks after the Focus Group, a draft curriculum development plan based on discussions during the Focus Group. The draft curriculum development plan shall include a list of course modules by category, course module priority designation, key learning objectives for priority course modules, training design element (PowerPoint, Design Tools, etc) to achieve learning, and the target schedule for course development.

The Contractor shall develop and deliver a training design document that describes all training elements to be used in the Internet-based training (e.g. home page, lesson objectives, graphics, streaming video, instructional materials, PowerPoint presentations, etc.) This document shall define the design criteria and format for each training element (e.g. Adobe Acrobat for instructional materials, MS PowerPoint for presentations), and must clearly state the format for NYSERDA, NASEO, ASERTTI, EPA, and DOE logos to be included on the web pages.

The Contractor shall establish a password protected project management website (PMW) to serve project management functions including electronic delivery of formal project deliverables, NYSERDA electronic review of project deliverables, management of the project schedule, and other needs as deemed necessary by the NYSERDA Project Manager and the Project Team. The PMW shall present deliverables in a manner consistent with the tasks defined in the statement of work. The PMW shall have links including, but not limited to those listed below, and all associated course learning objectives, presentations, additional web resources, and text-based instructional materials:

o Project Start-Up

- Overview Module

- Setting Goals and Objectives: CHPS and LEED ${ }^{\mathrm{TM}}$ Criteria

- Courses (25 courses on design, and 3 courses on operations and maintenance)

Project Outcome: Training Design Document provided as Attachment C. 


\section{Course Content Development}

The Contractor shall organize the content for the Internet training program into two distinct segments:

1) a short overview module, which introduces the user to the topic of high-performing, energyefficient schools; and 2) a comprehensive online training program on how to design and operate such facilities. The first segment will be suitable for anyone interested in high performance, energy-efficient schools. The second will constitute the core content of the Internet-based training program for professionals.

\section{Task 7.3. Develop Content for Overview Module}

The Contractor shall develop content for the overview module and submit to NYSERDA by the due date established in Table 1: Deliverables Summary. To begin this task, the Contractor shall review the following source materials that are expected to underpin the content for this portion of the Web site:

- SBIC’s High Performance School Buildings Resource and Strategy Guide

- SBIC's National Workshop Program Presentation Materials

- CHPS’ Best Practices Manual, Volume I

- CHPS' Workshop Program Presentation Materials

- DOE's Energy Design Guidelines series - Cool and Humid Climates

- U.S. DOE’s “High Performance Schools” video

- LEED $^{\mathrm{TM}} 2.0$ - Rating System and Reference Guide

- Southern California Edison's “Better Brighter Schools” video

- California Energy Commission’s Online Energy Training Videos

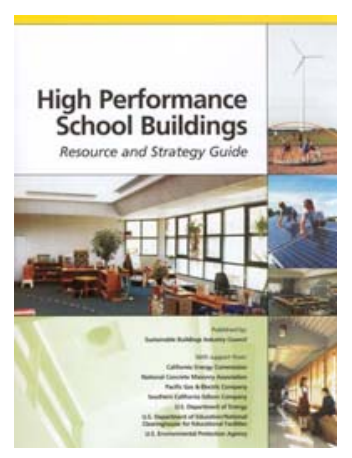

The purpose of the review will be to sift through the source materials and tease out the key messages and accompanying materials that can be used to orient an A/E firm to the basic components of a high-performance school and why they should strive to deliver one. The emphasis will be on feasibility and practicality - i.e., designing and operating such schools is feasible now and is being done with increasing frequency across the country. The bulk of the content for this section will be assembled from existing materials (much of which was developed by the project team), will be highly graphic in nature, and will include a variety of case study examples illustrating the key points. The section will include several screens of introductory material plus links to a more detailed PowerPoint presentation and to one or more online videos. The purpose will be to generate enthusiasm for, and provide an orientation to, the detailed training program that follows. Online tests will not be developed for this segment of the Web site.

Project Outcome: Content approved and implemented.

\section{Task 7.4. Develop Detailed Training Content}

The Contractor shall develop detailed training content to meet the technical learning objectives defined for the architects and engineering audience for this training. The training content for the Internet-based training program shall be based on three complementary sets of source material: DOE's National Best Practices Manual for Building High Performance Schools; Volumes II and IV (Maintenance and Operations), the CHPS Best Practices Manual, and materials - including a 
wide range of PowerPoint slides - developed by CHPS for an ongoing series of workshops for architects and engineers.

These materials are considered the most comprehensive and detailed sources available for training architects and engineers on how to design and operate energy-efficient schools. The materials have been vetted by numerous review bodies in California and nationally and have been tested in training workshops that have already educated over one thousand design professionals. Using these materials as a base, the Contractor can create state-of-the-art Internet-based training that will help building professionals deliver and operate the next generation of high-performance, energy-efficient K-12 schools.

To assemble these materials into an effective Web-based training program, the following subtasks are proposed.

\section{Task 7.4.1. Finalize Topic Categories and Course Module Subject Areas}

The Contractor shall deliver a final list of core curriculum, additional topic categories and course module subject areas to the NYSERDA Project Manager for review and comment by the due date in Table 1. The Contractor shall incorporate NYSERDA's comments and deliver the final version one week after receiving comments from the NYSERDA Project Manager. Pending Focus Group agreement, there shall be three tiers of courseware for the project: 1) Overview, Introduction, and Setting Goals and Objectives; 2) a 25 module core curriculum that forms the baseline deliverable for the project; and 3) additional courses, as appropriate, to enhance and expand the core curriculum. The list of course modules (see below) follows this three-tier approach.

Project Outcome: This task was modified. The 3-tier approach was changed to a single level 25course curriculum including the introductory overview. All 25 courses were developed as one comprehensive list of core courses available on the website, applicable to all climate zones defined by US. DOE . Three additional M\&O courses were added later as described in Section 3.

\section{Topic Categories}

The Contractor shall organize the total content for the training into one overview and 13 overall course categories. The categories, with the exception of the "Overview," conform to those in DOE's National Best Practices Manual. They cover the most important information needed to create highly energy-efficient schools. Each category will have its own home page, which will provide a Web-based overview of the topic - most likely in the form of a PowerPoint presentation enhanced, as appropriate, by streaming video - and will introduce the key course modules in that particular topic category.

\section{Course Modules}

Within each category are the actual course modules for the training: a total of 25 in the core curriculum. The modules are designed to closely track the specific topics presented in a very successful workshop series that CHPS is currently conducting to train A/Es in California. Each module will be structured to constitute one "contact hour" of training and will consist of a combination of Web-based and text-based instruction, including an online test. The Contractor shall, at a minimum, produce the overview module, and 25 course modules listed under core curriculum below. Following is a list of general topic categories and associated course modules: 


\begin{tabular}{|c|c|}
\hline $\begin{array}{l}\text { Overview } \\
\text { - } \quad \text { Introducing High Performance Schools and } \\
\text { the Online Curriculum } \\
\text { Design Criteria } \\
\text { - } \quad \text { CHPS and LEED }{ }^{\mathrm{TM}} \text { Criteria } \\
\text { Site Design } \\
\text { - } \quad \text { Site Selection, Planning, and Building } \\
\text { Orientation } \\
\text { - Landscaping } \\
\text { Daylighting and Windows } \\
\text { - } \quad \text { Daylighting Principles } \\
\text { - Fenestration } \\
\text { Lighting and Electrical Systems } \\
\text { - } \quad \text { Lighting Design } \\
\text { - Sources, Luminaires and Controls } \\
\text { - Lighting Strategies and Tools } \\
\text { Mechanical and Ventilation Systems } \\
\text { - Thermal Loads and Comfort } \\
\text { - } \quad \text { Ventilation - Natural and Mechanical } \\
\text { - } \quad \text { HVAC System Design and Selection } \\
\text { - } \quad \text { Special HVAC Systems, Equipment and } \\
\quad \text { Controls }\end{array}$ & $\begin{array}{l}\text { Commissioning } \\
\text { - } \quad \text { Building Commissioning } \\
\text { Energy-Efficient Building Shell } \\
\text { - } \quad \text { Good Building Envelope Design } \\
\text { - } \quad \text { Energy Efficient Materials and Methods } \\
\text { Resource-Efficient Building Products } \\
\text { - Healthy Interiors and Materials Efficiency } \\
\text { - } \quad \text { Flooring } \\
\text { - Other Interior Surfaces and Products } \\
\text { Health and Productivity } \\
\text { - Indoor Air Quality } \\
\text { - } \quad \text { Acoustics } \\
\text { Renewable Energy } \\
\text { - } \quad \text { Renewable Energy Systems } \\
\text { Transportation } \\
\text { - Site Design and Alternative Fuels } \\
\text { Recycling Systems, Waste Management and } \\
\text { Construction Management } \\
\text { - Buildings, Grounds, and Construction } \\
\quad \text { Waste } \\
\text { Water Conservation } \\
\text { - Water Management and Reuse }\end{array}$ \\
\hline
\end{tabular}

Project Outcome: Content approved and implemented.

\section{Task 7.4.2. $\quad$ Develop Detailed Content for Beta Course Module}

The Contractor shall fully develop the content for one course module to serve as the Beta Course Module, and submit to NYSERDA for review and approval. The specific topic area will be selected in consultation with NYSERDA personnel as part of the Focus Group discussions in Task 7.1. The Beta Course shall demonstrate content that is representative of each training design element defined in the training design document. The Contractor shall not proceed to Task1.4.3 until NYSERDA has reviewed and approved the Beta Course Module delivered as Task 1.10.

Project Outcome: Beta course on Water Conservation was developed on time.

\section{Task 7.4.3. Develop Detailed Content for Core Curriculum Modules}

Once the basic format and content for the Beta Course Module has been reviewed and approved (at the conclusion of Task 1.10), the Contractor will proceed to develop the remainder of the core curriculum modules to the same level of detail. The content will be developed so that it can be incorporated into the course software and delivered to NYSERDA in accordance with the two priority levels established in Task 1.4.2: priority courseware in July 2003 and the remainder in October 2003.

The Contractor shall fully develop the content for all core curriculum modules defined in the curriculum plan delivered under Task 1.4.1, and submit to NYSERDA for review and approval. The Contractor shall incorporate NYSERDA's comments and deliver the final version two weeks after receiving timely comments from the NYSERDA Project Manager. 
Project Outcome: Core curriculum was developed in two phases, with priority courses developed first.

\section{Task 7.4.4. Develop Additional Course Modules}

The Contractor shall develop additional course module content defined in the curriculum development plan delivered under Task 1.4.1, and submit to NYSERDA for review and approval. The Contractor shall work with NYSERDA and the Focus Group to determine recommended content to enhance and expand the core curriculum. This content may or may not be in the same format as the core modules; i.e., there may be less Web-based material and more reliance on textbased information, topics may be combined to create economies of scale, tests may not be provided for all modules, etc. The exact form and level of depth for these materials will be determined in discussions with NYSERDA as the project proceeds. Topics proposed for these "additional modules" may also be revisited at this time.

Project Outcome: Additional course modules were developed as part of the second phase core curriculum designed in accordance with the same format as set forth by the Focus Group.

\section{Task 7.5. $\quad$ Develop Learning Objectives}

The Contractor shall build learning objectives for each module, and submit to NYSERDA for review and comment by the due date established in Table 1 . The Contractor shall incorporate NYSERDA's comments and deliver the final version two weeks after receiving timely comments from the NYSERDA Project Manager. The goal will be to identify the key lessons in each module - i.e., the basic knowledge that will help the users design and operate more energyefficient schools - and restate these lessons as a series of learning objectives. The objectives, in turn, will become the organizing structure for the tests to be developed in Task 1.6. The Contractor shall not proceed to Task1.6 until NYSERDA has reviewed and approved the learning objectives for each module as described under this task.

Project Outcome: Learning objectives were developed by Dean Evans at NJIT, reviewed, and approved by the Focus Group.

\section{Task 7.6. Develop Test Content}

The Contractor shall create the questions and/or exercises that will test the user's knowledge of the key learning objectives for each module, and submit to NYSERDA for review and comment by the due date established in Table 1. The Contractor shall incorporate NYSERDA's comments and deliver the final version two weeks after receiving timely comments from the NYSERDA Project Manager.

The Contractor shall contact the AIA Continuing Education department to ensure that the type and number of questions are sufficient to qualify each one-hour module for one Learning Unit of credit. It is anticipated that the bulk of these tests will be multiple choice, with approximately 10 questions for each contact hour of course work. The exact number of questions, and what constitutes a "passing grade," will be determined in consultation with NYSERDA personnel.

Project Outcome: Test content was developed by Dean Evans at NJIT, edited by AEC, and later reviewed and approved by the Focus Group. 


\section{ANATOMY OF A COURSE MODULE: SOURCES AND LUMINAIRES}

The "Sources and Luminaires" course module will follow the same basic format as the other core courses in the training program. A user can begin by accessing the "Electric Lighting and Controls" home page, where he/she will receive a Web-based introduction to the overall topic. These introductions will typically include text and graphics and may also include streaming video if appropriate. Alternatively, the user may go directly to the "Sources and Luminaires" course module, which will have its own distinct home page. The home page will orient the user to the course, describe the learning objectives for module, and provide access to four core information components:

1. A PowerPoint presentation that provides an overview of energy-efficient electric light sources and luminaries in schools. The presentation will be based on materials already developed and tested in workshops across California by CHPS.

2. Additional resources that the user can access to broaden his/her understanding of the course content. In this case, resources might include the Advanced Lighting Guidelines, IESNA RP-3-00: Lighting for Educational Facilities, etc.

3. A PDF file containing the text-based instructional materials for this module. These materials will be taken directly from the U.S. DOE National Best Practices Manual and, together with the PowerPoint information, will constitute the core materials upon which the test is based. For this module, the relevant information is contained in the "Lighting and Electrical Systems" chapter, specifically the following sections: Overview and Guidelines EL 1, 2 and 3 - Pendant-Mounted Lighting; Recessed Lighting; and Surface-Mounted Lighting. A registered user would download and study these materials, concentrating on the learning objectives described on the module home page.

4. The final component is a secure online test designed to gauge the user's understanding of the content presented. The test will be organized in accordance with the learning objectives described on the course module home page and will be designed to provide the user instant feedback on his/her performance.

\section{Course Software Development}

\section{Task 7.7. Develop Basic Design and Layout}

To effectively distribute the content material developed in the previous tasks, the Contractor shall design, build, and implement an Internet-based distance-training platform with the following functionality:

- Online registration and payment through secure e-commerce

- Downloadable registration and payment forms for mail and fax submittal

- Log-in identification and password protection for all course contents

- Tracking, managing, and submitting reports of registered applicants and completion records

- Tracking, managing, and submitting fulfillment of continuing education hrs to state licensing boards

- Providing electronic certificates of completion for registered applicants completing the course

- Online quiz for each registered applicant

- Performance reporting by course and showing percentage completion for each registered applicant 
- Technical assistance phone support

- Asynchronous discussion thread with instructor

- Administrative functions for tracking progress of each registered applicant, including quiz scores by course

\section{Task 7.7.1. Develop Functional Design Document}

The Contractor shall develop and submit to the NYSERDA Project Manager a functional design document that addresses all functional, technical, marketing, content and usability requirements and objectives of the Internet-based training website. The functional design document shall include a flowchart (course map) showing how the course progresses from start to finish including the website home page, overview module home page, course home page, module home page, text-based instructional materials, Streaming PowerPoint presentations, links to additional resources, asynchronous conference thread and message board, online quiz, course evaluation, and other components of the course as defined in the training design document.

The Web Site shall comply with New York State policy for Universal Accessibility of web sites. Compliance must be demonstrated by running the Web Site through www.cast.org/bobby/ ("Bobby") or such other equivalent web site as approved in advance by NYSERDA. The Web Site shall comply with all Priority 1 issues. These requirements are further described in Section 5 of the Web-Related Contract Addendum of this Agreement.

\section{Task 7.7.2. Develop Design for Overview Module}

The Contractor shall develop the design and layout for the Overview Module, and submit to NYSERDA for review and comment by the due date established in Table 1. The Contractor shall submit a minimum of 2 static design concepts for NYSERDA review and approval prior to proceeding to prototype. Upon design approval, the Contractor shall create the basic page layouts and incorporate the navigational and interactive elements described in the functional design document. The Contractor shall incorporate NYSERDA's comments and deliver the final version two weeks after receiving timely comments from the NYSERDA Project Manager.

The process will begin with creation of an overall program home page and "Overview Module" designed to introduce the program to potential users. The page will include the content described in Task 7.3 and will provide the following functionality:

- Online registration and payment as well as downloadable forms for mail and fax submission

- Links to other partners

- An index of, and access to, all available online courses

- Software requirements

- $\quad$ Link to free download of the Windows Media Player, Adobe Acrobat, MS PowerPoint Viewer, MS Internet Explorer 5.0 and Netscape 6.0

- Other guidance and contact information

Upon registration, the applicant will be supplied with a log-in ID and password. These will be used to access the individual distance training modules. Each individual module will be designed to supply one course hour of training and will exist essentially as a separate Web site linked to the public home page - but accessible only by username and password.

The applicant's user name and password will then be entered into an online database. From that database, the Contractor and/or NYSERDA will be able track, manage, and submit reports and completion records of registered applicants to national professional organizations for continuing education credit. The records can also be used to trigger the award and transmittal of completion certificates in conformance with the requirements developed in Task 1.14. The Contractor shall 
provide a dynamic prototype interface of the Overview Module to show all design elements described in the functional design document for usability testing, and coordinate with select members of the Focus Group and NYSERDA to obtain reactions to the interface. The Contractor shall incorporate comments from the usability testing into the final design for the Overview Module. Once the interface prototype is tested and finalized, a template can be created. Using the flowchart (course map) delivered with the functional design document under Task 1.7 for reference, all the pages can be created with a blank space for the content. All these pages can be linked and the navigation tested for functionality. The Contractor shall implement and unit test the approved Overview Module prototype. During unit testing, the Contractor shall test the functionality of all design elements implemented per the functional design document. The Contractor shall provide the NYSERDA Project Manager with password-protected access to the website to review and test the website module.

\section{Task 7.7.3. Develop Design for Individual Course Modules}

The Contractor shall develop the design and layout for the Individual Course Modules that will form the core of the online training, and submit to NYSERDA for review and comment by the due date established in Table 1. The Contractor shall submit a minimum of 2 static design concepts for NYSERDA review and approval prior to proceeding to prototype. Upon design approval, the Contractor shall create the basic page layouts and incorporate the navigational and interactive elements described in the functional design document. The Contractor shall incorporate NYSERDA's comments and deliver the final version two weeks after receiving timely comments from the NYSERDA Project Manager.

The Contractor shall provide a dynamic prototype interface of the Individual Course Module to show all design elements described in the functional design document for usability testing, and coordinate with select members of the Focus Group and NYSERDA to obtain reactions to the interface. The Contractor shall incorporate comments from the usability testing into the final design for the Individual Course Module. Once the interface prototype is tested and finalized, a template can be created. Using the flowchart (course map) delivered with the functional design document under Task 1.7 for reference, all the pages can be created with a blank space for the content. All these pages can be linked and the navigation tested for functionality.

The Contractor shall implement and unit test the approved Overview Module prototype. During unit testing, the Contractor shall test the functionality of all design elements implemented per the functional design document. The Contractor shall provide the NYSERDA Project Manager with password-protected access to the website to review and test the website module.

Each of the modules will be organized in the following way.

\section{Module Home Page}

The Contractor shall design and develop the module home page and deliver to NYSERDA for review and comment by the due date established in Table 1 . The Contractor shall incorporate NYSERDA's comments and deliver the final version two weeks after receiving timely comments from the NYSERDA Project Manager. Upon accessing an individual course, the applicant will enter a module home page. The home page will be an HTML multi-page text and photo overview that will introduce the content and organization of the module. It will be laid out in a highly interactive, aesthetically pleasing, and easy-to-use interface and will include a brief body of instructional text. Photos of key components will be included with the text, and graphics as defined by branding requirements will also be displayed.

Links will be supplied at the end to the following components:

- $\quad$ Streaming PowerPoint Presentations

- Text-based Course Materials

- Links to Additional Resources 
- Asynchronous Discussion Thread and Message Board

- An Online Interactive Quiz

- An Electronic Course Evaluation Form

\section{Streaming PowerPoint}

The Contractor shall deliver sample PowerPoint presentations to NYSERDA for review and approval regarding the look and feel of the presentation as it relates to the branding and theme for the website. The Contractor shall incorporate NYSERDA's comments and deliver the final version along with all components of this task. These presentations will be drawn directly from the PowerPoint presentations created by Charles Eley for his seminar course work. They will be designed to supply the applicant with an engaging general introduction and will allow the viewer to explore case studies in cutaways to video footage highlighting the key points of the course, be it a skylight installation, high-performance chiller, or water conservation system.

The streaming PowerPoint presentations will use the Windows Media Player format and will be streamed for both broadband (Cable/DSL/Corporate LAN) and dial up (telephone modem). Should the viewer require it, a link will be supplied on the Web site for the free download of the Windows Media player. The download of this media player is straightforward and stable. The page will supply an onsite application that will pre-test the viewer's browser.

\section{Text-Based Instructional Materials}

Each module home page will supply easy to use linked access to the text-based instruction for that particular module. The information will be in the form of downloadable Adobe Acrobat PDF files and Corel WordPerfect version 9.0+. For those who do not have Adobe Acrobat Reader, a link to the Acrobat Reader download page will be supplied on the course home page

\section{Links to Additional Resources}

Each module home page will supply links to specific resources that can expand the learning experience for the user. The specific resources to be linked to each module home page shall be listed with the course content developed under Task 1.4.

Asynchronous Conference Thread and Message Board

An asynchronous conference thread and message board will be integrated into and dedicated to each course module. The asynchronous conference thread will allow an instructor to engage in online, on-demand dialogues with viewers taking the course.

The message board will serve as a universal posting place for the exchange of ideas and comments and a method for updates of the curriculum. Serving as an "Open Public Forum," the message board will encourage active participant involvement in asking and answering questions. All notes and exchanges garnered from the Message Board and Conference Thread will be stored for on-demand delivery by the administrators. This will be an open forum public board.

\section{Online Quiz}

Upon review of the course material, the applicant will take an online test. The test will be multiple choice and will be designed to incorporate graphic elements, including photos, graphs, and renderings. The applicant will be able to review his/her own test results and retake the test if necessary.

The results will be stored in an online database that will show performance reporting by course and percentage completion of each course module and for all modules making up the full online curriculum for each registered applicant. 
Administrative functions for tracking progress of each registered applicant, including quiz scores by course, will be password protected and can be remotely accessed online.

Course Evaluation

E-mail feedback forms will be supplied for each applicant with a detailed series of questions for a comprehensive online course evaluation.

Project Outcome: Individual course design, prototype, and unit testing was completed by Building Media and approved by the Focus Group and DOE Review Team. The DOE Review Team was convened to provide input to the look and feel of the website home page and overall marketing plan for the training. DOE Review Team comments on the website design and hosting plan can be found in Attachment D.

\section{Task 7.8. $\quad$ Establish Hardware Requirements}

The Contractor shall use established hardware requirements as defined in the Statement of Work for the platform supporting the online training program.

A dual server configuration will optimize the operating systems for the core database functions and streaming media content delivery. The servers will be located in the same facility for integrated monitoring and tech support. The proposed configuration provides for daily tape backup and off-site storage of files.

The Web server housing the Web site cluster will be a dedicated Linux server housing our site alone. We will have full root access. Streaming PowerPoint content will reside on a Windows Server 2000 with Windows Media Extensions. The Contractor will have Directory access and the drive space will be scalable, starting at 1 gigabyte.

Handoff of the distance-training Web site at the end of the two-year period will also be greatly facilitated by the dedicated server environment. NYSERDA, or other designated party such as US. DOE Rebuild America, NASEO, or ASERTTI has simply to take over the hosting contract. In addition, the Web server has been "spec'ed" to accommodate substantial increase in use and volume should NYSERDA decide to replicate the program both regionally and nationally.

All server and software components are designed to be robust and highly scalable. This means they can be readily expanded to accommodate an expansion of the distance training initiative both regionally and nationally. The Contractor shall use the following hardware for development and deployment of the Internet training courseware:

\section{Dedicated Web Server:}

- Dell Power Edge Server, Linux Operating System

Server System Specifications:

- Intel Pentium III 900 MHZ Processor

- 512 MEGS RAM

- $\quad$ RAID O Mirrored 9 Gigabyte SCSI Hard Drive

- $\quad$ Seagate DDS3 Back Up Tape Drive

Server Support:

- 24 x 7 Monitoring

- Daily Backup of all files to Tape and Offsite Storage

- Server on Uninterruptible Power Supply w/Diesel Generator Back Backup

Internet Connectivity:

- Connectivity through 100MBPS port, fully burstable

- Backbone connectivity utilizing redundant OC 3 connections 
- ISP has passed DOD and HIPPA for security and stability

Streaming Video Server:

- Dell Power Edge Server, Windows Server 2000 Operating System

Shared Windows Media Server Specifications:

- $\quad$ Intel Pentium III 900 MHZ Processor

- 512 megs RAM

- Directory Access

- 1 Gigabyte Space SCSI Hard drive

Project Outcome: Hardware and software system requirements for the web application are presented in Attachment E.

\section{Task 7.9. $\quad$ Establish Software Requirements}

The Contractor shall develop a website that meets the end-user software requirements for standard multimedia, internet-ready computers with either Macintosh or Windows-based operating system platforms. These requirements shall include Web browser requirements of Netscape 6.0 or later, and MS Internet Explorer 5.0 or later, and any plug-ins required to view the multimedia content such as Windows Media, Adobe Acrobat, or MS PowerPoint Viewer. For those computers equipped with earlier browser versions, the Contractor shall provide specific instructions and links to free downloads to allow the user to upgrade their browser to Netscape 6.0 and Internet Explorer 5.0 or later to optimally view the multimedia content. The Contractor shall define these requirements on the overall program home page for the training audience per Task 7.7.1.

The Contractor shall utilize "best practice" software for the training program as follows and more fully described below:

- Java 2 with Apache Tomcat as the Java application server

- Apache HTTP Server

- MySQL Open Source Database

\section{Platform Architecture}

The operating system (OS) on Building Media's Web server will be Linux. This is a highly stable open source code OS that is the platform of choice for the majority of the Web servers on the Internet. It is free and fully supported by Building Media’s ISP.

The product will be built on the Java 2 platform. Because the code resides on the server side, browsers do not have to be Java enabled to engage our distance training applications. Java is recommended over proprietary scripting languages such as PHP or Coldfusion. Java is an open, fully object-oriented programming language that is becoming the industry standard for Internet programming.

The Contractor will use Apache Tomcat and Apache HTTP Server as its Java application server and HTTP server software, respectively. These are stable and open source projects that fully integrate with the Linux operating environment.

MySQL will be used as the database application for the online testing mechanism. This is open source code that is has fundamental cornerstone of Web-based interactive database applications. MySQL is the world's most popular Open Source Database, designed for speed, power, and precision in heavy mission-critical load use. 
The Linux/ApacheTomcat/MySQL architecture, with Java as the programming language, guarantees a robust, highly stable, scalable environment in which to design and implement custom-built testing mechanisms and online database administration and integrate the Java-based discussion forum. The scalable nature of this architecture allows for simplified and cost-effective replication of online training and content delivery applications both regionally and nationally.

\section{Online Registration}

The Contractor shall create a custom online registration system integrated with the e-commerce package to register and monitor each applicant. The registration system is coded in Java with MySQL database.

\section{E-Commerce Payment}

The Contractor shall integrate its e-commerce component with its online registration database for seamless online payment and registration. Miva's Merchant E-commerce software will be used, which can be viewed at www.miva.com.

\section{Online Quiz, Monitoring, and Certification}

The Contractor shall design and create a sophisticated and stable Online Quiz Testing Mechanism that will integrate testing, instructional feedback, and electronic certification with administrative access tracking mechanisms. The test will be scalable and easily modified based on initial beta test input. The testing mechanism will incorporate graphics, including photos and illustrations, and will be multiple choice. Modular in format, it will allow applicants to complete portions of the training at different times while monitoring and tracking completion of each module of their progress. The application will be coded in Java with MySQL as database, allowing for a highly customizable application that can easily grow to meet regional and nationwide audiences.

\section{Asynchronous Conference Thread}

Jive Software's Jive Professional is an open architecture, Java ${ }^{\mathrm{TM}}$-based discussion forum application. Already in use by thousands of organizations around the world, Jive Forums is flexible and reliable discussion forum software - one of the few off-the-shelf applications that can handle the heavy traffic of a major site.

The Professional package is targeted at a growing medium-sized community that wants advanced features, statistics about the community, and basic support for implementing and maintaining the forums. The software may be reviewed at www.jivesoftware.com.

\section{Message Board}

Based on the software architecture of Jive Professional, the Contractor shall integrate its own custom coded Message Board with full administrator online access and control. All postings will be stored in the database as on-demand and end-of-contract deliverables.

\section{Electronic Tech Support}

To create a comprehensive technical support system, the Contractor shall integrate SupportClient, a Customer Relations Management (CRM) business solution, with pager-enabled telephone support for 24 x 7 online, seven days per week (from 7 a.m. through 10 p.m.) daily online tech and client services support. The SupportClient software can be reviewed at www.supportclient.com.

\section{Software Summary}

Software decisions have been based on creating the most robust, scalable, and cost-effective distance learning infrastructure possible. Ease of use for the applicant and maximum functionality for the administrator are our key determining factors in our design and selection of both 
commercially available and custom coded applications. A dedicated server environment will optimize control over all software components for seamless integration across all functions, allowing the Contractor to deliver a content rich, sophisticated, multifaceted environment, which can be readily expanded to accommodate the expansion of the distance training initiative both regionally and nationally.

Project Outcome: Hardware and software system requirements for the web application are presented in Attachment E.

\section{Task 7.10. Create BETA Version of One Course}

Once the design, hardware, and software for the proposed training have been established, they will be combined with the content developed in previous tasks to create the actual courses to be taught. The first of these will be considered a BETA version and will focus on one module selected by the Contractor and NYSERDA to be representative in terms of both content flexibility and electronic challenge.

The Contractor shall develop the BETA test module and deliver to NYSERDA by the due date established in Table 1 . The module will be posted on a secure URL and reviewed by participants in the Focus Group convened in Task 1.2 and designated NYSERDA representatives. The Contractor shall conduct coordinated Beta Testing, and reviewers shall be asked to "take" the course, complete the online tests and comment on the content and functionality of the module. The Contractor shall compile the test results and submit the results to the NYSERDA Project Manager for review and approval. The Contractor shall retest or conduct repairs to site functionality as requested by the NYSERDA Project Manager. The Contractor shall implement these repairs in the final Beta Module prior to conducting the demonstration defined in Task 1.11. NYSERDA will review the web site using multiple browsers to identify any potential site problems.

Project Outcome: Beta course on Water Conservation was developed, approved, and submitted with this final report on a separate CD-ROM titled Water Conservation Course, Demo CD Version 1.1.

\section{Task 7.11. Conduct Demonstration}

The Contractor shall provide a demonstration of the BETA course module while posted on a secure URL for NYSERDA personnel and school business officials at the NYSERDA booth during the June conference of the Association of School Business Officials (ASBO) in Buffalo, New York. The Contractor shall provide an alternate method of running the BETA demonstration should there be issues with the Internet Beta Course Module so as to guarantee that the demonstration can be successfully delivered during the conference. The Contractor shall include demonstration of the overall program page, the BETA Course Module, and any other components of the website that may provide a positive impression of the development effort accomplished by the Project Team.

Project Outcome: Beta course on Water Conservation was presented at the ASBO conference in 2003.

\section{Task 7.12. Create First Priority Course Modules}

The Contractor shall create the first priority course modules per the curriculum plan defined in Task 1.4.1, and deliver to NYSERDA for review and approval. Once the BETA version of the module has been reviewed and upgraded, it will serve as a template for all future modules. During 
this task, the "priority" modules in the core curriculum identified in Task 1.4.1 will be created following this template.

Project Outcome: All phase I course modules were developed according to template approved by DOE Review Team and the Focus Group.

\section{Task 7.13. Create Remainder of the Core Curriculum Course Modules}

The Contractor shall create the remainder of the core curriculum course modules per the curriculum plan defined in Task 1.4.1. and deliver to NYSERDA for review and approval by the due date established in Table 1. During this task, the remainder of the core curriculum modules will be created following the same procedures used in the preceding task.

Project Outcome: All phase II course modules were developed according to template approved by DOE Review Team and the Focus Group.

\section{Continuing Education and Certification Process Development}

\section{Task 7.14. Define Certification Requirements}

During this task the Contractor shall work with NYSERDA personnel to define the requirements for A/E certification under this program, with the goal of creating, launching, and maintaining a seamless online certification function as part of this project.

Successful completion of at least 25 modules shall be required for certification; a user will need to "pass" each individual module to qualify. This is the approach currently being used by the U.S. Green Building Council in its LEED ${ }^{\mathrm{TM}}$ Professional Accreditation program. Although there are no specific study requirements in the LEED ${ }^{\mathrm{TM}}$ process, there is a detailed, closed-book, twohour test. If a user passes, he or she is added to the national Directory of LEED ${ }^{\mathrm{TM}}$ Accredited Professionals; if the user fails, he/she is not accredited. The Internet training program could take a similar approach and require successful completion of all the course modules in order to be added to the Energy Smart School Designer and/or Operator referral list within respective states. A passing grade of 75 on each module - the same as the LEED ${ }^{\mathrm{TM}}$ exam - would be required.

NYSERDA and the Contractor shall evaluate the merit of requiring a different set of modules for Energy Smart Designers as opposed to Operators. The Designers, for example, may need to successfully pass all the modules except those contained in the Commissioning category and the Operation and Maintenance category; whereas these might be the only courses the Operators need to complete. This approach has the advantage of clearly delineating between the two user groups and their needs, but also runs the risk of undercutting a key principle of energy-efficient design: the need for an integrated approach to building design and operation. What the Designers don't know about operations and maintenance could negatively impact the functionality of their designs; what the Operators don't understand about design may restrict their ability to manage the school efficiently.

Project Outcome: The project team decided to modify this task. With the market recognition of the LEED $^{\mathrm{TM}}$ Professional Accreditation program, the focus group concluded that creating a separate certification program for High Performance School design or High Performance School operations would be at cross purposes. Members of the Focus Group recommended focusing team efforts on promoting continuing education through existing accrediting bodies such as AIA, rather than developing specific certification programs that may conflict with other national level 
program offerings such as LEED ${ }^{\mathrm{TM}}$. A certificate of completion was designed to be printed by the end-user upon the successful completion of the course (defined as receiving $80 \%$ or higher on the course quiz).

\section{Task 7.15. Upload Certification Procedures}

The Contractor shall incorporate the requirements and procedures for certification into the training software and tie them to the database management system. As an individual user completes various modules within the course, the results will be tracked. Once the individual successfully completes a module (receiving test score of $80 \%$ or higher), he/she will be issued a certificate of completion. The certificate will be forwarded electronically to the user and to the AIA for LU credit if the user is an AIA member. After completing all 25 course modules, the user's name and A/E firm will be added to a database of providers eligible to attend the National Training.

Project Outcome: Submission of electronic records to AIA for LU credit was completed by the implementation contractor for those users who identified themselves as AIA members.

\section{Task 7.16. Define Continuing Education Requirements}

As the course modules are being developed, the Contractor shall contact the continuing education departments within the American Institute of Architects (AIA), the Council of Educational Facility Planners International (CEFPI), the National Society of Professional Engineers (NSPE), and the Association for Energy Engineers (AEE) to determine what levels and types of credit each course module will qualify for within each organization. The Contractor shall provide this information to NYSERDA for information.

The Contractor shall 1) have the course modules reviewed by appropriate personnel, 2) determine the level and type of credit each organization is prepared to offer for each module, 3) determine the procedures needed to register the courseware within each continuing education system, and 4) implement these procedures so that the full training program is registered for continuing education credit with all appropriate professional societies.

The Contractor shall also contact the New York State Licensing Board to ensure that the courseware being developed qualifies for continuing education credit within the state. While professionals do not submit each course they take directly to the Licensing Board for inclusion in a continuing education database, they must have documentation of their course work available to indicate their compliance with the " 36 hours every three years" requirement that exists within the state. If the course is registered (as this one will be) with the AIA, architects can use their AIA transcript as documentation. If users do not have access to an AIA transcript, the certificates issued by the program will need to serve as documentation, and the Contractor will work with the Licensing Board to ensure that these certificates are acceptable.

The Contractor is confident that the bulk of the course modules proposed will qualify for "health, safety, welfare” credit but will work closely with the New York State Licensing Board to ensure that they do. This is a critical issue within New York State, as the Board seems to increasingly want all credits applied to New York licensure to be HSW. (It should be noted that currently the Licensing Board will only allow 30 percent of continuing education credits in any given time period to be derived from Web-based training. The Contractor has already contacted Kathy Robbins at the Board concerning this issue and will continue to explore its ramifications as the project proceeds). 
Project Outcome: The implementation contractor registered each course with AIA to allow AIA members to use their AIA transcript as documentation of their continuing education credits. The project team met with the New York State Department of State Licensing Board to define a process by which architects and engineers would be able to submit their certificates of completion to demonstrate successful completion of courses that would count toward continuing education requirements for those users who were not AIA members. The format used for the Certificate of Completion is presented in Attachment F.

\section{Task 7.17. Register Program}

Once the procedures and requirements for registering the training program for credit with national professional societies have been established, the Contractor shall proceed to register the program and create the necessary Internet linkages to ensure that credits are effectively tracked and transferred. This task may include revisiting and modifying the software developed in Task 1.9 in order to enhance registration, registrant tracking, and e-commerce procedures.

Project Outcome: This task was modified from the original scope. The Focus Group recommended offering the training free of charge for the first two years of implementation, and therefore the e-commerce package was not integrated with the registration package. Miva's Merchant E-commerce software may be used in the future to collect payment information for registered users. Registration fees could then be used as a funding mechanism for future courseware development and for overall site maintenance and technical support.

\section{Course Implementation: Marketing, Hosting, and Technical Support}

\section{Task 7.18. Market the Program}

The Contractor shall recommend specific marketing strategies and submit marketing materials to NYSERDA for approval prior to implementation. The Contractor shall work with key target audience industry organizations such as AIA, CEFPI, NSPE, AEE, and with NYSERDA, NASEO, DOE, and ASERTTI to aggressively promote the training program. All these organizations have newsletters, electronic and print, that can promote the training. They also have comprehensive Web sites that can provide direct links to the training. SBIC will also activate its own outreach network through its member organizations. The goal will be a robust and diverse list of target audiences who can and will be contacted and encouraged to access the online training. Marketing to these organizations shall begin approximately three months prior to the launch of the site and continue until the conclusion of the contract period.

Project Outcome: The DOE Review Team approved a marketing plan provided as Attachment $\mathrm{G}$, and the implementation contractor developed a news release for publication submitted as Attachment $\mathrm{H}$.

\section{Task 7.19. Launch the Program}

The Contractor shall officially launch the fully functional Internet-training website including all priority core curriculum course modules defined in the curriculum plan by the due date established in Table 1. The Contractor shall provide opportunity for limited access to the fully functional Internet-training website three weeks prior to the official launch for review and functionality testing by NYSERDA and select members of the Focus Group. 
Project Outcome: Completed on-time, visit the Online Training for High Performance School Design at: http://www.hpschooldesigntraining.com

\section{Task 7.20. Launch Second Set of Modules}

The Contractor shall officially launch the second set of remaining core curriculum modules as defined in the curriculum plan by the due date established in Table 1. As appropriate, additional modules may be added to the website during the period between this second launch date and completion of the contract.

Project Outcome: Completed on-time, visit the Online Training for High Performance School Design at: http://www.hpschooldesigntraining.com

\section{Task 7.21 Host the Program and Provide Technical Support}

From the date of launch through contract completion, SBIC will host the site with technical support from Building Media and content support from AEC. Building Media will provide an escalating technical support system that offers participants several options for fulfillment of technical issues. The escalating procedures include opt-in email technical question support answered by trained technician, self-testing system that detects technical issues and provides selfguided fix, and a tracking number system that directs participants to software that relays information to a technical assistant who diagnose problems/issues and provide call-back technical support. The Online Training System and software platform are being constructed for ease of use and reliability of system. Should technical issues arise, Building Media is developing a special help center that provides resources, FAQs, and easy-to-use testing equipment that will answer most - if not all - basic technical inquiries.

To ensure uninterrupted operation and maintenance of the website for a period of six months beyond the completion date of the current contract, U.S. DOE has requested that NYSERDA extend the hosting and support services contract, and authorize BMI and SBIC to continue to provide support services through April 1, 2005. No additional funding is authorized. Specifically, BMI will provide the following services:

- Hosting and maintenance of dedicated server housing the NYSERDA website

- Streaming media hosting and storage services

- Basic technical support services to troubleshoot site maintenance and user issues

Specifically, SBIC will provide the following services:

- Content support services

- Administrative support services, including tracking AIA member credits and reporting to the AIA Continuing Education System.

Project Outcome: An Administrator’s Handbook is submitted as Attachment I.

Task 7.22

Implement New York Specific Code and Guideline Information

The Contractor shall create a link to New York specific information on the Curriculum page for each course (as necessary). NYSERDA will provide the content for each course link including, but not limited to, NYSED Guidelines, New York State Building Code, and New York State Energy Conservation Construction Code (ECCC) in order to supplement the guidelines provided 
in the National Best Practices Manual. This will serve as a model for other states as to how to add customized state-specific information on the training site.

Project Outcome: The project team removed this task from the scope of work. Focus Group and DOE Review Team members recommend individual states provide funding and technical support for state-specific implementation.

\section{Task 7.23. Transfer Assets}

At the conclusion of the contract period (September 2004), the Contractor shall transfer the online training program and all associated assets sufficient to reestablish a fully functioning Web Site at a different location to NYSERDA or whomever NYSERDA designates within 5 business days. The Contractor shall provide all documentation and technical assistance necessary to assure availability of the Web Site upon transfer of Web Site assets. It is anticipated that the procedures for this transfer will be discussed and planned for well in advance during the period when the Contractor is hosting the fully operational site. All deliverables, including multimedia lectures and related video for the Operations and Maintenance (O\&M) courses are to be delivered for NYSERDA review and approval.

Project Outcome: At the conclusion of this contract period, it was requested by Dan Sze/Margo Appel of the U.S. DOE Rebuild America team to have SBIC manage technical support and have $\mathrm{BMI}$ as the sub-contractor to SBIC continue hosting the website for an additional 6 months through April 1, 2005. These services were bundled together and billed in the last program invoice on 9/30/04. At the end of this period, NYSERDA and SBIC shall transfer the assets to NASEO and/or DOE's Rebuild America, Energy Smart Schools team. A migration plan, database schema, Windows streaming media installation, and spreadsheet documenting the streaming media links are provided as Attachments J, K, L, and M, respectively.

The project team provided all website assets and administrative documentation on two CD-ROMs included in the delivery of this final report as follows: (1) CD-ROM disk 1 of 2: New York State Energy Research and Development Authority: High Performance School Design; and (2) CD-ROM disk 2 of 2: New York State Energy Research and Development Authority: High Performance School Design. 


\section{Task 8}

\section{Applied Engineering and Design Assistance National Training Program for A/E Firms}

The Contractor shall conduct a one-day workshop to allow in-depth review and discussion of key issues that $\mathrm{A} / \mathrm{E}$ firms will need to know in order to provide effective technical assistance in the school facilities sector. Instructors experienced in planning, designing, and teaching about highperformance schools will detail current "state-of-the-art" strategies, energy-efficient technologies, best design practices, and cost-effective operational strategies available for new construction and existing K-12 buildings in the "Cool and Humid" climate zone. The training will show professionals how to use the design resources available and discuss "lessons learned from the field.” The training will be a combination of lecture, multimedia, and interactive exercises modeled on the successful High Performance School Buildings workshops that SBIC has conducted across the country over the last three years.

\section{Task 8.1. Develop Preliminary Training Program Outline}

The Contractor shall develop a preliminary outline for the training in cooperation with NYSERDA personnel. The training shall address both the technical and tactical aspects of providing technical assistance. For this reason, the task has been broken into two subtasks to address each of these aspects individually.

\section{Task 8.1.1. Develop Technical Program Content}

The Contractor shall develop the technical program content for the National Training Program. The technical content of the training program will be drawn from the National Best Practices Manual for Building High Performance Schools and the companion online training, as well as from New York case studies. The content will be modified so that it directly complements the online training program developed under this Statement of Work. This will primarily be a process of eliminating information that repeats what is already included in the Web-based training and focusing on specific technical areas that may need more elaboration than is possible on the Web.

The Contractor shall provide an outline of the technical content of the training program including topic areas to be covered within the various core areas for NYSERDA's review and comment. After receiving comments from NYSERDA, the Contractor shall develop the preliminary technical program content per this task. The goal is to build on and expand, rather than simply repeat, the Web-based information.

As an aid to this process, everyone attending the training will be required to take the online course, which should be substantially complete by the time the training program is offered. The feasibility and desirability of this requirement will be discussed with NYSERDA during this task. These technical discussions will make up roughly 60 to 70 percent of the overall agenda.

Project Outcome: The technical presentations are provided in MS Powerpoint format as Attachment N, and in Adobe Acrobat format as Attachment $\mathrm{O}$.

\section{Task 8.1.2. Develop Tactical Content}

The Contractor shall develop tactical content for the National Training Program that provides practical knowledge for the technical assistance provider. The training shall provide attendees with the information they need to provide effective technical assistance in the area of school design and operation. 
Advice on how to reach and influence decision-makers is just as critical as training on the technical components of high-performance schools. The Contractor shall devote a significant portion of the training to describing successful approaches to actually implementing technical assistance in the field of high-performance schools.

The Contractor shall review case studies for high-performance schools in New York. Additional case studies of successful programs around the nation will be profiled, starting with a detailed analysis of how highly sustainable schools in the country - for example, Roy Lee Walker Elementary in McKinney, Texas - came into being. Specifically, the role of the "highperformance consultants" and their interactions with the design architecture team will be discussed. Discussions will then expand to more structured programs of intervention and assistance at the jurisdictional level. The focus will be on how these programs are structured and how the audience members can use similar tactics to diffuse information on high-performance schools to their target audiences. Special attention will be paid to identifying when and how the process of designing a high-performance school can "go wrong." What are the key indicators of a process losing direction and/or momentum, and how can A/E firms intervene successfully to reverse these trends? The Contractor shall develop a specific training agenda from the key lessons from these experiences. These "tactical" presentations will make up roughly 30 to 40 percent of the agenda.

Project Outcome: The tactical presentations (case studies) are provided in MS Powerpoint format as Attachment P.

\section{Task 8.2. $\quad$ Review and Finalize Training Content and Format}

The Contractor shall circulate the two-tier preliminary training program outline to the listserve developed in Task 1.2 - and to other organizations and individuals NYSERDA suggests - for review and comment. The Contractor shall guide the Focus Group members and other individuals toward providing specific comments as to which content to emphasize and which content to deemphasize. The Contractor shall use best efforts to obtain additional case studies from school projects in the Cool and Humid climate zone.

In response to suggestions from the reviewers and to ongoing input from NYSERDA, the core content and format of the training program will be finalized. It is anticipated that these modifications will result in certain technical content areas (e.g., Transportation) being deemphasized in favor of other content areas (e.g., "Mechanical and Ventilation Systems"). Additional tactical content issues and/or case studies may also be added. The goal will be to finetune the content so that the training targets the key areas where the $\mathrm{A} / \mathrm{E}$ firms can provide the greatest added value to their clients.

Project Outcome: This task was completed on time.

\section{Task 8.3. Develop Agenda, Program Brochure, and Draft Course Manual}

Once Task 2.2 is complete, the Contractor shall develop a final agenda for the training program along with a promotional brochure. SBIC will work closely with NYSERDA staff to target the marketing precisely to the intended audience. The Contractor shall develop and deliver to NYSERDA the draft course manual comprising the content materials identified in Task 2.1 for review and comment by the due date established in Table 1 . The Contractor shall incorporate NYSERDA's comments and deliver the final version two weeks after receiving timely comments from the NYSERDA Project Manager. 
Project Outcome: The agenda for the Technical Assistance Workshop is included as Attachment Q.

\section{Task 8.4. Send Out Invitations}

The Contractor shall develop a targeted list of invitees to the workshop, drawing from NASEO and ASERTTI networks. The invitees will receive formal invitations to the training.

Project Outcome: Over 60 attendees from approximately 30 firms attended the full day training session. The list of attendees is included as Attachment R.

\section{Task 8.5. $\quad$ Finalize Course Presentations}

The Contractor shall finalize the presentations for the National Training Program before the workshop date and deliver to NYSERDA in time for review and comment. The Contractor shall incorporate NYSERDA's comments and deliver the final version two weeks after receiving comments from the NYSERDA Project Manager. The Contractor shall deliver a model presentation to NYSERDA prior to finalizing the course presentations in order to receive comments regarding the look and feel, graphics, and overall design including branding requirements. The presentations will be PowerPoint based and will draw extensively from material already prepared and used by the presenters in other venues.

Project Outcome: Technical, and tactical case studies are presented as Attachment $\mathrm{O}$ and $\mathrm{P}$, respectively.

\section{Task 8.6. Coordinate Registration and Workshop Logistics}

The Contractor shall coordinate the registration of participants and the basic logistics of technical and other services needed to successfully complete the workshop. This will include coordinating the travel and participation of speakers and presenters.

Project Outcome: This task was modified to include specific regional outreach events to promote High Performance School design and construction. A series of four Community Forums were held to attract the interest of the School Superintendent, parents and teacher association members, health associations, and others with vested interest in the health and cost benefits of sustainable, energy-efficient school design. The Community Forum presentation includes a summary of the cost and benefits of a high performance school, the health benefits of sustainable school construction as presented by the Healthy Schools Network (a non-profit outreach group based in Albany, New York) and a listing of state technical and financial assistance program offerings from NYSERDA, and is included with this report as Attachment S.

\section{Task 8.7. Conduct Workshop}

The Contractor shall conduct the workshop in Albany, New York, for representatives of approximately 20 design firms, following the agenda and using the presentation materials developed in previous tasks. The Contractor shall provide the key instructors and all course materials. The Contractor shall also prepare certificates of completion for all attendees and will maintain a list of all the firms who successfully complete the training.

The Contractor shall develop program evaluation forms and submit to NYSERDA for review and comment. The evaluation shall include questions regarding the likelihood of the participants to implement and use the information acquired during the training, and the usefulness of the training in changing the practices of the participants. General tracking indicators to include, but not limited to: number of organizations participating in the training, number of participants from each 
organization, list of potential school projects, anticipated energy savings for potential projects. The Contractor shall incorporate NYSERDA's comments and deliver the final version two weeks after receiving comments from the NYSERDA Project Manager. The Contractor shall distribute and collect program evaluation forms to be developed in cooperation with NYSERDA staff.

Project Outcome: Over 60 attendees from approximately 30 firms attended the full day training session. Approximately 15\% (5 of the 30 firms) participating in the conference had endeavored to initiate sustainable school renovation projects with energy-efficiency and sustainable features incorporated into the design. Design features included energy-efficient lighting, daylighting, lighting controls, improved indoor air quality through demand control ventilation where applicable, sustainable flooring materials, and recycling. The list of attendees is included as Attachment R.

\section{Task 8.8 Analyze Evaluation Forms and Report}

The Contractor shall submit an analysis of the evaluation forms filled out at the workshop within two weeks of the workshop. The analysis will contain a tabulation of the various responses, together with a set of recommendations for how any future training workshops might be improved, enhanced, or expanded. The goal will be to provide NYSERDA and NASEO with tactical advice on how to conduct future training programs across the country.

Project Outcome: The feedback from workshop attendees indicated expectations for receiving both in-depth technical training and guidance in working with school administrators. Future workshops for A/Es might seek to 1) improve A/Es' technical capabilities for designing high performance facilities with focus in specific areas of interest such as whole-building commissioning, use of design tools for sustainable design, and 2) improve tactical capabilities, such as how to negotiate the procurement process, understand school construction financing, selling school boards and administrators on "green", or 3) provide guidance on how to market high performance design services (first cost vs. life-cycle cots; studies and statistics that support high performance design). The feedback is included in this report as Attachment T.

\section{Task 8.9 Conduct Webcast}

The Contractor shall conduct a 90 minute webcast for representatives of State Energy Offices, ASERTTI, NASEO, Rebuild America, and other associations invited by NYSERDA. The purpose of this webcast is to present the Online Training in context of other resources available to states as powerful tools to build programs promoting high performance school design and operation.

Project Outcome: The implementation contractor and NYSERDA presented a summary of the project to representatives of ASERTTI, NASEO, Rebuild America and other members of the DOE Review Team. Each organization planned to market the High Performance Schools Online Training program to its members, and develop strategies to further integrate the applied assistance within the states. The DOE Review Team recommendations for further action are represented in Attachment U.

SECTION 3: Online Training for High Performance School Maintenance and Operations The contractor shall develop three online course modules covering M\&O issues that are most relevant to the NYSERDA Online Training for High Performance School Design. These are 1) 
Building Envelope; 2) Electrical Systems/Lighting; and 3) HVAC/Mechanical Equipment. The structure, format and functionality of the proposed M\&O course modules will be the same as the modules in the design curriculum (outlined in Section 1). The contractor shall add these three courses to the Web site (www.hpschooldesigntraining.com) no later than September 25, 2004.

Project Outcome: All tasks were completed on time.

\section{Task 8.10: $\quad$ Develop Detailed Training Content}

The Contractor shall develop detailed training content to meet the technical learning objectives defined for the school facility operators audience for this training. The training content for the Internet-based training program shall be based on the CHPS Best Practices Manual Volume IV: Maintenance and Operations.

\section{Task 8.10.1: Develop Learning Objectives}

The Contractor shall build learning objectives for each module, and submit to NYSERDA for review and comment by the due date established in Table 1 . The Contractor shall incorporate NYSERDA's comments and deliver the final version two weeks after receiving timely comments from the NYSERDA Project Manager. The goal will be to identify the key lessons in each module - i.e., the basic knowledge that will help the users design and operate more energyefficient schools - and restate these lessons as a series of learning objectives. The objectives, in turn, will become the organizing structure for the tests to be developed in Task 1.6. The Contractor shall not proceed until NYSERDA has reviewed and approved the learning objectives for each module as described under this task.

\section{Deliverable: Learning Objectives for Course Modules}

Responsible Team Members: AEC, NJIT

\section{Task 8.10.2: Develop Test Content}

The Contractor shall create the questions and/or exercises that will test the user's knowledge of the key learning objectives for each module, and submit to NYSERDA for review and comment by the due date established in Table 1 . The Contractor shall incorporate NYSERDA's comments and deliver the final version two weeks after receiving timely comments from the NYSERDA Project Manager.

The Contractor shall identify the organization(s) that approves continuing education credits for the school facility M\&O audience and ensure that the type and number of questions are sufficient to qualify each one-hour module for one learning unit of credit, as defined by the American Institute of Architects (AIA). It is anticipated that the test format will be the same as that for the design curriculum.

Deliverable: Test Content for Course Modules

Responsible Team Members: AEC, NJIT

\section{Task 8.10.3: Define Continuing Education Requirements}

As the course modules are being developed, the Contractor shall contact the continuing education departments within building operator and facility management organizations to determine what levels and types of credit each course module will qualify for within each organization. The Contractor shall provide this information to NYSERDA for information.

The Contractor shall 1) have the course modules reviewed by appropriate personnel, 2) determine the level and type of credit each organization is prepared to offer for each module and 3) determine the procedures needed to register the courseware within each continuing education system. 


\section{Deliverable: Continuing Education Requirements}

Responsible Team Member: SBIC

\section{Task 8.10.4: Produce Multimedia Lectures}

The Contractor shall identify instructors for the multimedia element of the courses, and produce, edit, and upload these to the Website. The Contractor may "capture" instructor presentations from CHPS M\&O seminar(s) as necessary (with permission from the instructors).

Using NYSERDA Section I as the basis, the Project Team will design, build and implement an Internet-based, distance-training platform incorporating the following functionality:

- Online registration and payment through secure e-commerce

- Downloadable registration and payment forms for mail and fax submittal

- Log-in identification and password protection for all course contents

- Track, manage, and submit reports of registered applicants and completion records to NYSERDA

- Track and manage continuing education hours

- Provide electronic certificates of completion for registered applicants who complete the course

- Online test for each registered applicant

- Performance reporting by course that shows percentage completion for each registered applicant

- Technical assistance phone support

- Asynchronous discussion thread with instructor

- Administrative functions for tracking progress of each registered applicant, including test scores by course

Many of the steps to develop and implement this platform have been achieved under Section I. The contractor shall implement the following tasks to complete the $\mathrm{M} \& \mathrm{O}$ training modules:

- Re-design entry page

- Update database

- Coordinate continuing education software requirements

- Upgrade d-Base management

- Provide Website design services

- Produce multi-media lectures

- Create presentation tools

- Provide testing, hosting and maintenance

Multi-media lectures and video content shall be produced, edited, and delivered on separate CDROM.

\section{Task 8.10.5: Launch three M\&O Courses}

The Contractor shall upload the courses to the Website, test to make sure there are no errors and that functions are working properly, and alert NYSERDA that the courses are ready to be officially launched.

The transition toward sustainable, energy-efficient design in school buildings requires an organized program to train architects and engineers on energy efficient technologies, and design 
practices. Training curriculum and related educational resources can be effectively transitioned from the national level and implemented at the regional level through applied engineering and design assistance to school districts. This project encompassed three main objectives 1) develop an internet-based training curriculum for the A/E Community, 2) develop a model national training program to help the A/E Community deploy "state-of-the-art" design strategies within their respective states, and 3) to integrate design strategies with the important tasks of the general operation and maintenance of the school building.

Each state has unique policies and school construction guidelines, which can be supported by regional based provider training. First level information sessions or "Community Forums" worked well to inform the public regarding the definition of a high performance school, and answers as to why a community would want to fund sustainable high performance school design for new school construction projects. Technical training for the A/E Community integrating concepts of high performance school design with local construction guidelines, energy-efficiency code, and available technical and financial assistance programs is necessary to build the infrastructure of support for school districts interested in high performance school design.

The NYSERDA model includes four steps to applied engineering assistance 1) Community Outreach to educate school administers, families, and teacher/health associations on the costs and benefits of high performance school design; 2) readily accessible technical training via the internet for busy A/E professionals and school design teams; 3) technical assistance training to inform providers of relationships between state-level school construction guidelines and high performance school design, and possible financial assistance programs offered within the region, and 4) a referral program to connect interested school districts with trained providers and regional financial incentive programs. This model was deployed in New York by the effective implementation of community outreach, internet training, regional technical assistance training, and technical/financial assistance through the New York Energy \$mart New Construction Program. Providers that completed all 25 online courses, attended the full day Technical Assistance Workshop, and had been selected through a competitive process for the New Construction Program implemented technical design assistance for schools interested in sustainable design. Noteworthy case studies were presented to providers during the Technical Assistance Workshop, such as the Roxboro Middle School in North Syracuse.

Although the interest in funding high performance school design is just beginning to take hold in school districts across New York State, significant progress continues in support of CHPS/LEED guidelines for new school construction projects. It is important to educate community and design teams who may then serve as advocates for HPS design. The New York State Education Department, Construction Management Group is very interested in regional involvement in High Performance School initiatives promoting healthy, sustainable, energy-efficient school design. During this project period, over 20 school projects were implemented in New York, each implementing several components of high performance school design. The state of Massachusetts awards 2\% funding incentive for projects that meet criteria for High Performance School design, which further encourages school districts and design teams to consider sustainable, energyefficient design strategies.

\section{Commercialization Potential}

The DOE Review Team convened in September 2004 to discuss the marketing of the High Performance Schools Online Training Program. The Team agreed to market the online training 
through each of the respective membership lists of the major sponsors to the program (Rebuild America would forward the news release to the RA listserve, ASERTTI to its membership at the Fall 2004 conference, and NASEO to its membership at the September 2004 annual meeting). The training was to be promoted at each of the Rebuild America Basic High Performance School (HPS) seminars scheduled in 2004.

Regional advisory committees on High Performance School Design have also presented interest in further customizing the website to reflect specific needs of individual climate zones. Northeast Energy Efficiency Partnerships, Inc. (NEEP) has proposed interest in hosting the website and modifying course content to reflect regional guidelines and building code. Regions may benefit from leveraging content from the four volume set of the Best Practices Manual for High Performance Schools developed by the Collaborative for High Performance Schools (CHPS). Guidelines for licensing are set by the CHPS Board. Licensing fees for states have been pro-rated by state population, calculated by multiplying the state population by 0.004 , and rounding to the nearest $\$ 1000$. Whereas the state of Massachusetts via the Massachusetts Technology Collaborative (MTC) has paid \$15,000 license fee, New York has paid a \$35,000 license fee. The Distributor's License between CHPS, NYSERDA, and the National Association of State Energy Officials for the purposes of the development and delivery of the Online Training for High Performance Schools is presented in Appendix A.

\section{Marketing Status to Date}

1. The training is hosted by SBIC and Building Media through April 1, 2005 under the following URL:

http://www.hpschooldesigntraining.com

2. The training is currently posted as a link on the US DOE/Rebuild America web site at: http://www.rebuild.org/lawson/newconstruction.asp

From this New Construction page, scroll down to the heading for Design and Documentation, and click on the link for High Performance School Design.

3. SBIC disseminated the news release announcing the Online Training to the following groups identified in the marketing plan: (1) American Institute of Architects (AIA), (2) Sustainable Buildings Industry Council (SBIC) membership, (3) American Council for an Energy Efficient Economy (ACEEE).

4. NASEO and ASERTTI distributed the news release and HPS flyer (1500 copies printed by Potomac Communications) to their networks at their respective fall conferences, including.

- NASEO Annual Meeting September 27-30, 2004

- DOE/Rebuild America regional meetings

- ASERTTI Fall Conference

\section{Recommendations}

The following recommendations are provided for each step of the applied engineering assistance process which may be implemented at the regional level by states: 


\begin{abstract}
Step 1: Community Forums
Community Outreach - Stakeholders involved in the design process need to be educated on the costs and benefits of High Performance School design. The presentation (Attachment S: Community Forums) delivered by this project team at four regional forums effectively demonstrates the WHAT, WHY, and HOW of High Performance School design. It is recommended to direct these forums to the highest level decision-makers within the district. Each participant attending the Community Forum received a copy of the SBIC High Performance School Buildings Resource and Strategy Guide.

Further information on how to implement HPS can be found on the High Performance School Buildings Information and Training Center available on the Sustainable Buildings Industry Council website at:

http://www.buildingmedia.com/sbic/
\end{abstract}

\title{
Step 2: Internet Training for A/E Community and School Design Teams
}

Useful for the School Design Team - School design teams may choose to encourage all design team participants to complete specific courses available on the Online Training for High Performance Schools website. This provides a solid background in High Performance Design and facilitates better communication and understanding of design concepts.

Integration with e-Commerce - During the first two years, the training was offered free of charge, and therefore the e-commerce package was not integrated with the registration package. Miva's Merchant E-commerce software may be used in the future to collect payment information for registered users. Registration fees could then be used as a funding mechanism for future courseware development and for overall site maintenance and technical support.

Future Course Development - Additional courses may be developed in subject areas including 1) Selling HPS design to the school district; 2) Implementing LEED/CHPS in your state, etc.

\section{Step 3: Technical Assistance Workshop}

Regional Case Studies - Noteworthy case studies were presented to providers during the Technical Assistance Workshop, such as the Roxboro Middle School in North Syracuse. Additional case studies from various climate zones are available in the SBIC High Performance School Buildings Resource and Strategy Guide, which may be ordered directly from SBIC, or visit their website at: http://www.sbicouncil.org/

Advanced Training - TA Workshop participants recommended that providers receive more indepth technical training in certain subject areas such as building commissioning, and skills in how to sell concepts of High Performance School design.

\section{Step 4: Referral Program for Schools/TA Providers}

Integration with Regional Technical and Financial Assistance Programs - NYSERDA has a comprehensive program offering to support new school construction and major renovation projects. It is recommended to add requirements for technical assistance providers to complete 
online training courses and receive continuing education credits to remain on the active referral list for HPS construction projects within their respective states. 


\section{Conclusion}

Energy Smart Schools are the wave of the future. The objective of this project was to set an example of the wide variety of activities school districts can engage in to increase their energy efficiency while at the same time driving down their energy costs.

The main goal in implementing this project is to have a set of stories that can be shared among all the state energy offices and school districts. The sharing and replication of these projects does should not conclude simply because these objectives have been implemented.

We can also conclude that the options for the implementation of Energy Smart Schools are endless based on the wide range of options offered in this project. 